\title{
Recent advances on the organocatalyzed enantioselective $\alpha$-functionalization of carbonyl compounds $\dagger$
}

\section{Gabriela Guillena* and Diego J. Ramón*}

Departamento de Química Orgánica and Instituto de Síntesis Orgánica, Facultad de Ciencias,

Universidad de Alicante, Apdo. 99, 03080 Alicante, Spain

$\dagger$ Dedicated to Dr. Cecilio Márquez on the occasion of his retirement. 


\begin{abstract}
This review covers literature on organocatalyzed enantioselective $\alpha$ heterofunctionalization of carbonyl compounds from 2006 to 2009. In this review, we will consider those reactions in which a new carbon-heteroatom bond is formed using a chiral organic molecule as catalyst, excluding those processes, which involve the modification on the hybridization of a previously functionalized carbonyl compound. Using this straightforward synthetic strategy, a wide range of valuable chiral building blocks such as $\alpha$-amino acids, $\alpha$-amino alcohols, epoxides, 1,2diols, $\alpha$-sulfenylated, $\alpha$-selenenylated and $\alpha$-halogenated carbonyl derivatives can be obtained by this simple and advantageous methodology.
\end{abstract}

Key words: enantioselective synthesis, organocatalysis, functionalized carbonyl compounds, $\alpha$ amino acids, $\alpha$-amino alcohols, $\alpha$-halogenated carbonyl compounds. 
Index

1. Introduction

2. Enantioselective $\alpha$-amination

2.1 Aziridination of $\alpha, \beta$-unsaturated carbonyl compounds

2.2 Direct $\alpha$-amination

3. Enantioselective $\alpha$-chalcogenation

3.1 C-O bond formation

3.1.1 Darzens reaction

3.1.2 Epoxidation of $\alpha$, $\beta$-unsaturated carbonyl compounds

3.1.3 Aminoxylation of aldehydes and ketones

3.1.4 Miscellaneous oxidation processes

\subsection{Sulfenylation and selenenylation processes}

4. Enantioselective $\alpha$-halogenation of carbonyl compounds

5. Conclusions and outlook 


\section{Introduction}

Nowadays chiral compounds can be obtained by using catalytic enantioselective reactions [1] in high selectivity and atom efficiency [2]. Whereas in Nature these processes are efficiently accomplished by enzymes [3], chemists can build complex chiral architectures by using several synthetic strategies [4], with one of them being the so-called organocatalyzed approach [5].

An organocatalyzed reaction is defined as the acceleration of a chemical reaction by an ideal substoichiometric amount of an organic catalyst, in which all reagents and catalyst are small molecules containing only $\mathrm{C}, \mathrm{H}, \mathrm{O}, \mathrm{N}, \mathrm{P}, \mathrm{S}$ and/or halogen atoms. Therefore, processes in which a metal (including boron or silicon atom) or high molecular weight organic molecules such as enzymes or even polymers are used, should be strictly excluded. However, we will consider here processes in which the silyl group has a mere steric role as well as the immobilization of the organocatalyst in a polymer, dendrimer or inorganic material for recovery purposes.

Although this synthetic strategy is an old tool in the enantioselective research field [6], it was only in the last decade that it has shown its great potential. Probably, this recent interest is due to the advantages of this type of catalysts compared to the use of biocatalyst or metal transition type complexes as catalysts. Organocatalysts are usually stable, cheap, and readily available and used under mild reaction conditions, having a wide substrate scope. These type of reactions guaranteed the total absence of metallic traces in the final products, which makes this strategy very attractive for the agrochemical and pharmaceutical industries. These facts, together with the easy incorporation of these catalysts onto supports, allowing their recovery and reuse, and the possibility of the direct synthesis of structurally complex molecules through simple C-C bond processes [7a], or by more complicated multicomponent [7b] or domino [8] reactions lead a simple and straightforward methodology for the synthesis of high value chiral compounds, which meets the current demand of sustainable chemical protocols [9].

This review covers the recent achievements in the organocatalyzed $\alpha$-heterofunctionalization of carbonyl compounds which leads to the formation of important chiral building blocks such $\alpha$-amino acids, $\alpha$-amino alcohols, aziridines, epoxides, 1,2-diols, $\alpha$-sulfenylated, $\alpha$-selenenylated and $\alpha$-halogenated carbonyl derivatives. Since two revisions on this topic were published in 2006 [10], the research developed after that 
year to the present time will only be considered. This new revision has been organized by the type of reactions, in which a new carbon-heteroatom bond is formed, excluding the reactions, which involved the modification of the hybridization of a previously functionalized carbonyl compound.

\section{Enantioselective $\alpha$-amination of carbonyl compound}

The amino group is probably the most important functional group in organic chemistry [11]. For instance, most of the products pipeline in pharmaceutical industries bears one o more nitrogen atoms. Nature has chosen also nitrogen-containing compounds as the raw material to construct life building blocks. Therefore, the synthesis of carbonyl compounds having a nitrogen atom at the $\alpha$-position in an asymmetric way, either via aziridination of a $\alpha, \beta$-unsaturated carbonyl and subsequent ring opening of the obtained chiral aziridine [12] or via electrophilic amination [13], are of great interest for the synthesis of chiral $\alpha$-amino acids, esters, ketones and alcohols.

\subsection{Aziridination of $\alpha, \beta$-unsaturated carbonyl compounds}

Historically, the first organocatalyzed synthesis of chiral aziridines was accomplished by using phase transfer catalysis [14], and $\alpha, \beta$-unsaturated esters and cyclic $\alpha, \beta$-unsaturated ketones as starting materials. Chalcones 1 can be aziridinated using a one-pot process, which involves the in situ generation of a hydrazinium salt derived from $O$-mesitylenesulfonylhydroxylamine (2), deprotonation of a hydrazinium salt to form an aminimide, and subsequent aziridination. Thus, using a $60 \mathrm{~mol} \%$ of chiral Tröger's base as catalyst, $\mathrm{CsOH} \cdot \mathrm{H}_{2} \mathrm{O}$ ( 3 equiv) and a mixture of acetonitrile-dichloromethane as a solvent at $0{ }^{\circ} \mathrm{C}$, aziridine 4 a was obtained in only

$55 \%$ ee (Scheme 1). A slightly better enantioselectivity was obtained by using 4-chlorochalcone (1b) as starting material affording aziridine $\mathbf{4 b}$ in $67 \%$ ee. This ee value can be improved up to $98 \%$ upon recrystallization [15]. 
<smiles>Cc1cc(C)c(S(=O)(=O)O)c(C)c1</smiles>

1a: $\mathrm{Ar}=\mathrm{Ph} \quad 2$

1b: $\mathrm{Ar}=4-\mathrm{ClC}_{6} \mathrm{H}_{4}$

$\mathrm{CsOH} / \mathrm{CH}_{3} \mathrm{CN}-\mathrm{CH}_{2} \mathrm{Cl}_{2}, 0^{\circ} \mathrm{C}$<smiles>Cc1ccc2c(c1)CN1CCN2Cc2cc(C)ccc21</smiles>

3

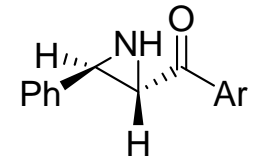

4a: $85 \%$, ee $55 \%$

4b: $66 \%$, ee $67 \%$

\section{Scheme 1}

Similar results (64\% yield and 56\% ee for 4 a) were obtained in the aziridination of chalcone 1a, using 105 mol\% of quinine (5, Figure 1) as catalyst, $O$-(diphenylphosphinyl)hydroxylamine (1.05 equiv) as a nitrogen source and $\mathrm{NaH}$ (2 equiv) as base in a mixture of isopropanol-dichloromethane as solvent at room temperature $[16]$.<smiles>C=CC1CC2CCC1N2C[C@H](O)c1ccnc2ccc(OC)cc12</smiles>

5

Figure 1 
Different carbamates have been used as nitrogen source to perform this type of transformation under different reaction conditions giving an increased level of enantioselectivity. Thus, dimethylpyrazole acrylate (6) can be aziridinated using $N$-chloro- $N$-sodium benzylcarbamate (7) under solid-liquid phase transfer conditions using $10 \mathrm{~mol} \%$ of cinchoninium salt $\mathbf{8 a}$ in dichloromethane, affording the corresponding aziridine in $84 \%$ yield and $70 \%$ ee [17], which can be further transformed in the methyl-ester substituted aziridine 9 by using $N, N$-dimethylaminopyridine (DMAP, $30 \mathrm{~mol} \%$ ) in $\mathrm{MeOH}$ (Scheme 2). As expected, using the pseudoenantiomeric cinchonidinium salt, the aziridine with the opposite absolute configuration was obtained.
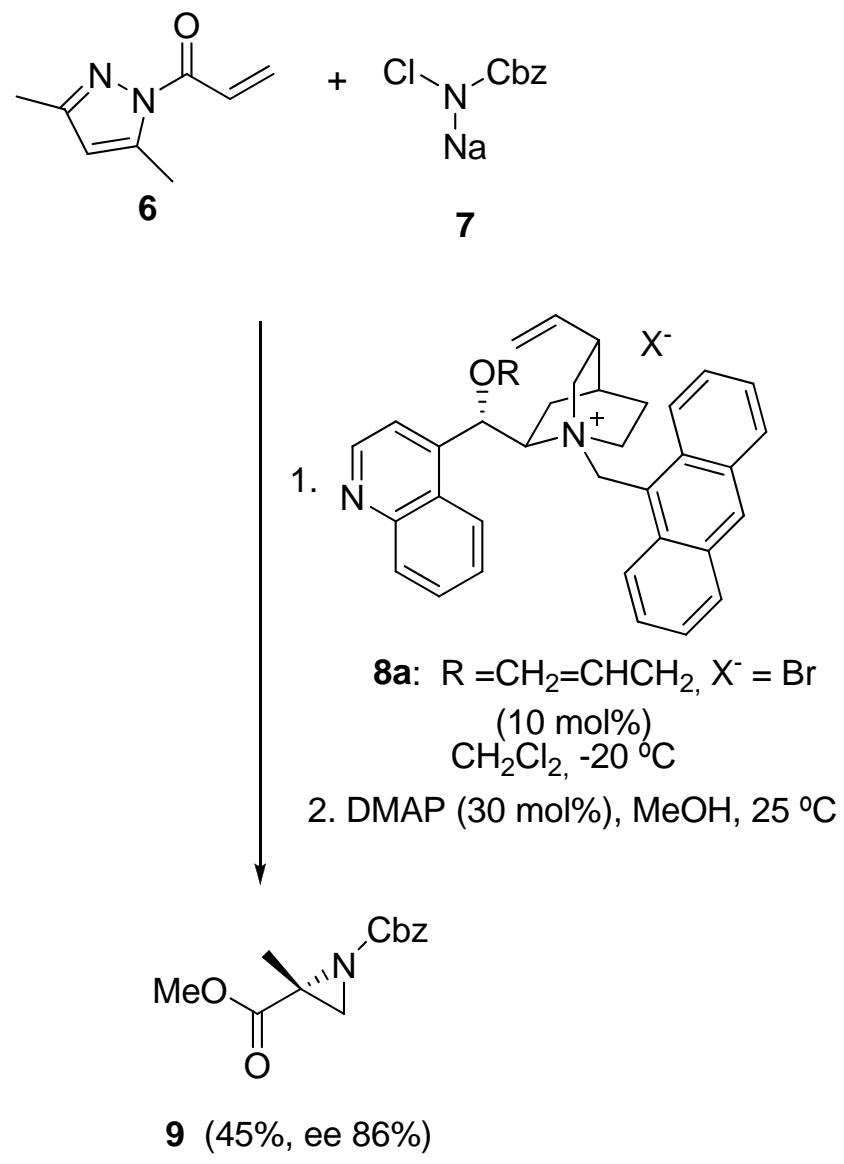

\section{Scheme 2}

Salt $12(20 \mathrm{~mol} \%)$ was able to promote the aziridination of aliphatic and aromatic $\alpha, \beta$-unsaturated ketones, using tosylated carbamate 11a and $\mathrm{NaHCO}_{3}$ as base at room temperature, yielding the corresponding aziridines 13 in high yields, diastereo- and enantioselectivities (Scheme 3) [18]. The reaction seemed to be tolerant to steric and electronic demands on the starting poor olefin systems. These reaction conditions were also applied 
to cyclohexenone and $\beta$-methyl cyclohexenone, leading to the corresponding aziridine with 98 and $73 \%$ ee, respectively.<smiles>[R]C=CC([R])=O</smiles>

10

$11 \mathrm{a}$

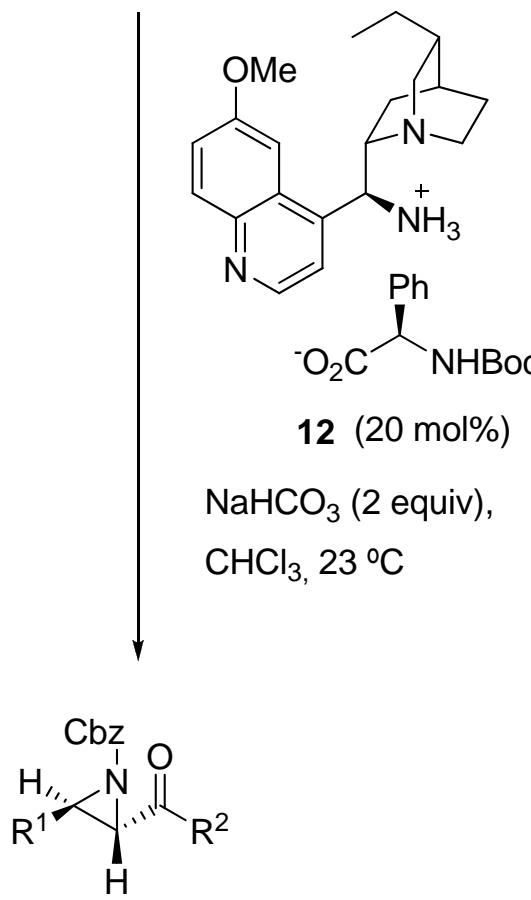

13

(74-96 \%, dr up to 19:1, ee 73-99 \%)

\section{Scheme 3}

Prolinol derived organocatalyst have been successfully used in the asymmetric aziridination of $\alpha, \beta$ unsaturated aldehydes. Thus, compound 15a catalyzed the formation of aliphatic 2-formylaziridines 16 in moderated to high yields and with high levels of diastereo- and enantioselectivities (Table 1) [19]. Products 16 decomposed during prolonged reaction times, therefore temperatures of $40{ }^{\circ} \mathrm{C}$ were used to perform the reaction faster. The achieved absolute configuration for 2-formylaziridines $\mathbf{1 6}$ were attributed to the efficient shielding of the Si face of the chiral iminium intermediate by the aryl groups of the catalyst, leading to the stereoselective Re-facial nucleophilic conjugate attack of the $\beta$ carbon atom of the electrophile by the nitrogen source 11. The formed chiral enamine intermediate gave a 3-exo-tet nucleophilic attack on the now electrophilic nitrogen atom, releasing acetic acid. Catalyst $\mathbf{1 5 b}$ was able to promote the aziridination reaction of aliphatic $\alpha, \beta$-unsaturated 
aldehydes with similar results to catalyst 15a (Table 1, compare entries 1 and 3 with 2 and 4) [20], but in this case, the presence of a base was mandatory to obtain the corresponding 2-formylaziridines $\mathbf{1 6}$. This catalyst was also used for the aziridination of aromatic $\alpha, \beta$-unsaturated aldehydes. $N$-4Methoxybenzenesulfonyloxycarbamate, instead of $N$-4-methylbenzenesulfonyloxycarbamate, could be used as an alternative nitrogen source to give the corresponding aziridine $\mathbf{1 6}$ in moderated yields, which was sensitive to silica gel purification (Table 1, entry 7). Other aromatic aldehydes bearing electron-withdrawing groups were also suitable substrates to yield products $\mathbf{1 6}$ in high yield and enantioselectivity (Table 1, entry 8). Further oxidation transformations of products $\mathbf{1 6}$ allowed the synthesis of chiral $\beta$-amino esters derivatives [19, 20].

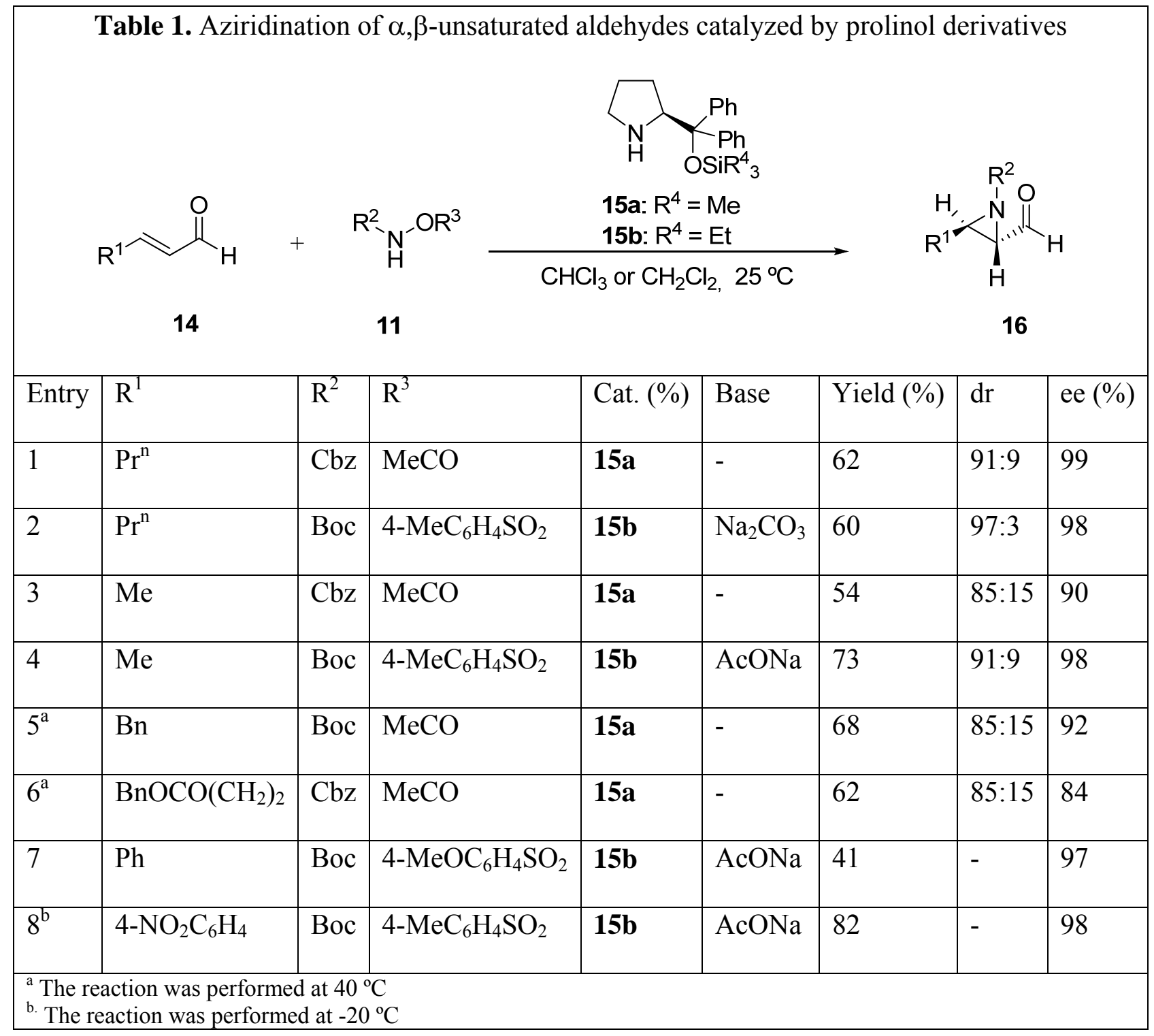

\subsection{Direct $\alpha$-amination}


The direct organocatalyzed $\alpha$-amination of carbonyl compounds using different types of catalysts is the most simple and straightforward approach to access to chiral $\alpha$-amino acids, aldehydes and alcohols, with a great development in this area and in their application to a wide scope of substrates being achieved. In this sense, this synthetic strategy has been applied to molecules containing quaternary stereocenters [21] such as $\alpha, \alpha$-disubstituted amino acids, of great interest due to their biological activities. (S)-proline (50 mol\%) has shown to be an effective catalysts in the $\alpha$-amination of $\alpha, \alpha$-disubstituted aldehydes $\mathbf{1 7}$ using azodicarboxylates 18 as a nitrogen source (Scheme 4) [22]. Dibenzyl azodicarboxylate provided better selectivities than the corresponding diethyl azodicarboxylate. Whereas non-aromatic $\alpha, \alpha$-dialkyl aldehydes gave compounds 20 in low enantiomeric excesses (4-39\%), $\alpha$-alkyl $\alpha$-aryl acetaldehydes lead to improved results, with the presence of electron-withdrawing substituent lowering the yields and stereoselectivities.

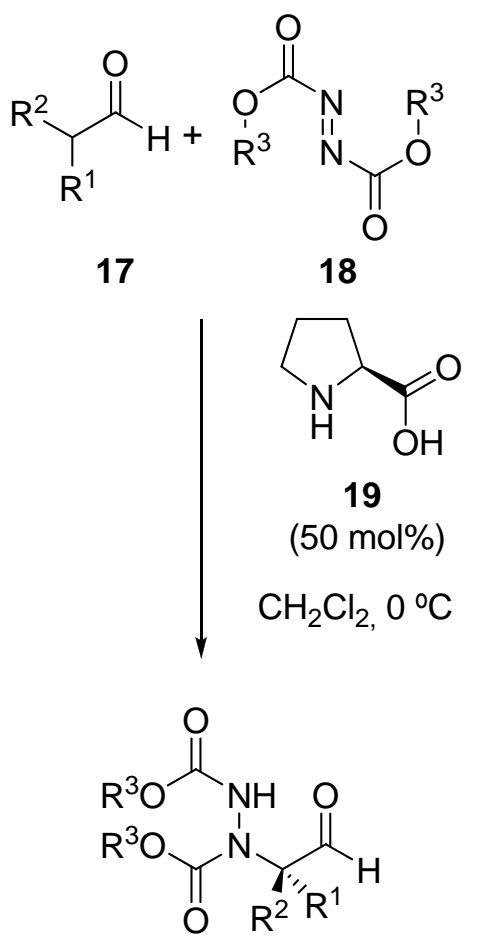

20

(29-99\%, ee 4-86\%)

\section{Scheme 4}

A high catalyst loading was needed in order to reduce reaction times since chiral compounds $\mathbf{2 0}$ were highly labile. However, these compounds could be further converted in the more stable corresponding $(R)$ - 
oxazolidinones by the in situ reduction and cyclization. Due to the high catalyst loading used and the relatively long reaction times needed for completion, microwave conditions were applied to carry out this process [23]. By using constant microwave power $\left(200 \mathrm{~W}, 60 \mathrm{~min} ., 60^{\circ} \mathrm{C}\right)$ in acetonitrile as solvent, an increase of the yields and enantioselectivities were observed $(54-97 \%, 52-90 \%)$ compared to those obtained at room temperature using $\alpha$-alkyl aryl aldehydes as substrates. In addition, a considerable reduction on the reaction time (from days to $60 \mathrm{~min}$ ) was achieved under these new reaction conditions. However, the catalyst loading (50 mol\%) could not be decreased further without affecting the yield and enantioselectivity.

$\alpha$-Branched aldehydes can also be stereoselectively aminated by using sulfonyl azides as an electrophile, (S)-proline (10 mol\%) as catalyst and technical ethanol as solvent (Scheme 5) [24]. From the azides employed, 2-nitrobenzenesulfonyl azide gave the best enantiomeric excess. While $\alpha$-disubstituted alkyl aldehydes gave the highest chemical yields (49-54\%) and the lowest enantioselectivities (5-28\%), the use of $\alpha$-alkyl $\alpha$-aryl acetaldehydes provided the sulfamidated products 22 generally in lower yields and better enantioselectivities, with the presence of electron-donating substituents in the aromatic ring enhancing the stereoselectivity of the process. When the same procedure was applied to a linear aliphatic aldehyde, the corresponding achiral sulfonyl imide was obtained instead of the chiral $\alpha$-sulfamidated aldehyde. The absolute configuration of some products 22, determined from the X-ray structures, was found to be $S$, with a mechanism featuring as a central step, a regioselective 1,3-dipolar cycloaddition between the sulfonyl azide 21 and enamine derived from compound 17 being proposed.

In the more simple $\alpha$-amination of linear aldehydes $\left(\mathrm{R}^{2}=\mathrm{H}\right.$, for compound 17) a mechanistic rationalization of the unusual product-acceleration behavior observed was done based on kinetic measurements [25]. From these studies, a two parallel catalytic cycle was proposed. Besides, the conventional catalytic cycle, a product-assisted cycle was suggested, in which a high reactive product-proline adduct is reversible formed. However, the kinetic data does not provide further information about the nature of this product-proline adduct. On the basis of computational calculations, hydrogen bonded product-proline complex, resembling an "open" proline conformation, was proposed as responsible for the rate acceleration of the reaction. 
$\underbrace{\mathrm{R}^{2}}_{\mathrm{R}^{1}} \mathrm{O}+\mathrm{R}^{3} \mathrm{SO}_{2} \mathrm{~N}_{3}$

17

21
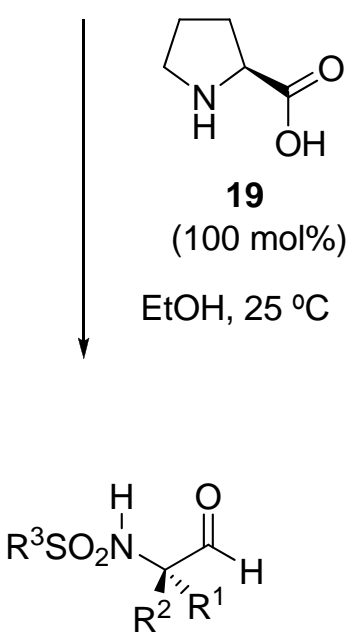

22

(21-55\%, ee 5-86\%)

\section{Scheme 5}

The usefulness of the $\alpha$-amination of aldehydes organocatalyzed by $(S)$-proline has been demonstrated by its application as the key step in the synthesis of several interesting chiral products. For instance, the enantioselective synthesis of the tuberculostatic antibiotic $(S, S)$-ethambutol (23) [26], an effective drug for the treatment of Parkinson's and Alzheimer's diseases, $(R)$-selegiline (24) [27], proteogenic and non-proteogenic amino acids such as (R)-pipecolic acid (25), (R)-proline (ent-19) [28], piperazic acid derivative (26) [29], and the antibiotic (-)-anisomycin (27) [30] (Figure 2) has been accomplished. In addition, this synthetic approach has been used in the diastereoselective synthesis of Cernuane-type lycopodium alkaloids such as cermizine D $28[31]$. 


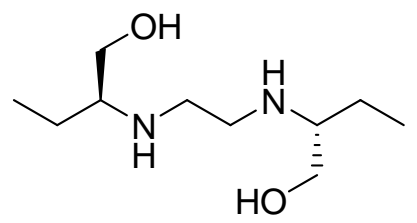<smiles>[Z4]CN(C)[C@@H](C)Cc1ccccc1</smiles>

23<smiles>O=C(O)[C@H]1CCCCN1</smiles>

25

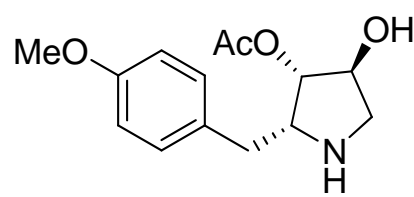

27<smiles>CCCCC(=O)OC(=O)N1C[C@@H](O)[C@@H](O)[C@H]1C(=O)O</smiles>

26

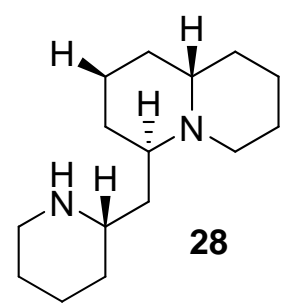

\section{Figure 2}

The sequential use of the organocatalytic $\alpha$-amination of aldehydes by azodicarboxylates with another process has provided a useful tool for the synthesis of complex molecules. Thus, the combination of the amination of linear aldehydes catalyzed by $(S)$-proline $(10 \mathrm{~mol} \%)$ and the Passerini reaction allowed the rapid access to norstatine based peptidomimetics albeit with low diastereoselectivities (36-98\% yield, up to 4:1 dr) [32]. Moreover, the enantioselective synthesis of $\gamma$-amino- $\alpha, \beta$-unsaturated esters can be performed via the sequential $\alpha$-amination catalyzed by $(S)$-proline $(10 \mathrm{~mol} \%)$ and Horner-Wadsworth-Emmons olefination of aldehydes affording the expected products in high yields and enantioselectivities (85-90\% yield, ee 92-99\%) [33]. Following a similar $\alpha$-amination and intramolecular Wittig olefination sequential process, chiral 3,6dihydropyridazines 31 were obtained in high yields and enantioselectivities (Scheme 6) using pyrrolidinyl tetrazole (30, $10 \mathrm{~mol} \%$ ) as catalyst [34]. While bulkier substituents at the $\alpha$-position of aldehydes provided higher yields and enantioselectivities, unbranched aldehydes rendered the expected products with lower results, probably due to the facile homo-aldol coupling displayed by these substrates. With respect to the nitrogen source, di-tert-butyl azodicarboxylate (18b) gave improved selectivities compared to dibenzyl (18a) or diethyl azodicarboxylates. The scope of this process was extended to the reaction with a range of cyclic ketones using a $20 \mathrm{~mol} \%$ of catalyst 30, affording the corresponding products with moderated yields and enantioselectivities 
(25-50\%, ee 76-84\%) [34b]. When 2-butanone was used as nucleophile, it was necessary to increased the amount of the ketone (5 equiv) and catalyst (30 mol\%) to give the expected 3,6-dihydropyridazine as a $2: 1$ regioisomeric mixture in 58\% yield and $65 \%$ ee.

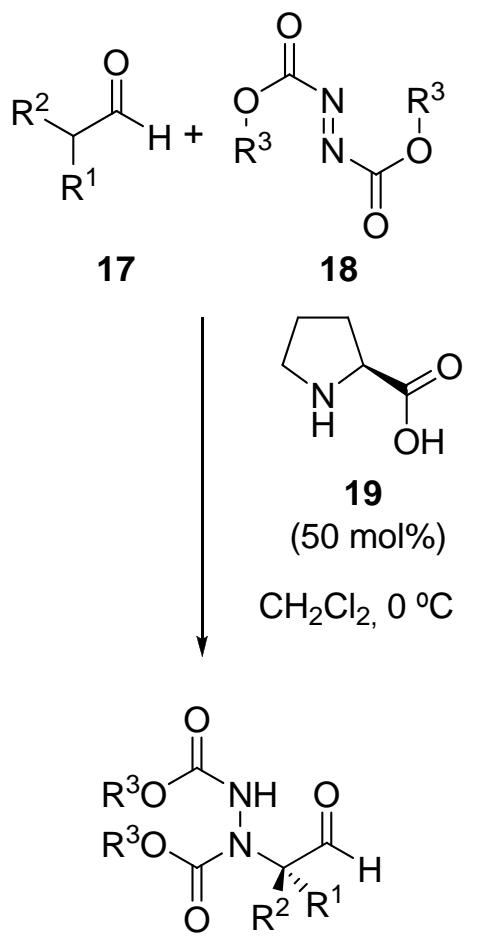

20

(29-99\%, ee 4-86\%)

\section{Scheme 6}

The use of an one-pot sequential $\alpha$-amination-allylation sequence of aldehydes followed by a ring-closing metathesis strategy has permitted the synthesis of chiral cyclic hydrazines [35]. Thus, the $\alpha$-amination of several unbranched aldehydes using $(S)$-proline as catalyst $(10 \mathrm{~mol} \%)$ and dibenzyl azodicarboxylate (18a) in acetonitrile at $-20^{\circ} \mathrm{C}$ for $12 \mathrm{~h}$, followed by the addition of indium powder and allyl bromide at room temperature gave the corresponding allylic 1,2-amino alcohols in high yields (67-88\%) and diastereoselectivities (de 62-98\%) and excellent enantioselectivities (ee 98-99\%). These compounds were further transformed to the corresponding chiral 8-membered cyclic hydrazines in moderated to high yields (59$92 \%$ ) by reaction with Grubb's catalyst. 
More challenging it has been the application of a combination of catalysts in cycle-specific organocascade processes [36]. Using this concept, $\beta$-methylcinnamaldehyde (32), was converted to product 35 via an amination-hydrogenation sequence using $(S)$-proline and imidazolidinone $\mathbf{3 4}$ as catalysts combination in high yields and excellent diastereo- and enantioselectivities (Scheme 7). The use of $(R)$-proline, in the same process, resulted in complete reversal of diastereocontrol providing the syn-35 in 82\% yield and 99\% ee.<smiles>CCOC(=O)C1=C(C)NC(C)=C(C(=O)OCc2ccccc2)[C@H]1C(=O)OCC(C)(C)C</smiles>

32

$18 \mathrm{a}$

33

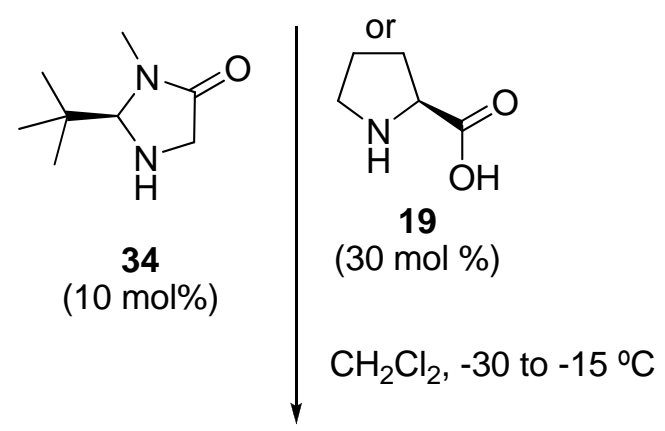<smiles>CC(c1ccccc1)C(C=O)N(C(=O)OCc1ccccc1)C(=O)OCc1ccccc1</smiles>

35

(75\%, dr 6:1, ee 99\%)

\section{Scheme 7}

The scope of the olefine in this process was proven by using crotonaldehyde as an enal substrate and 1methylindole, silyloxyoxazole and a silyloxycarbamate as nucleophiles under a similar catalysts combination giving products 36, 37 and 38, respectively with high levels of diastereo- and enantioselectivities (Figure 3). 
<smiles>CC(c1cn(C)c2ccccc12)C(C=O)N(NC(=O)OCc1ccccc1)C(=O)OCc1ccccc1</smiles>

36<smiles>CC([C@H](C=O)N(NC(=O)OCc1ccccc1)C(=O)OCc1ccccc1)[C@]1(C)C=C(c2ccccc2)OC1=O</smiles>

37

$(94 \%$, dr 14:1, ee $99 \%) \quad(77 \%$, dr 5:1, ee $99 \%)$

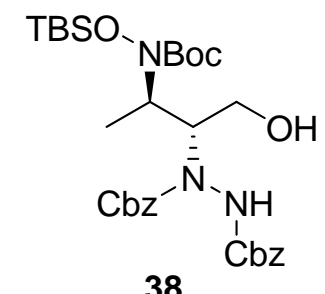

$(84 \%$, dr 17:1, ee 99\%)

Figure 3 Representative examples of products obtained by cycle-specific organocascade catalyst

Ketones are also suitable substrates for the organocatalyzed $\alpha$-amination reaction. Several catalysts have been developed to perform this reaction. Thus, silyloxyproline 39 (10 mol\%) was able to catalyze the reaction of several cyclic and acyclic ketones with dibenzyl azodicarboxylate (Scheme 8). In order to achieve high yields and enantioselectivities, 9 equivalents of water were added to the reaction mixture, although this addition retards the reaction [37]. When these conditions were applied in the reaction with cyclopentanone, the major obtained product was the $\alpha, \alpha^{\prime}$-diaminated cyclopentanone in $46 \%$ yield and $99 \%$ ee. In this process, contrary to that observed for the case of aldehydes, a linear correlation between the enantiomeric excess of the product versus the catalyst was found. Quantum mechanical calculations suggested that the most stable transition state was that in which the anti enamine reacts with the azodicarboxylate in the trans conformation. 


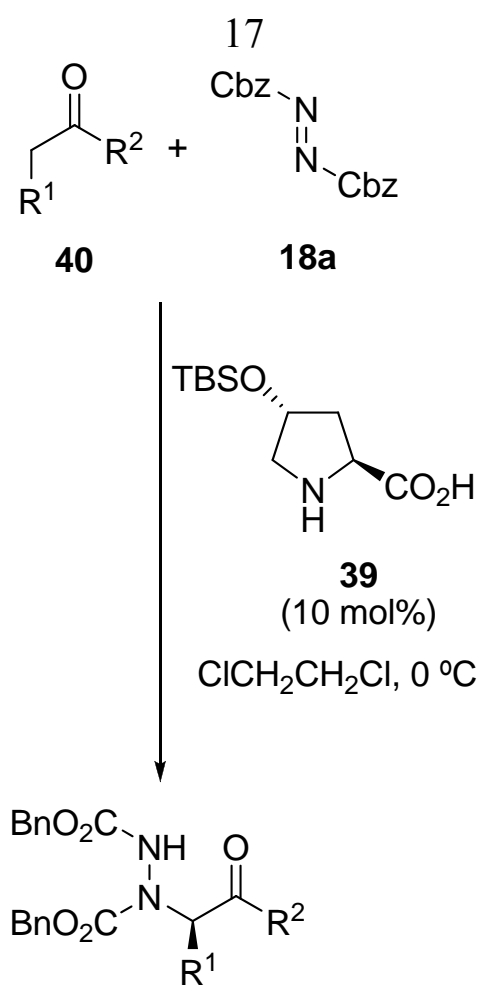

41

$(64-91 \%$, ee $78-98 \%)$

\section{Scheme 8}

Benzimidazole-pyrrolidine 42 (Figure 4) in combination with trifluoroacetic acetic (10-20 mol\%) was also applied as catalysts for this transformation in dicloromethane at room temperature affording the aminated products 41 in lower yields and enantioselectivities (65-92\%, ee 66-71\%) [38]. Aryl ketones can be also aminated using as catalyst the amine 43 derived from cinchona alkaloids (Figure 4, 20 mol\%) [39]. For this reaction, the addition of $p$-toluenesulfonic acid (40 mol\%), and $4 \AA$ molecular sieves were compulsory in order to achieve good enantioselectivities. Under similar conditions, aryl ketones, such as propiophenones, butyrophenones, heteroaryl ketones or even cyclic 1-tetralone, and diethyl azodicarboxylate in isopropanol as solvent, yielded at $40{ }^{\circ} \mathrm{C}$ the aminated products with good results $(39-77 \%$, ee $88-97 \%)$.

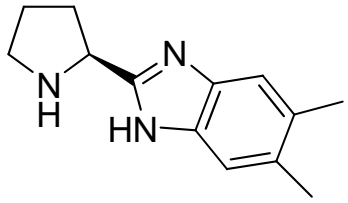

42<smiles>C=CC1CC2CCC1N2C[C@H](N)c1ccnc2ccccc12</smiles>

43 
The direct organocatalyzed $\alpha$-amination reaction has been also applied to 1,3-dicarbonylic compounds, providing a method for the construction of chiral nitrogen-substituted quaternary stereocenters. Chiral binaphthyl phosphonium salt 46 (3 mol\%) has been used as catalyst for the electrophilic amination of several cyclic $\beta$-ketoesters 44 (Scheme 9) under phase-transfer conditions at $-20^{\circ} \mathrm{C}$ [40a]. The reaction was relatively insensitive to the electronic effects of the substituents on the aromatic ring $(99 \%$, ee $77-91 \%)$, but rendered worse yields when six membered ring cyclic $\beta$-diketone was used as substrate $(55 \%$, ee $87 \%)$. Better results in terms of yields and enantioselectivities for compounds 45 (99\%, ee 76-97\%) were obtained by using spyro-type chiral ammonium salt $47(1 \mathrm{~mol} \%)$ at $-40^{\circ} \mathrm{C}$ under similar phase-transfer reaction conditions [40b,c].

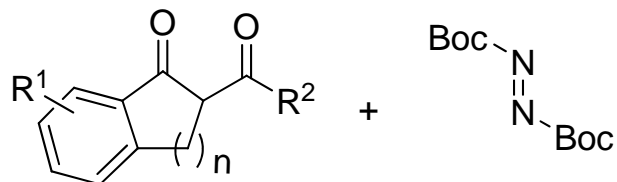

44

$18 b$

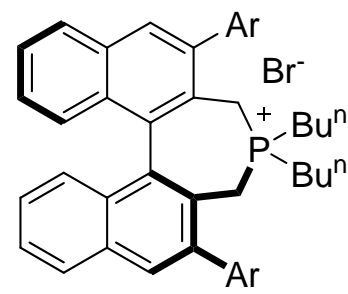

46, $\mathrm{Ar}=3,5-\left(\mathrm{CF}_{3}\right)_{2} \mathrm{C}_{6} \mathrm{H}_{3}$

(1 mol\%)<smiles>Brc1cc(Br)cc(-c2cc3ccccc3c3c2CN(C2(Br)CCOC2)Cc2c-3c(-c3cc(Br)cc(Br)c3)cc3ccccc23)c1</smiles>

47, $\mathrm{Ar}=3,5-\left(\mathrm{CF}_{3}\right)_{2} \mathrm{C}_{6} \mathrm{H}_{3}$

(3 mol\%)

$\mathrm{K}_{2} \mathrm{HPO}_{4}$, toluene, -20 or $-40^{\circ} \mathrm{C}$

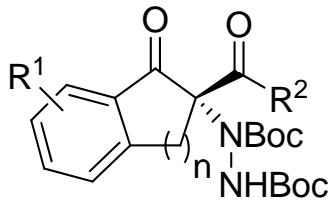


Similar results (85-95\%, ee 93-99\%) were obtained by using bifunctional thiourea 48 (10 mol\%, Figure 5) for the amination of cyclic tert-butyl $\beta$-ketoesters 44 , in toluene at $-30{ }^{\circ} \mathrm{C}$ [41]. DFT studies have been performed for the related bifunctional urea 49 in the reaction between 2-acetylcyclopentanone and dimethyl azodicarboxylate (18c) [42]. Based on the obtained results, a mechanism involving initial nucleophile activation via protonation of the amino group and electrophile activation through substrate binding to the urea moiety and then, $\mathrm{C}-\mathrm{N}$ bond formation between these two activated components, was proposed. The catalytic cycle finished with the proton transfer from the protonated amino group to the adduct, followed by its dissociation to give the final product. Four reaction channels corresponding to the different coordinate modes of two isomers of the enolate of the $\beta$-ketoester and the diazocarboxylate to the catalyst were characterized in detail, finding that the enantioselectivity of the reaction was controlled by the $\mathrm{C}-\mathrm{N}$ bond-forming step, which was the rate-determining step.

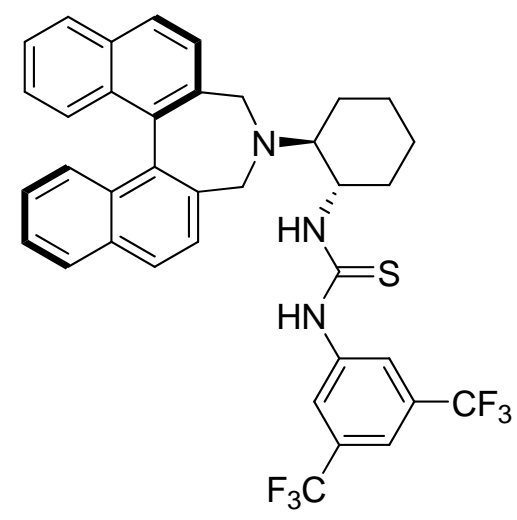

48

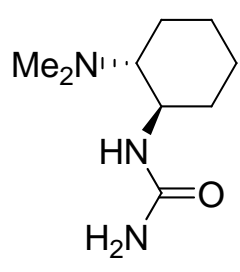

49

Figure 5

Novel chiral axially guanidine $\mathbf{5 1}(2 \mathrm{~mol} \%)$ has been used as catalyst for the electrophilic amination of several acyclic and cyclic $\beta$-ketoesters with di-tert-butyl azodicarboxylate (18b), affording excellent enantioselectivities for five and six-membered ring cyclic $\beta$-ketoesters 45 (99\%, ee 91-98\%) [43]. Also, good results were obtained with $\alpha$-methyl acyclic $\beta$-ketoesters 50 (Scheme 10). Unfortunately, the related $\beta$ ketolactone gave the aminated product in only $15 \%$ of enantiomeric excess. 
<smiles></smiles>

Boc $\stackrel{N}{N}$

50

$\mathrm{R}=\mathrm{H}, \mathrm{Me}, \mathrm{Et}$<smiles></smiles><smiles>[R]C(=O)OC(=O)N[C@@](C)(N[R16](=O)OCc1ccccc1)C([R])=O</smiles>

52

(54-99\%, ee 62-88\%)

\section{Scheme 10}

The aforementioned catalyst $48(10 \mathrm{~mol} \%)$ has been successfully used in the electrophilic amination of cyclic and acyclic $\alpha$-cyanoketones 53 [44]. Cyclic aromatic and aliphatic $\alpha$-cyanoketones reacted with di-tertbutyl azodicarboxylate (18b), giving the aminated products in good yields (77-95\%) and excellent enantioselectivities (94-99\%). Aliphatic $\alpha$-cyanoketones 53 gave also high levels of enantioselectivity under similar reaction conditions (Scheme 11). However, phenyl $\alpha$-cyanoacetate $\left(\mathrm{R}^{1}=\mathrm{Ph}, \mathrm{R}^{2}=\mathrm{CO}_{2} \mathrm{Et}\right)$ gave lower yield and enantiomeric excess $(86 \%$, ee $65 \%)$.

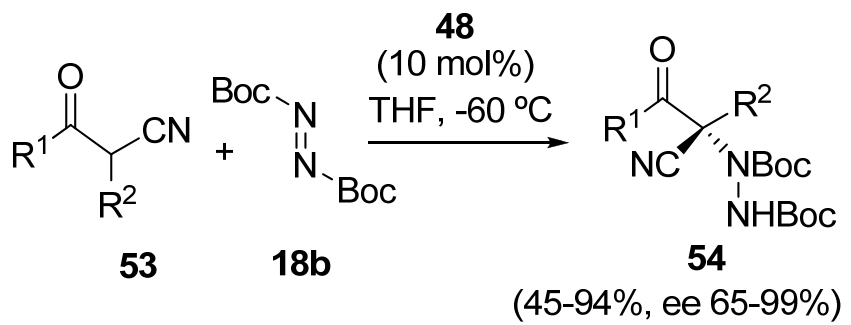

\section{Scheme 11}


Other chiral amines incorporating the $\alpha$-phenylethyl auxiliary such as compound 55 (50 mol\%) and diazabicyclo derivatives such as 56 (25 mol\%), have been tested in the reaction of diazocarboxylate $\mathbf{1 8 b}$ with phenyl $\alpha$-cyanoacetate $53\left(\mathrm{R}^{1}=\mathrm{Ph}, \mathrm{R}^{2}=\mathrm{CO}_{2} \mathrm{R}\right)$ in toluene at $-78^{\circ} \mathrm{C}$ affording the aminated products in similar results, up to $84 \%$ and $40 \%$ ee's (Figure 6) [45].

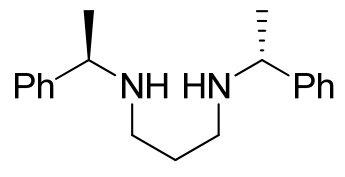

55

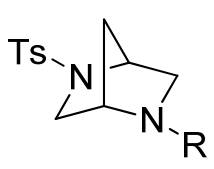

56

$$
\mathrm{R}=\left(\mathrm{CH}_{2}\right)_{2} \mathrm{NH}_{2},\left(\mathrm{CH}_{2}\right) \mathrm{CH},\left(\mathrm{CH}_{2}\right)_{3} \mathrm{OH}
$$

\section{Figure 6}

Aza- $\beta$-lactams are interesting compounds due to their biological activity, but their enantioselective synthesis has been scarcely developed. Like the enantioselective synthesis of other $\beta$-lactones and lactams, their synthesis can be performed by using a ketene as the starting material [46]. Planar-chiral derivative 58 (5 mol\%) has served as an efficient catalyst for the [2+2] cycloaddition of a ketene 57 with dimethyl azodicarboxylate (18c) generating aryl alkyl aza- $\beta$-lactams 59 with good results (Scheme 12) [47]. While small alkyl group in the ketene afforded the expected product with moderated yields and enantioselectivities, better results were obtained when a bulky secondary alkyl group was attached to the ketene. 


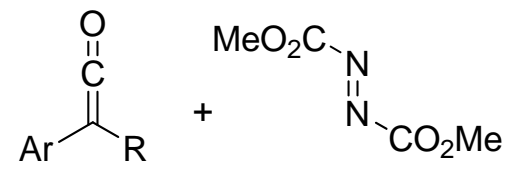

57 $18 \mathrm{C}$

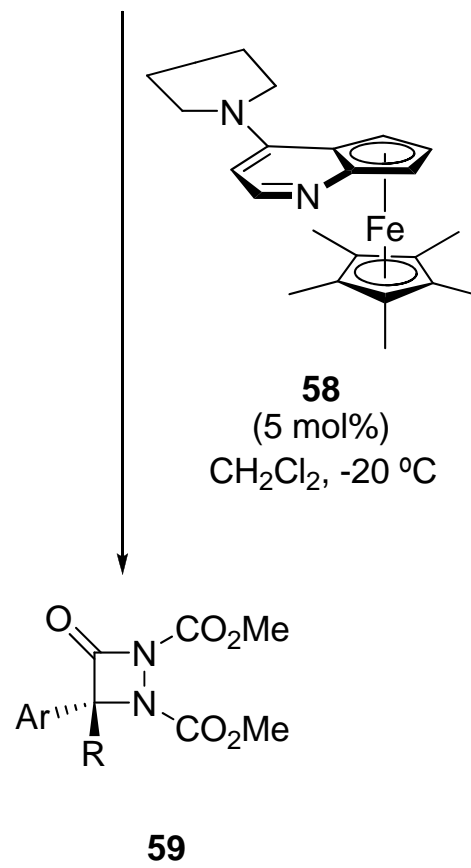

$(67-96 \%$, ee $46-91 \%)$

\section{Scheme 12}

Another strategy to perform an electrophilic amination of a carbonyl compound is through the reaction of an enamine or enolate with a nitroso derivative. As the nitroso compound contains two nucleophilic atoms, two possible processes could take place. The first one, generally promoted by the presence of carboxylic groups in the catalysts, is the $\mathrm{C}-\mathrm{O}$ bond forming reaction (aminoxylation or $\mathrm{O}$-nitroso aldol reaction) which will be discussed in section 3.1.2. On the other hand, the reaction through the nitrogen atom of the nitroso compound is the so-called hydroxyamination, oxyamination or $N$-nitroso aldol reaction, which has been less developed by organocatalytic methods. The regio- and enantioselectivity of the hydroxyamination process in the reaction between achiral enamines and nitrosobenzene (60a) promoted by chiral Brønsted acid catalyst, such TADDOL, have been studied by means of DFT calculations [48]. For this purpose, a model involving a simple organic acid $(\mathrm{MeOH}$ or $\mathrm{AcOH}$, resembling TADDOL or 1-naphthylglycolic acid) was used. From the results, a transition state, which involves the enamine, nitrosobenzene, and two or more organic acid molecules, forming a cluster-like structure was proposed. In this transition state, three hydrogen-bonds played an important role: the hydrogen-bond between the most acidic hydrogen atom of the organic acid and the $\mathrm{N}=\mathrm{O}$ group; the hydrogen- 
bond between the ortho hydrogen in the nitrosobenzene and the oxygen atom of the organic acid; and finally, the hydrogen-bond between hydrogen of the $N$-alkyl part in the $N, N$-dimethylcyclohexylenamine and the oxygen atom of the organic acid. From the relative stabilities of the founded transition states with $\mathrm{MeOH}$ and $\mathrm{AcOH}$ as organic acids, could be concluded that the alcohol catalysts (MeOH or TADDOL) promotes C-N bond formation due to the formation of a more-stable seven-membered ring structure, which is formed when the alcohol catalyst coordinates the oxygen atom of the $\mathrm{N}=\mathrm{O}$ group. Therefore, the nitrogen atom is activated and attacked. Meanwhile, the carboxylic acid catalyst promotes the $\mathrm{C}-\mathrm{O}$ bond formation by a eight-membered ring structure, formed when the carboxylic acid catalyst coordinates the nitrogen atom of the $\mathrm{N}=\mathrm{O}$ group, so the oxygen atom is activated and attacked. The observed enantioselectivity, when TADDOL was used as catalyst, was confirmed by the calculation of the energy values of the transition states for the $(R)$ - and $(S)$-products, which were $0.9 \mathrm{Kcal} / \mathrm{mol}$ more stable in favor of the formation of the $(S)$-enantiomer.

$N$-hydroxy- $\beta$-amino alcohols 62 were achieved in high yields and enantioselectivities using axially chiral secondary amine catalyst $\mathbf{6 1}(10 \mathrm{~mol} \%)$ to perform the hydroxyamination of linear aldehydes 29 with nitrosobenzene (60a, Scheme 13) [49]. Due to the instability of the resulting hydroxyamination product, in situ reduction to the corresponding alcohol was carried out using $\mathrm{NaBH}_{4}$. When $p$-methoxynitrosobenzene was used instead of nitrosobenzene, a one-pot procedure to transform the hydroxyamination product into the chiral corresponding $\beta$-amino alcohol or 1,2-diamine were developed using $\mathrm{LiAlH}_{4}$ as a reducing agent. 
$\overbrace{29}^{\mathrm{O}}+\mathrm{Ph}^{-N}$

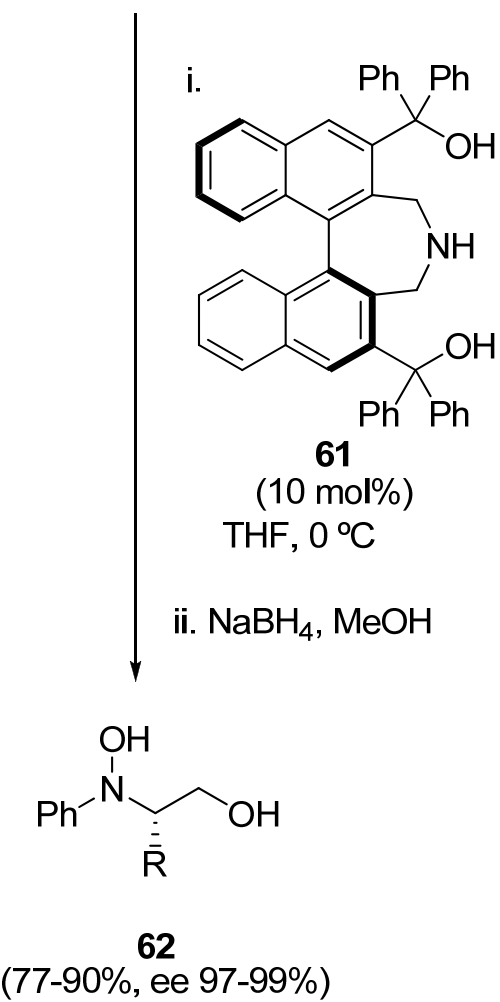

\section{Scheme 13}

Catalyst 15a (20 mol\%) provided products 62 in moderated yields and high enantiomeric excesses (40$75 \%$, ee $91-99 \%$ ) in the reaction of nitrosobenzene (60a) with linear aldehydes in dichloromethane at $0{ }^{\circ} \mathrm{C}$ [50]. Room temperature and longer reaction times were needed for long-chain aldehydes to achieve the expected products. DFT calculations showed that the free activation energy $\Delta \mathrm{G}^{\neq}$for the non-catalyzed hydroxyamination was higher than the $\Delta \mathrm{G}^{\neq}$values obtained in the presence of water or $N, N$ dimethylhydroxyamine, which mimics product 62 or its precursor. In addition, the encountered $\Delta \mathrm{G}^{\neq}$values for the catalyzed aminoxylation process are higher than those of the hydroxyamination. In this case, an enamine intermediate with a steric control approach from the Si face was proposed to rationalize the observed $(S)$ preference for the product 62. However, further theoretical investigations on the mechanism suggested that the reaction proceeds via an enol intermediate that has the lowest energy barrier among the initial possible reactions between the aldehyde and the catalyst [51]. The proposed transition state corresponded to two simultaneous hydrogen-exchanges between the aldehyde and the catalyst to form a trans-enol. Immediately, the trans-enol 
formed a complex with the catalyst via hydrogen bonding and subsequently, the nitrosobenzene attacks from the Si face of the enol via a new transition state. This transition state consisted in a simultaneous C-N bond formation between the enol and the nitrosobenzene; a hydrogen-shift from the oxygen of the enol to the nitrogen of the catalyst and a hydrogen-shift from the nitrogen of the catalyst to the oxygen of the nitrosobenzene, with the last hydrogen shift dictating the stereochemical outcome of the reaction.

$\alpha$-Branched aldehydes 17 can be aminated by nitrosobenzene (60a) using catalyst 30 (20 mol\%) in good yields and moderated enantiomeric excesses (Scheme 14) [52]. In this case, the regioselectivity of the process was rationalized by the steric repulsion between the $\alpha$-methyl group of the enamine and the phenyl group of the nitrosobenzene. However, the regioselectivity towards product 63 was very low with the exception of the case of $\alpha$-methyl- $\alpha$-aryl substituted aldehydes in which up to 20:1 63:64 were obtained. The use of 5-cis-phenyl proline as catalyst for this reaction gave a complete regioselectivity towards the formation of $\mathbf{6 3}$ although the product was racemic.

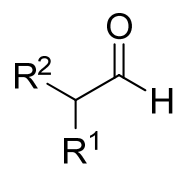

17
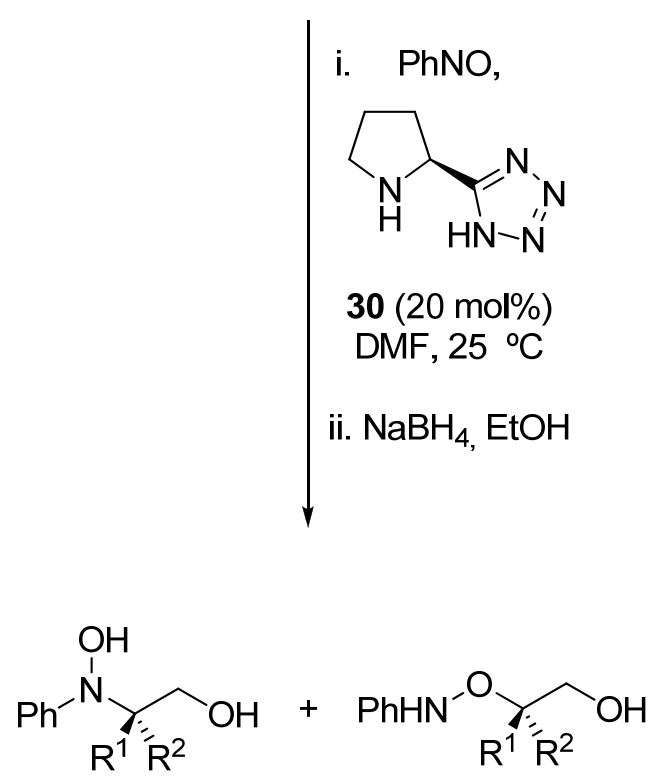

$63 \quad 64$

(ee 5-90\%)

\section{Scheme 14}


The synthesis of chiral 2-oxa-3-aza-bicycloketones 67 could be accomplished by using catalyst 66 (30 mol\%) by a hydroxyamination process, followed by a Michael addition (Scheme 15) [53]. When R was methyl in the starting enamine 65, the bicyclic product 67 was obtained as a single product with $90 \%$ yield and $90 \%$ ee. However, when the reaction was performed using enamine 65 bearing a phenyl group $(\mathrm{R}=\mathrm{Ph})$ the only obtained product was the hydroxyamination product 68 in $27 \%$ yield and $61 \%$ ee.
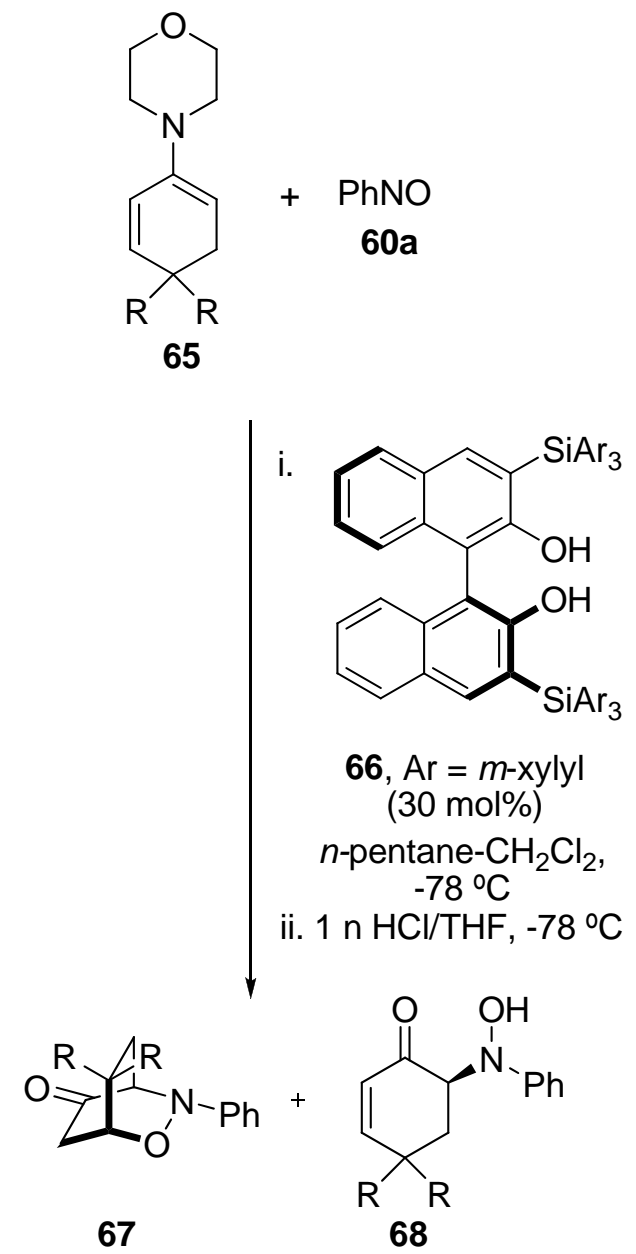

\section{Scheme 15}

$\alpha$-Aryl- $\alpha$-cyanoacetates 69 were also suitable substrates to perform the amination reaction using nitrosobenzene (60a) as a nitrogen source and cinchona alkaloids as catalysts affording exclusively the amination products, which are unstable and therefore have to be transformed into products $\mathbf{7 0}$ by treatment with $\mathrm{Zn}$ and $\mathrm{AcOH}$ [54]. From the tested cinchona alkaloids as catalysts for this reaction, quinine (5) provided the bests results (Scheme 16), with the methoxy group at the C6' position of the catalyst playing an important role in the transition state, as its absence inverts the outcome of the reaction. In addition, the same inversion in the 
enantioselectivity was observed when coordinating solvents such as THF, $\mathrm{Et}_{2} \mathrm{O}$, DMF or acetone were used, possibly, in these cases, due to the blocking of the hydroxy group present in the catalyst, which was then unable to activate the electrophile and therefore a complete different transition state is formed, driving to the opposite enantiomer. An unusual effect of the catalyst loading was also observed. So, the enantiomeric excess decreased when the catalyst loading increased and it was even inverted when 1 or 2 equiv were used. The study of the enantioselectivity of the reaction as a function of the molarity showed a maximum between 0.1 and $0.12 \mathrm{M}$, with phenomena of autocatalysis, kinetic resolution or autoinduction being ruled out.

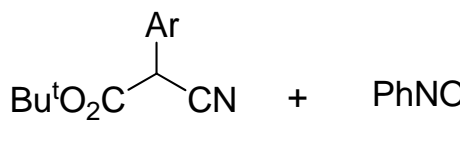

69

$60 a$

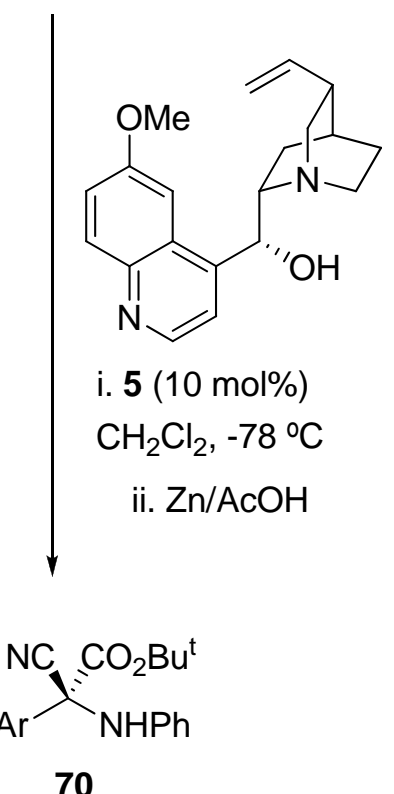

70

(73-85\%, ee 22-59\%)

\section{Scheme 16}

\section{Enantioselective $\alpha$-chalcogenation}

\subsection{C-O Formation}

The asymmetric oxyfunctionalization of carbonyl compounds involving the oxidation of a preexisting $\mathrm{C}-\mathrm{H}$ bond is a fundamental reaction in organic synthesis, due to the presence of these moieties in several natural products and in many versatile synthetic intermediates. Besides the early works in the field of the epoxidation 
of electron poor olefin by means of polyamino acids, several organocatalytic methods to perform this task have been recently developed.

\subsubsection{Darzens reaction}

Chiral $\alpha, \beta$-epoxy carbonyl compounds can be easily transformed to many interesting optically active molecules which serve as useful synthetic intermediates. The Darzens reaction, which involves a sequential aldol reaction followed by an intramolecular cyclization with control of the two new formed stereogenic centers, is one of the most useful methodologies for the construction of $\alpha, \beta$-epoxy carbonyl compounds. Although phase-transfer catalysis has shown its primacy in this context, recently the use of proline derivative 72a $\left(\mathrm{R}^{3}=\mathrm{SiMe}_{3}, 10 \mathrm{~mol} \%\right)$, to perform a domino Michael-Darzens condensation giving highly functionalized complex epoxycyclohexanone derivatives $\mathbf{7 3}$ with up to four stereogenic centers with high diastereo-and enantioselectivities, have been reported (Scheme 17) [55]. The reaction was quite general and $\gamma$-chloro- $\beta$ ketoesters $\mathbf{7 1}$ bearing different ester groups and Michael acceptors having different $\beta$-substituents could be used, with products 73 being obtained in similar yields and stereoselectivities. The proposed mechanism consisted in the Michael addition of the $\beta$-ketoester, which approach the planar iminum-ion intermediate from the $R e$ face due to the steric hindrance of the bulky substituents in 72a, followed by the aldol reaction promoted by $\mathrm{AcONa}$ and finally, deprotonation of the obtained alcohol to enable the intramolecular $\mathrm{S}_{\mathrm{N}} 2$ reaction to achieve the expected products 73 . 
<smiles>[R]C=CC=O</smiles>

14

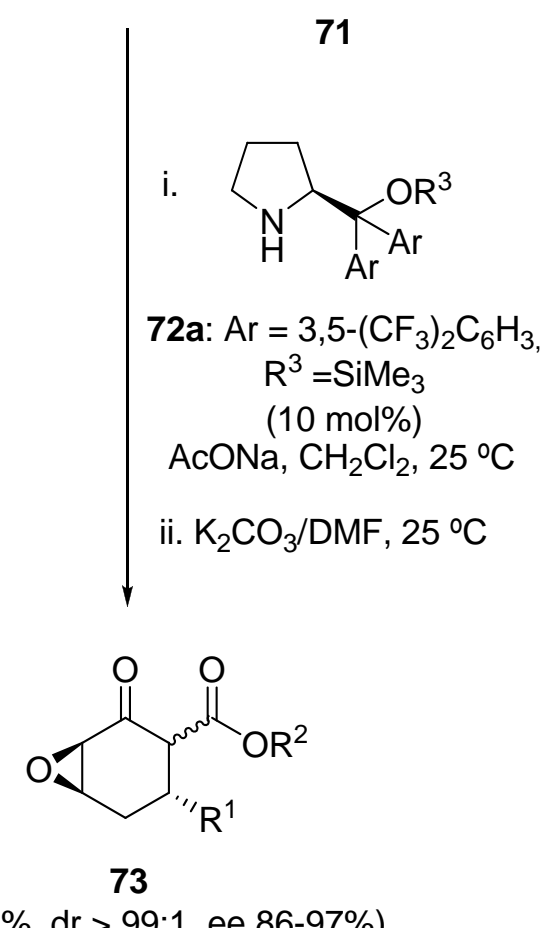

$(40-57 \%, d r>99: 1$, ee $86-97 \%)$

\section{Scheme 17}

Different aza-crown ethers derived from glucose $\mathbf{7 6}$ have been proposed as an alternative to chiral ammonium salts as phase-transfer catalysts and they have being tested in the Darzens reaction between $\alpha$ chloroacetophenone (74) and benzaldehyde (75a) in toluene-aqueous alkaline two-phase system to give the corresponding chiral trans epoxyketone 4a in moderated yield and enantioselectivity (Scheme 18) [56]. The influence of the structure of different glucose aza-crown derivatives was evaluated, achieving the best results when $\mathrm{R}^{1}$ was hydroxypropyl group and the glucose moiety was protected as a 4,6-O-benzylidene group. 


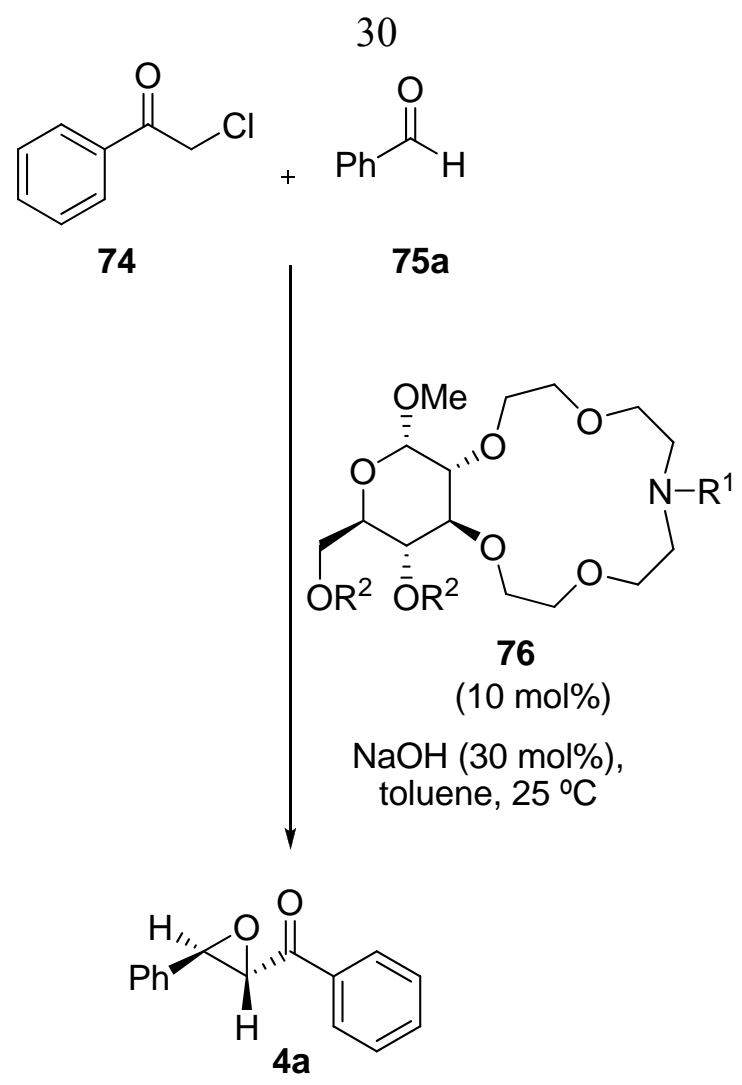

(30-76\%, ee 5-72\%)

\section{Scheme 18}

This synthetic methodology has been applied to the asymmetric synthesis of $\alpha, \beta$-epoxy sulfonyl compounds 79 (Scheme 19) using as a phase-transfer catalyst quinine salt 78 (10 mol\%) [57]. Several aromatic aldehydes $\mathbf{7 5}$ have been used in this reaction affording products $\mathbf{7 9}$ in good yields and high enantioselectivities. 


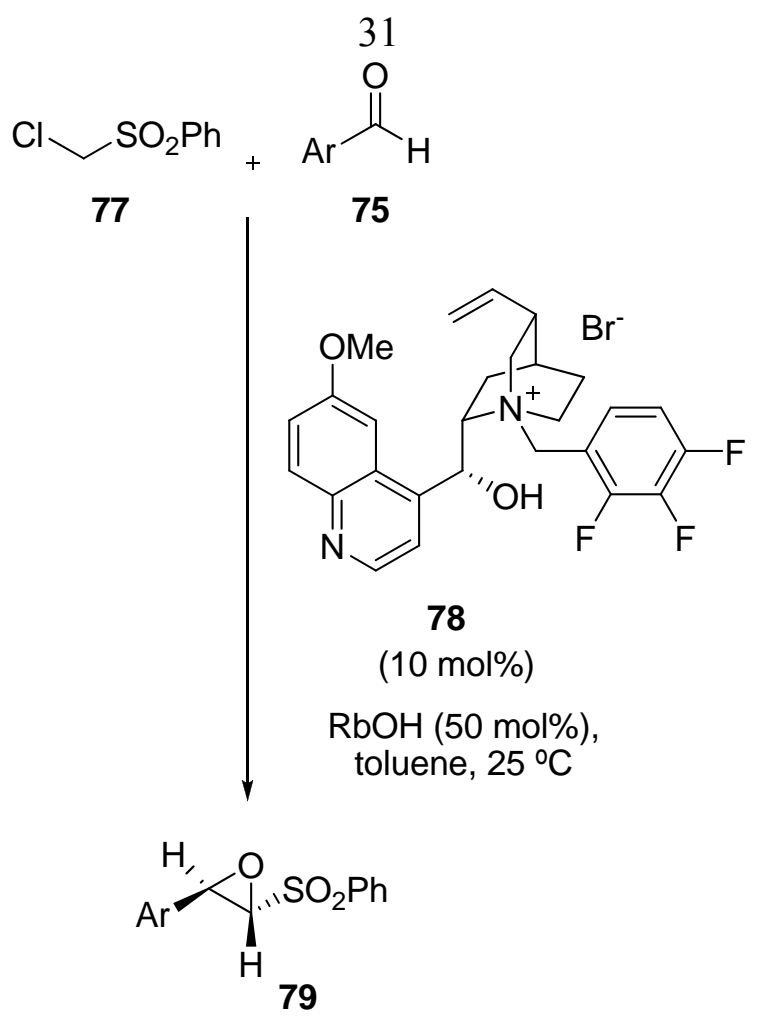

(80-95\%, ee $71-97 \%)$

\section{Scheme 19}

\subsubsection{Epoxidation of $\alpha, \beta$-unsaturated carbonyl compounds}

In the last years, significant progress has been made in the development of organocatalyzed methods for the asymmetric epoxidation of $\alpha, \beta$-unsaturated carbonyl compounds using different oxidative reagents [58], with obtained chiral epoxides having great importance as building blocks for the synthesis of natural and pharmaceutical products. Since 30 years ago, chiral transfer reagents have been applied to this transformation, with excellent levels of enantioselectivities being achieved. Cinchona alkaloid derivatives, such as catalyst 81a ( $1 \mathrm{~mol} \%)$ are able to promote the epoxidation of several non-enolizable $\alpha, \beta$-unsaturated ketones with high efficiency (Table 2, entries 1,5) [59] under mild reaction conditions. Apolar solvents are compulsory in order to achieve good enantioselectivity. When $\mathrm{R}^{1}$ was a carbonyl moiety, the obtained enantioselectivities were generally lower (Table 2, entry 5) and trisubstituted chalcones did not undergo epoxidation under these reaction conditions. These reaction conditions have been also applied to the diastereoselective epoxidation of interesting substrates such as carbohydrates precursors and epoxysuccinyl peptides [59b]. The one-pot conversion of allylic alcohols to chiral $\alpha, \beta$-epoxyketones 80 were also possible using catalyst $81 \mathrm{a}$ (5 mol\%) giving similar results when a slow addition of the substrate to the reaction mixture was performed. 
The dimeric cinchona catalyst $82(1 \mathrm{~mol} \%)$ catalyzed the epoxidation of $(E)$-diarylenones 10 with high levels of enantioselectivities (Table 2, entries 6 and 7) [60]. The length of the spacer between the two cinchona units in 82 and the use of different surfactants influenced yields and selectivities of the reaction, with the best achieved results being obtained using surfactant Span 20. A plausible transition state with the chalcone located between the two cinchona units, in which the $\beta$-phenyl group of the chalcone has a $\pi-\pi$ stacking interaction with one of the quinolidine moiety, was proposed. The carbonyl oxygen atom is placed close to the nitrogen center. Meanwhile, the other nitrogen was ion-paired with the hydrogen peroxide ion forcing the approach of the oxidant to the $\beta$ carbon atom of the chalcone from the upside, giving the epoxide $\mathbf{8 0}$ with the absolute configuration observed experimentally.

Moderated enantioselectivities were obtained in the epoxidation of $(E)$-diarylenones $\mathbf{1 0}$ with soluble chiral polymeric ammonium salts anchored to diacetamido- $\mathrm{PEG}_{2000}$ chloride resins [61]. The best results were obtained by using quininium salt $83(5 \mathrm{~mol} \%$, Table 2 , entry 8$)$ and chalcone 10a $\left(\mathrm{R}^{1}=\mathrm{R}^{2}=\mathrm{Ph}\right)$ as substrate. Other chalcones afforded the corresponding chiral epoxides $\mathbf{8 0}$ with lower yields and enantioselectivities.

Another successful catalyst used in the enantioselective epoxidation of $(E)$-enones was the aza-crown ether-type ammonium salt 84 [62] derived from (S)-BINOL. The kind of base and the length of the carbon chains at the nitrogen were determinant to obtain good results, with potassium hydroxide and ammonium salt 84, bearing an octyl group, providing the best enantioselectivities (Table 2, entry 9). While electron-poor chalcones gave the epoxidated products $\mathbf{8 0}$ with homogeneous yields and enantioselectivities, electron rich chalcones were unsuitable substrates. 
Table 2. Epoxidation of $\alpha, \beta$-unsaturated ketones catalyzed by cinchona alkaloid derivatives

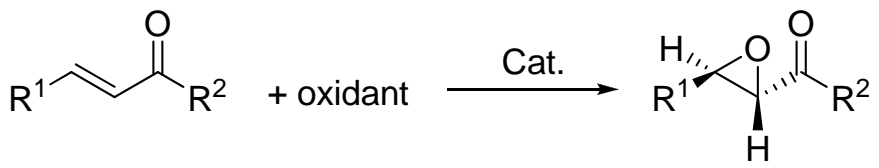

10

80<smiles>CCC1CC2CCC1[N+]2(Cc1c2ccccc2cc2ccccc12)[C@H](OCc1ccccc1)c1ccnc2ccc(OC)cc12</smiles>

$81 a$

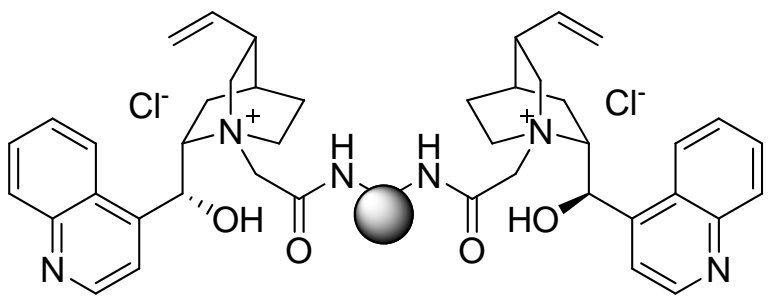

83<smiles>C=CC1CC2CCC1[N+]2(Cc1cccc(C[N+]2([C@@H](O)c3ccnc4ccc(OC)cc34)CCCC2C=C)c1F)[C@H](O)c1ccnc2ccc(OC)cc12</smiles>

82

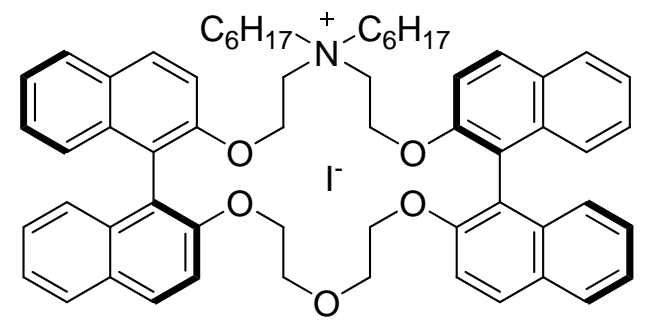

84

\begin{tabular}{|c|c|c|c|c|c|c|c|}
\hline Entry & $\mathrm{R}^{1}$ & $\mathrm{R}^{2}$ & Cat. (\%) & Oxidant & Reaction conditions & Yield (\%) & ee $(\%)$ \\
\hline 1 & $\mathrm{Ph}$ & $\mathrm{Ph}$ & 81(1) & $\mathrm{NaOCl}$ & Toluene, $25^{\circ} \mathrm{C}$ & 98 & 86 \\
\hline 2 & $\mathrm{Ph}$ & $4-\mathrm{FC}_{6} \mathrm{H}_{4}$ & 81(1) & $\mathrm{NaOCl}$ & Toluene, $25^{\circ} \mathrm{C}$ & 94 & 87 \\
\hline 3 & $\mathrm{Ph}$ & $\mathrm{Bu}^{\mathrm{t}}$ & 81(1) & $\mathrm{NaOCl}$ & Toluene, $25^{\circ} \mathrm{C}$ & 83 & 87 \\
\hline 4 & $\mathrm{C}_{6} \mathrm{H}_{11}{ }^{\mathrm{n}}$ & $\mathrm{Ph}$ & 81(1) & $\mathrm{NaOCl}$ & Toluene, $25^{\circ} \mathrm{C}$ & 90 & 81 \\
\hline $5^{a}$ & $\mathrm{PhCO}$ & $\mathrm{Ph}$ & 81(1) & $\mathrm{NaOCl}$ & Toluene, $25^{\circ} \mathrm{C}$ & 93 & 68 \\
\hline $6^{\mathrm{a}}$ & $\mathrm{Ph}$ & $\mathrm{Ph}$ & 82(1) & $\mathrm{H}_{2} \mathrm{O}_{2}$ & $\begin{array}{l}\mathrm{KOH}, \text { Span } 20, \\
\operatorname{Pr}_{2}^{\mathrm{i}} \mathrm{O}, 25^{\circ} \mathrm{C}\end{array}$ & 95 & 99 \\
\hline 7 & $\mathrm{Ph}$ & $4-\mathrm{FC}_{6} \mathrm{H}_{4}$ & 82(1) & $\mathrm{H}_{2} \mathrm{O}_{2}$ & $\begin{array}{l}\mathrm{KOH}, \text { Span } 20, \\
\operatorname{Pr}_{2}{ }^{\mathrm{i}} \mathrm{O}, 25^{\circ} \mathrm{C}\end{array}$ & 94 & 98 \\
\hline 8 & $\mathrm{Ph}$ & $\mathrm{Ph}$ & $83(5)$ & $\mathrm{Bu}^{t} \mathrm{OOH}$ & $\mathrm{KOH}, \mathrm{CH}_{2} \mathrm{Cl}_{2}, 0^{\circ} \mathrm{C}$ & 90 & 86 \\
\hline 9 & $\mathrm{Ph}$ & $\mathrm{Ph}$ & 84(10) & $\mathrm{H}_{2} \mathrm{O}_{2}$ & $\mathrm{KOH}$, Toluene, $0^{\circ} \mathrm{C}$ & 85 & 70 \\
\hline
\end{tabular}

Glucopyranoside derived aza-crown ethers 76 (5 mol\%) have also been used in the epoxidation of $(E)$ diarylenones 10 [56]. The best results were obtained when $\mathrm{R}^{1}$ in catalyst $\mathbf{7 6}$ was a hydroxyethyl or 
hydroxypropyl group and tert-butylhydroperoxide was used as oxidant in a liquid-liquid two-phase system using toluene and $20 \%$ aqueous sodium hydroxide at $3{ }^{\circ} \mathrm{C}$. Under these conditions, product 80a was obtained in $81 \%$ yield and $92 \%$ ee. When the $\beta$-phenyl group in $\mathbf{8 0 a}$ was replaced by other groups, the observed yields and enantioselectivities were lower. However, when $\mathrm{R}^{2}$ in the starting enone 10, was substituted by a phenyl ring having a methyl or alkoxy substituent at the ortho position, the corresponding epoxides $\mathbf{8 0}$ were obtained in yields ranging from 46 to $55 \%$ and with good enantioselectivities $(70-83 \%$ ee). In order to determine the absolute configuration of these epoxides, electronic absorption and CD spectra were measured. The assignment of the UV and CD spectra was done on the basis of DFT calculations, with a carbonyl band at $320 \mathrm{~nm}$ and two strong bands corresponding to overlapping signals of $\pi-\pi^{*}$ and $n_{\text {epoxy }}-\pi^{*}$ being observed. These three bands were indicative of the absolute configuration of the obtained epoxides [63]. In further epoxidation studies, it was shown that the configuration of the sugar annelated to the crown ether has a crucial influence over the enantioselectivity. Molecular modeling and DFT calculations indicated that the glucopyranoside and mannopyranoside based aza-crown ethers gave the formation of opposite enantiomers for the corresponding epoxide 80. Based on the results of the calculations, it was proposed that the annelated sugars selected the energetic ordering of the chiral transition states through their hydrogen-bonding capabilities [64].

Other phase transfer catalysts are guanidine base type structures (Figure 7), which have been used in the epoxidation of $(E)$-enones 10. While pentacyclic guanidine $85(10 \mathrm{~mol} \%)$, which have a characteristic closedtype cavity, gave products $\mathbf{8 0}$ in moderated yields (22-99\%) and enantioselectivities (35-60\% ee) using tertbutylhydroperoxide as oxidant in a liquid-liquid dichloromethane and aqueous potassium hydroxide two-phase system at $0{ }^{\circ} \mathrm{C}$, trycyclic guanidine $86(10 \mathrm{~mol} \%)$ afforded epoxides 80 almost quantitatively with the same levels of enantioselectivity [65] in similar reaction conditions. Higher enantioselectivities $(60-73 \%$ ee) were obtained by using acyclic hydroxy-guanidine $87(10 \mathrm{~mol} \%)$, in which a plausible transition state involving the coordination of the carbonyl group with the guanidine through hydrogen bonding and an interaction of the hydroxy group with the tert-butylhydroperoxide anion was proposed to explain the observed stereososelectivity [66]. Hydrogen peroxide was also used as oxidant in reactions involving guanidines as catalysts. Thus, several axial stereogenic guanidines 88 (10 mol\%) were used in the enantioselective epoxidation of chalcone 10a in the presence of $30 \%$ aqueous hydrogen peroxide in toluene at room temperature [67]. The highest catalytic activity was obtained when $\mathrm{R}^{1}$ in $\mathbf{8 8}$ was a phenyl moiety bearing a tert-butyl substituent at the para position, but the 
achieved enantioselectivities were very modest. In order to increase them, a chiral substituent was incorporated to the nitrogen atom of the guanidine moiety $\left(\mathrm{R}^{2}\right.$ in 88$)$, with the best results being obtained for the $(S)$ phenethyl and (S)-naphthylethyl derivatives (50 and 52\% ee, respectively). The highest enantioselectivities for this series were achieved when guanidine-urea bifunctional catalyst 89 (5 mol\%) with Ar being 3,5ditrifluoromethylphenyl groups was used for the epoxidation of $(E)$-enones $\mathbf{1 0}$ in the presence of $30 \%$ aqueous hydrogen peroxide and sodium hydroxide as a base in toluene at $-10^{\circ} \mathrm{C}$ [68]. Under these reaction conditions a variety of $(E)$-diarylenones 10, having electron-withdrawing or electron-donating groups could be used affording the corresponding epoxides $\mathbf{8 0}$ in $91-99 \%$ yield and $85-96 \%$ of enantiomeric excesses. Furthermore, the catalyst can be recovered from the reaction mixture by chromatographic purification and was reused up to five times giving the same level of enantioselectivity.<smiles>CO[C@@H]1NC2(CCC[C@H](C)C2)C[C@H]2[C@@H](OC)C3=[N+]2[C@H]1CC1(CCC[C@@H](C)C1)N3</smiles>

85

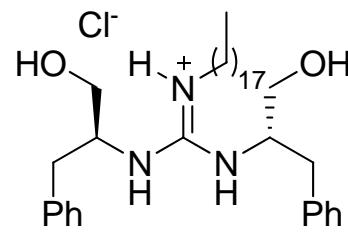

87<smiles>CO[C@@H]1[C@H](OC)[C@H]2C[C@H](Cc3ccccc3)NC3=[N+]2[C@@H]1CC(Cc1ccccc1)N3</smiles>

86<smiles>[R][X]=C(NC)NCc1c([R])cc2ccccc2c1-c1c([R])cc2ccccc2c1CNC(=N[R2])NC</smiles>

88<smiles>C[14C](C)=[N+](C)[N+](C)=C(NC[C@H](Cc1ccccc1)NC(=O)N[Al])NC(=O)N[Al]</smiles>

89

Figure 7

The organocatalytic epoxidation of $(Z)$-enones has been less developed than the epoxidation of the corresponding $(E)$-enones, with an efficient method to perform this task being highly desirable. (Z)-10a was slowly epoxidized, requiring $10 \mathrm{~mol} \%$ of catalyst $\mathbf{8 1 a}\left(\mathrm{R}^{1}=\mathrm{H}, \mathrm{OR}^{2}=\mathrm{OBn}\right)$, to afford cis-80a in $72 \%$ yield 
albeit with moderated enantioselectivity (53\% ee) [59a]. In this context, 2-methylnaphtoquinone (vitamin $\mathrm{K}_{3}$, 90) was epoxidized to compound 91 with good results (Scheme 20) [69]. Different structural modifications, such as the use of free hydroxyl group in $\mathrm{C6}^{\prime}\left(\mathrm{R}^{1}=\mathrm{OH}\right)$ instead of methoxy, the introduction of additional elements of chirality through the alkylation of the nitrogen in the quinuclidine core and the alkylation of the hydroxy group in the $\mathrm{C} 9$ atom of the quinine derivative $\mathbf{8 1}$, were done in order to study its influence in the stereochemical outcome of the reaction. From the experimental results, it can be concluded that the introduction of additional elements of chirality led to a decrease on the observed enantioselectivities, the alkylation of the hydroxy group at the $\mathrm{C} 9$ atom $\left(\mathrm{OR}^{2}=\mathrm{OBn}\right)$ switched the sense of stereoinduction and finally, a free hydroxy group at $\mathrm{C}^{\prime}\left(\mathrm{R}^{1}=\mathrm{OH}\right)$ remarkably increased the enantioselectivity. Conformational analysis of the two possible diastereomeric enolate-catalyst complexes based in the Corey's model, showed for the best catalyst 81b $\left(\mathrm{R}^{1}=\mathrm{OR}^{2}=\mathrm{OH}\right)$, the expected $\pi$ - $\pi$-stacking between the catalyst and the substrate, and an additional stabilization through a hydrogen bond between the hydroxy group at $\mathrm{C} 9$ and the carbonyl oxygen atom of the substrate, providing a rational explanation of the stereochemical outcome of the reaction. 
<smiles>CC1=CC(=O)c2ccccc2C1=O</smiles>

90

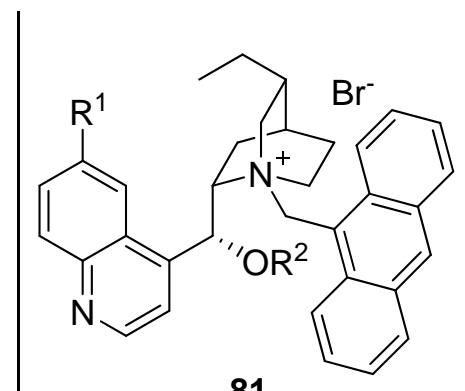

81

(2.5 mol\%)

$\mathrm{NaOCl}$,

$\mathrm{PhCl},-10^{\circ} \mathrm{C}$<smiles>CC1(C)C(=O)C(=O)c2ccccc2C1=O</smiles>

91

(73\%, ee $85 \%)$

\section{Scheme 20}

Catalyst 81a $\left(5 \mathrm{~mol} \%, \mathrm{R}^{1}=\mathrm{H}, \mathrm{OR}^{2}=\mathrm{OBn}\right)$ have been successfully used to carry out the one-pot aldol condensation-epoxidation starting from aromatic aldehydes 75 and aryl methyl ketones, giving the corresponding condensation products, which were subsequently epoxydated using trichloroisocyanuric acid (TCCA) affording trans-diarylepoxides 80 in moderated yields and good enantioselectivities $(61-99 \%, 75-96 \%$ ee) [70].

One of the most efficient methods for the epoxidation of $(E)$-enones is the use of oligopeptide catalysts (Juliá-Colonna reaction). The progress of the reaction kinetic analysis have been studied using the polyleucine 92a (Figure 8) in the catalyzed epoxidation of diarylenones 10 [71]. Reaction rate was monitored as a function of time using reaction calorimetry. The reaction progress curve revealed a brief induction period rather than a substrate inhibition before the steady-state cycle, with a well-behaved first-order in chalcone concentration relationship rate being established. Form the analysis of the obtained results, it was demonstrated that the reaction proceeded via a reversible addition of the diarylenone to the polyleucine-bound hydroperoxide, which 
forms a fleeting hydroperoxy enolate species. This hydroperoxy enolate species was involved in the ratelimiting step.

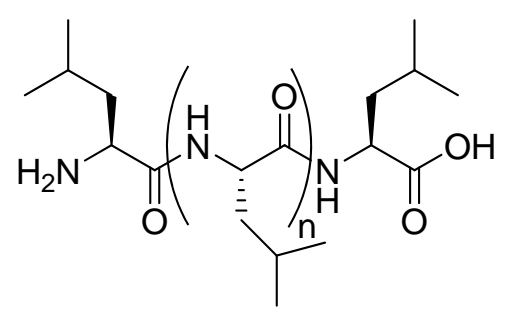

$92 a$

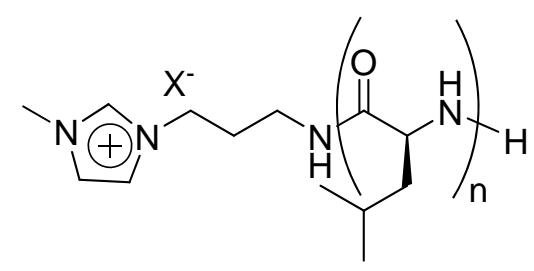

[3-apmim][X]-PLL, $92 \mathbf{b}$

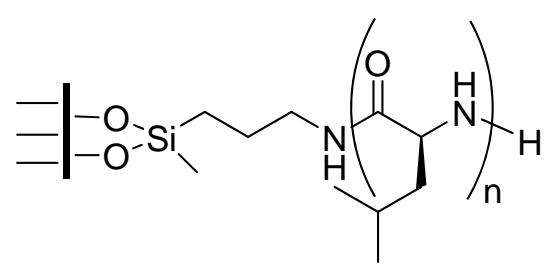

Silica gel-AP-PLL, 92c

\section{Figure 8}

The original triphasic conditions of the Juliá-Colonna reaction has at least three factors limiting its practical applicability: The high catalyst loading required (around $200 \mathrm{wt} \%$ ), the long time required for the catalyst pre-activation and for the reaction completion, and finally the tedious recovery of the catalyst owing to the voluminous gel-like catalyst formed. Improved protocols to overcome these problems have been developed. One of them was the use of a phase transfer reagent as a co-catalyst in combination with the triphasic conditions [72], which is more attractive, from the industrial point of view, since no pre-activation of the catalyst is required and the base and oxidant used are rather inexpensive. On the other hand, if the polymerization of the amino acid was done in toluene at reflux instead of the usual standard conditions at $50{ }^{\circ} \mathrm{C}$, a very active catalyst was obtained. The use of this new catalyst and tetrabutylammonium bromide (TBAB) as the phase transfer co-catalyst was able to accelerate the generation of the complex between hydrogen peroxide and the polyleucine, reducing the time of the reaction from hours to minutes. Under these new reaction 
conditions the amount of catalyst, oxidant and base could be reduced significantly without compromising the results. Thus, using the high temperature polymerized polyleucine (92a, $5 \mathrm{wt} \%)$, TBAB (3 mol\%), aqueous hydrogen peroxide (1.5 equiv) and sodium hydroxide (1.5 equiv) in toluene, several (E)-enones 10 were epoxidized, achieving high conversions and enantioselectivities for diarylenones $(97-99 \%, 84-93 \%)$ and more moderate results for $\beta$-phenyl alkyl enones $\left(\mathbf{1 0}, \mathrm{R}^{1}=\mathrm{Ph}, \mathrm{R}^{2}=\right.$ alkyl) in shorter reaction times to those previously described.

Several strategies have been used in order to recover the polyamino acid catalyst from the reaction mixture. For instance, if the polymerization was initiated by 1-(3-aminopropyl)-3-methylimidazolium ([3apmim $][\mathrm{X}]$ ) as a nucleophile in the preparation of polyleucine (92a), a catalyst with a structure [3-apmim][X]PLL (92b, Figure 8) was obtained [73]. The introduction of this quaternary ammonium salt, provided a catalyst with phase-transfer ability, which was used $(20 \mathrm{~mol} \%)$ for the epoxidation of diarylenones 10 in dimethyl ether using sodium percarbonate as oxidant and base. Under these conditions, epoxides 80 were obtained in short reaction times, high yields and enantioselectivities $(90-98 \%, 93-99 \%$ ee) with the exception of ortho $\beta$ methoxyphenyl phenylenone which gave much lower yield (24\%) and moderate enantioselectivity $(77 \%$ ee). The reusability of [3-apmim][Cl]-polyleucine (92b) was evaluated, being reused after filtration for seven times without losing its catalytic efficiency.

Another strategy used for the recovery of the catalyst is its incorporation to a heterogeneous support. Thus, polyleucine was immobilizated in a silica-grafted support [74]. For this purpose, 3(aminopropyl)triethoxysilane (APTESi) was used as initiator in the polymerization of L-leucine leading to the formation of AP-PLL (aminopropyl functionalized polyleucine) which was covalently grafted on the silica surface by reaction of silanol groups with triethoxysilane groups of the polymer. This silica gel-AP-PLL (92c, Figure 8) was used as catalysts for the epoxidation of diarylenones $\mathbf{1 0}$ in dimethyl ether using sodium percarbonate as oxidant and base, giving, for instance, the epoxide 80a in 95\% yield and 95\% enantiomeric excess. The catalytic activity and enantioselectivity improved when the chain length was increased, with best results being achieved with a degree of polymerization of 50. This catalyst can be recovered and reused for six times without detrimental results. However, the catalytic activity and selectivity were notably decreased after the sixth reaction cycle. 
Polyethylene glycol-polyleucine was used as catalyst in a laboratory-batch and continuous-reactor conditions [75]. For the continuous runs, a setup consisting in two micromixers and two tubular microreactors were used, the first for the deprotonation step and the second for the epoxidation step. In the first mixer the hydrogen peroxide and catalyst were mixed with 1,8-diazabyciclo[5.4.0]undec-7-ene (DBU) before their incorporation to the first reactor. In the second mixer, diarylenone 10a $\left(\mathrm{R}^{1}=\mathrm{R}^{2}=\mathrm{Ph}\right)$ was mixed with the oxidant-catalyst mixture before entrance to the second reactor. With this setup, a production rate of $1 \mathrm{~g} / \mathrm{day}$ was achieved with comparable results in terms of yield and enantioselectivy to those obtained in the batch process.

A series of optically active dynamic helical polyphenylacetylenes bearing oligopeptide pendants (from monomer to trimer) consisting in the combination of (S)-alanine and glycine residues (93, Figure 9) were synthesized and tested as polymeric organocatalyst for the asymmetric epoxidation [76]. CD spectra of the obtained polymers showed typical patterns for one-handed helical conformation with the same helical sense biased by the inner $(S)$-alanine residue incorporated in the pedant oligopeptides, independently of their sizes or sequences. The highest enantioselectivities achieved (34\% ee for $R^{1}=R^{2}=P h$ in 10) was obtained with the system 93, for the epoxidation of $(E)$-diarylenones 10, using 35\% aqueous hydrogen peroxide and sodium hydroxide in toluene at room temperature. In sharp contrast, the corresponding monomers showed almost no enantioselectivity. The introduction of electron-donating or withdrawing groups in the phenyl ring of the substrate led to a significant decrease in the obtained enantioselectivities.

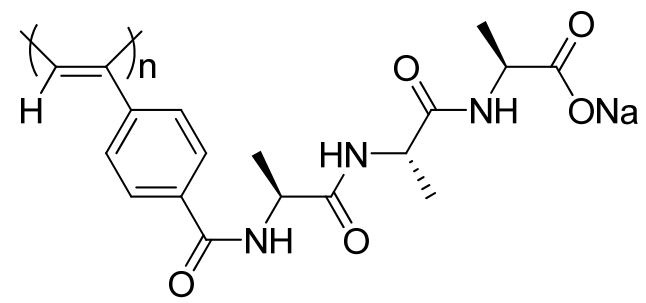

93

\section{Figure 9}

Although the epoxidation of enones using phase transfer catalysts or polyamino acid catalysts is well established, the related reaction with $\alpha, \beta$-unsaturated aldehydes has been only successfully performed using secondary amine catalysts. In this area, diarylprolinols such as $\mathbf{1 5}$ have shown previously their primacy over other catalysts. Thus, using catalyst 15a $(10 \mathrm{~mol} \%)$ and $50 \%$ aqueous hydrogen peroxide, several $\alpha, \beta-$ 
unsaturated aldehydes 14 were epoxidized in good yields and with high diastereo- and enantioselectivities in dichloromethane at room temperature $(55-90 \%$, dr up to $95: 5,91-98 \%$ ee) [77]. The achieved enantioselectivities were higher for aromatic aldehydes derivatives than for aliphatic $\alpha, \beta$-unsaturated aldehydes. Also, $\beta, \beta$-dialkyl $\alpha, \beta$-unsaturated aldehydes were suitable substrates for this reaction, affording the corresponding epoxides in good yields and diasteroselectivities, but with lower enantioselectivities. However, the reaction failed when the same conditions were applied to $\alpha, \beta$-unsaturated ketones. Several parameters such as oxidant, solvent and different catalyst were studied in this transformation, finding that catalysts bearing diarylprolinol structures such as $\mathbf{1 5}$ gave the best results in terms of enantioselectivity. Also, it was found that the epoxidation reaction using hydrogen peroxide as oxidant could be performed in water, affording good levels of enantioselectivity albeit with lower diastereoselectivity. However, sodium percarbonate was a suitable oxidant in chloroform giving similar results to that encountered with hydrogen peroxide. The absolute configuration of the obtained epoxides was determined to be $(2 S, 3 R)$ with a chiral iminium ion intermediate with a efficient shielding of the Si-face by the bulky aryl groups present in the catalyst being proposed to rationalize the obtained results. The use of the standard epoxidation conditions have permitted the development of several tandem transformations such as epoxidation-epoxide ring opening to afford chiral triols 94 (Scheme 21) [77a], epoxidation-Wittig sequences to give $\alpha, \beta$-unsaturated 4-epoxides with good overall yields and excellent diastereo- and enantioselectivities (39-56\%, dr $>10: 1,97 \%$ ee), and cascade epoxidation-Mannich reactions yielding protected 2-keto-4-amino-5-epoxides with good results (45-75\%, dr up to 19:1, ee > 95\%). 
<smiles>[R]C=CC=O</smiles>

14<smiles>CSC(O[Na])(c1ccccc1)C1CCCN1</smiles>

$15 \mathrm{a}$

(20 mol\%)

$\mathrm{H}_{2} \mathrm{O}_{2}, \mathrm{CHCl}_{3}$,

$25^{\circ} \mathrm{C}$

ii. $\mathrm{NaBH}_{4}, \mathrm{MeOH}-\mathrm{CHCl}_{3}, 0^{\circ} \mathrm{C}$

iii. $\mathrm{H}_{2} \mathrm{SO}_{4}(0.5 \mathrm{~N}), 25^{\circ} \mathrm{C}$<smiles>[R]C(O)C(O)CO</smiles>

94

(38-63\%, dr 2:1-50:1, ee 68-93\%)

\section{Scheme 21}

The aforementioned epoxidation has been also performed using imidazolidinone 95 (20 mol\%, Figure 10) in combination with perchloric acid and (nosylimino)iodo benzene (NsNIPh) as hypervalent iodine oxidant. In this manner, several $\alpha, \beta$-unsaturated aliphatic aldehydes were epoxidized in high yields and enantioselectivities $(72-93 \%, 87-97 \%$ ee) [78], with only enals possessing an electron-withdrawing group being unreactive under these reaction conditions. NMR studies were undertaken in order to explore the controlled release of monomeric iodosobenzene from NsNIPh and its concentration effect on the rate of imidazolidinone catalyst oxidation. From the results, it can be concluded that NsNIPh undergoes a slow hydrolysis to provide a steady increase in the concentration of monomeric iodosobenzene. Moreover, when ${ }^{15} \mathrm{~N}$ isotopically labeled imidazolidinone was used as catalyst for the epoxidation of cinnamaldehyde $14 a\left(R^{1}=P h\right)$ using iodosobenzene and $\mathrm{NsNIPh}$ as reaction oxidants, it was observed that while iodosobenzene leads to the formation of three catalyst derived amines over the reaction course, NsNIPh leads only to the formation of the corresponding imine.

The new catalytic salt 96, derived from 3,3'-bis(2,4,6-triisopropylphenyl)-1,1'-binaphthyl-2,2'-diyl hydrogen phosphate (TRIP, $10 \mathrm{~mol} \%$, Figure 10) in combination with tert-butylhydroperoxide was able to 
catalyze the epoxidation of several $\alpha, \beta$-unsaturated aldehydes in good yields $(60-84 \%)$ and with excellent diastereo- and enantioselectivities (up to 99:1 dr, 70-96\% ee), with lower results being found for simple alkylsubstituted enals [79]. Furthermore, $\beta, \beta$-disubstituted $\alpha, \beta$-unsaturated aldehydes were suitable substrates for this transformation allowing the synthesis of the corresponding epoxides in good yields and moderated enantioselectivities $(75-95 \%, 54-94 \%$ ee).

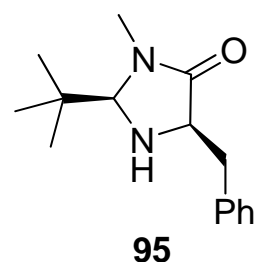

95

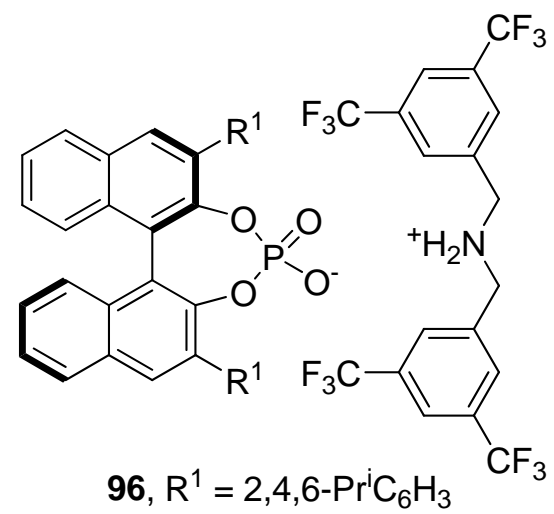

Figure 10

Although catalyst 15a was unable to catalyze the asymmetric epoxidation of $\alpha, \beta$-unsaturated ketones, related diaryl-2-pyrrolidinemethanols promoted this transformation with high efficiency (Table 3). Thus, the epoxidation of several (E)-enones 10 was catalyzed by $97(10 \mathrm{~mol} \%)$ using tert-butylhydroperoxide as oxidant under mild reaction conditions affording products $\mathbf{8 0}$ with high yields and enantioselectivities (Table 3 , entries 1-4) [80]. Diarylenones bearing electron-donating or electron-withdrawing groups are suitable substrates for this reaction, with conversions for $\beta$-phenyl derivatives having electron-donating groups being lower. In the case of alkyl substituted $\alpha, \beta$-unsaturated ketones, while lower enantioselectivity but good conversion were observed for $\beta$-alkyl derivatives, lower conversion but high enantioselectivity were obtained for $\beta$-phenyl alkyl derivatives (Table 3, entries 3-4). A study to understand the structural requirements of the catalytic system was carried out. So, the pyrrolidine ring was substituted for the corresponding azetidine or pyperidine ring. These two new catalysts gave the corresponding epoxide 80a in similar reaction conditions with lower conversions but with similar levels of enantioselectivy to that achieved with catalyst $\mathbf{9 7}$. Instead of catalyst $\mathbf{9 7}$, several primary amino alcohols such as $\beta$-amino alcohols with sterically rigid scaffolds, $\beta$-amino alcohols with a two stereogenic center containing the amino and hydroxy group, or acyclic amino alcohols containing structurally 
related gem-diphenyl carbonyl group as in the case of catalyst $\mathbf{9 7}$, were used as catalyst, affording the desired compound 80a in moderated yield and enantioselectivity. This result suggested that for primary amine catalyst, the epoxidation reaction does not proceed through an iminium intermediate. Therefore, some secondary $\beta$ amino alcohols were evaluated in the reaction with acyclic derivatives, with this compounds being very poor catalyst compared to cyclic secondary $\alpha, \alpha$-diphenyl prolinol. Finally, tertiary $\beta$-amino alcohols were inactive under similar reaction conditions. From these results, a catalytic cycle was proposed in which the oxidant undergoes deprotonation by the $\beta$-amino alcohol, generating the catalytic species, that is, the ammonium derivative tert-butyl peroxy anion ion pair. Then, the hydroxy group of the promoter activated the $\alpha, \beta$ unsaturated ketone by hydrogen bonding with the carbonyl group, for the nucleophilic 1,4-addition of the tertbutyl peroxy anion according to the accepted Weitz-Scheffer epoxidation mechanism. The structure of the ammonium ion involved in the ion pair was studied through DFT calculations, showing that the lowest-energy conformers have an intramolecular hydrogen bond between the oxygen of the hydroxy group with the N-H bond from the same side of the plane, leading to high levels of enantioselectivities [80b].

Different 4-substituted-diaryl-2-pyrrolidinemethanols of type $\mathbf{9 8}$ showed to be efficient catalyst for this transformation [81]. The relative configuration at the $\mathrm{C} 2$ and $\mathrm{C} 4$ position of the heterocyclic ring and the substitution pattern of the hydroxy group in the $\mathrm{C} 4$ position had a great influence on the reactivity and in the selectivity of the reaction, with catalyst 98 (30 mol\%) giving the best results. Several $(E)$-enones with different substitution at the phenyl ring conjugated with the carbonyl, were tested as substrates (Table 3, entries 5 and 6). While enones possessing electron-donating groups, at the aforementioned aromatic ring, gave lower yields but increased levels of enantioselectivies, the opposite effect was encountered for substrates bearing electronwithdrawing groups. $\beta$-Methyl-substituted enones and even aliphatic enones were suitable substrates for this reaction (Table 3, entries 7 and 8), albeit somehow lower yields and enantioselectivities were found compared to those obtained with diarylenones. Other types of electron-deficient $\alpha, \beta$-unsaturated carbonyl compounds could be used as substrates in the epoxidation promoted by catalyst 98 [81b]. Thus, $\beta, \gamma$-unsaturated $\alpha$ ketoesters are epoxidized using catalyst $98(10 \mathrm{~mol} \%)$ giving the corresponding epoxides in good yields and enantioselectivities $(52-96 \%, 92-98 \%$ ee). Also, $\alpha, \beta$-unsaturated trichloro- or trifluoromethyl ketones were tested as substrates using the catalyst 98 (20 mol\%), giving similar results $(43-93 \%, 56-99 \%$ ee for 
trichloromethyl ketones and 52-88\%,21-95\% ee for trifluoromethyl ketones). Interestingly, $\alpha, \beta$-epoxy trichloromethyl ketones could be converted in other functional groups such as $\alpha, \beta$-epoxy esters and amides due to the ability of the trichloromethyl group to act as a good leaving group, providing a useful intermediate for the synthesis of chiral natural products.

Epibatidine analog such as $99(20 \mathrm{~mol} \%)$ was able to catalyze the asymmetric epoxidation of $(E)-\alpha, \beta-$ unsaturated ketones in hexane at room temperature with lower yields and levels of enantioselectivities (25-88\%, $69-88 \%$ ee) than those achieved with catalyst 97 using tert-butylhydroperoxide as oxidant (Table 3, compare entries 1-4 with 9-11) [82].

Table 3. Epoxidation of $\alpha, \beta$-unsaturated ketones catalyzed by diaryl-2-pyrrolidinemethanols

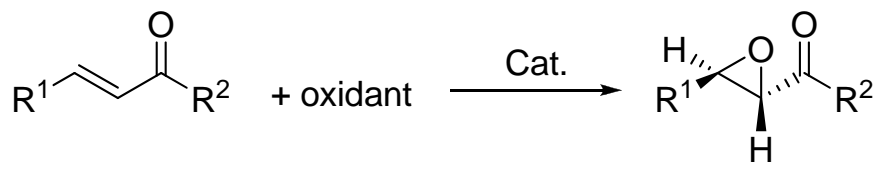

80<smiles>COc1ccc(C(O)(c2cc(C)c(OC)c(C)c2)C2CCCN2)cc1C</smiles><smiles>Cc1cc(C)cc(C(O)(c2cc(C)cc(C)c2)[C@H]2C[C@@H](Oc3ccccc3)CN2)c1</smiles>

98<smiles>OC(c1ccccc1)(c1ccccc1)C1NC2CCC1C2</smiles>

99<smiles>CCOc1cccc(C(C)(c2ccccc2)c2ccccc2)c1OCc1cc(OCc2ccccc2)cc(OCc2ccccc2)c1</smiles><smiles>OC(c1ccc(C(F)(F)F)cc1)(c1ccc(C(F)(F)F)cc1)C1CCCN1</smiles>

\begin{tabular}{|l|l|l|l|l|l|l|l|}
\hline Entry & $\mathrm{R}^{1}$ & $\mathrm{R}^{2}$ & Cat. (\%) & Oxidant & Reaction conditions & Yield (\%) & ee (\%) \\
\hline
\end{tabular}




\begin{tabular}{|l|l|l|l|l|l|l|l|}
\hline 1 & $\mathrm{Ph}$ & $\mathrm{Ph}$ & $\mathbf{9 7}(10)$ & TBHP & Hexane, $25^{\circ} \mathrm{C}$ & 93 & 89 \\
\hline 2 & $\mathrm{Ph}$ & $4-\mathrm{BrC}_{6} \mathrm{H}_{4}$ & $\mathbf{9 7}(10)$ & TBHP & Hexane, $25^{\circ} \mathrm{C}$ & 98 & 86 \\
\hline 3 & $\mathrm{Ph}$ & $\mathrm{Me}$ & $\mathbf{9 7}(20)$ & TBHP & Hexane, $25^{\circ} \mathrm{C}$ & 55 & 83 \\
\hline 4 & $\mathrm{Me}$ & $\mathrm{Ph}$ & $\mathbf{9 7}(10)$ & TBHP & Hexane, $25^{\circ} \mathrm{C}$ & 95 & 67 \\
\hline 5 & $\mathrm{Ph}$ & $\mathrm{Ph}$ & $\mathbf{9 8}(30)$ & TBHP & Hexane, $25^{\circ} \mathrm{C}$ & 75 & 94 \\
\hline 6 & $\mathrm{Ph}$ & $4-\mathrm{ClC}_{6} \mathrm{H}_{4}$ & $\mathbf{9 8}(30)$ & TBHP & Hexane, $25^{\circ} \mathrm{C}$ & 76 & 96 \\
\hline 7 & $\mathrm{Me}$ & $\mathrm{Ph}$ & $\mathbf{9 8}(30)$ & TBHP & Hexane, $25^{\circ} \mathrm{C}$ & 49 & 94 \\
\hline 8 & $\mathrm{CH}$ & $\mathrm{CH}{ }_{3}\left(\mathrm{CH}_{2}\right)_{4}$ & $\mathbf{9 8}(30)$ & TBHP & Hexane, $25^{\circ} \mathrm{C}$ & 61 & 72 \\
\hline 9 & $\mathrm{Ph}$ & $\mathrm{Ph}$ & $\mathbf{9 9}(20)$ & TBHP & Hexane, $25^{\circ} \mathrm{C}$ & 81 & 88 \\
\hline 10 & $\mathrm{Ph}$ & $4-\mathrm{BrC}_{6} \mathrm{H}_{4}$ & $\mathbf{9 9}(20)$ & TBHP & Hexane, $25^{\circ} \mathrm{C}$ & 84 & 82 \\
\hline 11 & $\mathrm{Ph}$ & $\mathrm{Me}$ & $\mathbf{9 9}(20)$ & TBHP & Hexane, $25^{\circ} \mathrm{C}$ & 25 & 69 \\
\hline 12 & $\mathrm{Ph}$ & $\mathrm{Ph}$ & $\mathbf{1 0 0}(30)$ & TBHP & $\mathrm{CCl} 4,25^{\circ} \mathrm{C}$ & 65 & 84 \\
\hline 13 & $\mathrm{Ph}$ & $\mathrm{Ph}$ & $\mathbf{1 0 1}(30)$ & TBHP & $\mathrm{CCl} 4,4 \AA \AA^{\circ S}, 25^{\circ} \mathrm{C}$ & 84 & 74 \\
\hline
\end{tabular}

In order to recover the catalyst after the reaction, fluoro prolinols of type $\mathbf{1 0 0}$ were prepared [83]. The epoxidation of compound 10a using catalyst $100(30 \mathrm{~mol} \%)$ and TBHP as oxidant in carbon tetrachloride afforded the epoxide 80a with moderated yield but with good enantioselectivity (Table 3, entry 12). Various (E)-diarylenones with different substituent of electron nature in the carbonyl side gave satisfactory results, except for para-nitro substituted phenyl enone $\left(\mathbf{1 0}, \mathrm{R}^{1}=\mathrm{Ph}, \mathrm{R}^{2}=4-\mathrm{NO}_{2} \mathrm{C}_{6} \mathrm{H}_{4}\right)$ with a modest $65 \%$ enantiomeric excess being obtained for the corresponding epoxide. Fluorous catalyst $\mathbf{1 0 0}$ was recovered by simply cooling the organic phase followed by filtration and reused at least three times without detrimental effects on the results.

Another way to recover the diaryl prolinol catalyst was through the synthesis of the related dendrimeric species 101 [84]. The second generation dendrimer (101a, $n=2,30 \mathrm{~mol} \%)$ provided the best results in the epoxidation of enone 10a (Table 3, entry 13), the addition of $4 \AA$ MS enhancing the obtained yield and enantioselectivity. Whereas, several enones with different electronic substitution on the phenyl ring conjugated with the carbonyl group or para-electron-withdrawing substituents in the $\beta$-phenyl group gave similar results, electron donating substituents in the $\beta$-phenyl group were not suitable substrates under these reaction 
conditions. After the reaction completion, catalytic dendrimer 101a $(n=2)$ was precipitated by adding dry methanol to the reaction mixture and recovered through filtration. The recovered catalyst was reused at least five times with little or no loss of activity.

Also primary amine salts derived from cinchona alkaloids such as compound 102 (10 mol\%, Scheme 22) and perchloric acetic acid was able to catalyzed the epoxidation of several linear and branched $\alpha, \beta-$ unsaturated ketones using hydrogen peroxide $(50 \mathrm{wt} \%)$ as oxidant in dioxane at $50{ }^{\circ} \mathrm{C}$ [85], with peroxyhemiketals of type $\mathbf{1 0 3}$ being obtained as initial products. Epoxides $\mathbf{8 0}$ were obtained in good yields and high enantioselectivities after basic work-up with sodium hydroxide, with only substrates having aliphatic substituents on the double bond being tolerated and with aromatic or trisubstituted compounds being unreactive. When these reaction conditions were applied to both $(E)$ - and $(Z)$-enones, the same enantiomer of trans-epoxide was achieved. This fact indicated that perhaps the $Z$ isomer rapidly isomerized to the corresponding $E$ isomer via a dienamine intermediate. The mechanism of the reaction was proposed to take place through an inimium intermediate, followed by a nucleophilic conjugate addition of hydrogen peroxide to give a $\beta$-peroxy enamine intermediate. The second basic amine site of the catalyst activated the hydrogen peroxide through general base catalysis and organized the transition state, directing the attack of the hydrogen peroxide toward one enantioface of the double bond. The obtained enamine intermediate can undergo a ring closure to give either the epoxide $\mathbf{8 0}$ or by hydrolysis to provide compound 103. Catalyst $102(10 \mathrm{~mol} \%)$ in the presence of trifluoroacetic acid $(20 \mathrm{~mol} \%)$ and using cumene hydroperoxide as oxidant in toluene at room temperature gave epoxides 80 in high yields and enantioselectivities $(88-91 \%, 97 \%$ ee) together with the corresponding chiral $\beta$-peroxide [85b], which can be obtained as the main product just by changing the oxidant or the reaction conditions. 
<smiles>[R]C=CC([R])=O</smiles>

10

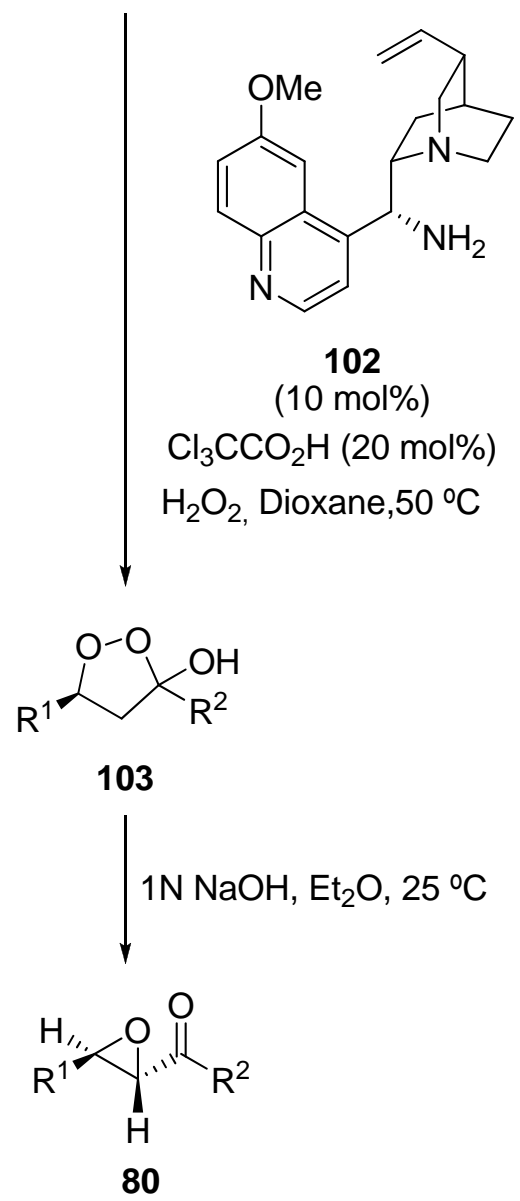

(55-90\%, ee 97-99\%)

\section{Scheme 22}

Simple cyclic enones, such as cyclohexenone, are also suitable substrates for this transformation using hydrogen peroxide as oxidant and catalyst $102(10 \mathrm{~mol} \%)$ in the presence of trifluoroacetic acid ( 1 or 2 equiv) in dioxane at $30-50{ }^{\circ} \mathrm{C}$ [86]. Under these reaction conditions, different substituted cyclohexenones were epoxydated in good yields and excellent enantioselectivities $(49-80 \%, 92-98 \%$ ee). Whereas various $2-$ cycloheptenones provided excellent results $(82-85 \%, 98-99 \%$ ee), 2-cyclopentanone exhibited lower reactivity $(33 \%, 78 \%$ ee $)$.

Finally, the epoxidation reaction using either chiral ketones or amines as organocatalyst has been used as a key step for the synthesis of chiral drug with interesting medical applications. Thus, fructose-derived ketone 104 (Figure 11) has been successfully applied as catalyst in the synthesis of an intermediate for the preparation of dipeptide isosteres with HIV inhibition and blood pressure modulation properties [87a]. Ketone 
104 was also used for the asymmetric epoxidation of cis-1-propenylphosphoric acid affording the antibiotic fosfomycin. Better results were obtained using D-mannitol chiral amine 105 for the synthesis of the aforementioned compound $(100 \%, 74 \%$ ee) [87b]. Finally, chiral dioxirane 106 was used as catalyst in a largescale preparation of key intermediate in the synthesis of anti-hypertensive agent diltiazem [87c], showing the great potential of this methodology for industrial purposes.<smiles>CC1(C)O[C@H]2CO[C@]3(COC(C)(C)O3)C(=O)[C@@H]2O1</smiles>

104<smiles>c1ccc(C2OC[C@@H]3NC4COC(c5ccccc5)O[C@H]4OC3O2)cc1</smiles>

105<smiles>O=C(O)COC(=O)c1ccc2ccccc2c1-c1c(C(=O)OCC(=O)O)ccc2ccccc12</smiles>

106

\section{Figure 11}

\subsubsection{Aminoxylation of aldehydes and ketones}

A straightforward way of introducing a hydroxy group at the $\alpha$-position of a carbonyl compound is by means of the direct $\alpha$-aminoxylation reaction using nitroso compounds. Thus, the organocatalyzed addition of electrophilic nitrosoaryl derivatives, carefully controlling the nitrogen versus oxygen reactivity (see above, section 2.2), allowed the enantioselective synthesis of $\alpha$-hydroxy carbonyl derivatives and their further transformation to other interesting chiral compounds by tandem or domino reactions [7b].

(S)-Proline (19) has shown its primacy as catalyst in this type of reaction using aldehydes as substrates, with the addition of bifunctional urea $\mathbf{1 0 7}$ to the reaction mixture increasing significantly the reaction rate (Scheme 23)[88]. Under these conditions, ethyl acetate could be used as solvent to perform the reaction, instead of DMSO or $\mathrm{CHCl}_{3}$. The origin of the increased reaction rate was proposed to be due to a hydrogen bond interaction between the bifunctional thiourea and the formed oxazolidine [89] intermediate, which enhanced the rate of the enamine formation. Moreover, the addition of urea 107 removed the autoinduction behavior typically 
observed in this reaction and therefore, an alternative catalytic cycle, which takes place in the presence of the urea and involucrated the intermediate oxazolidinone, was suggested.

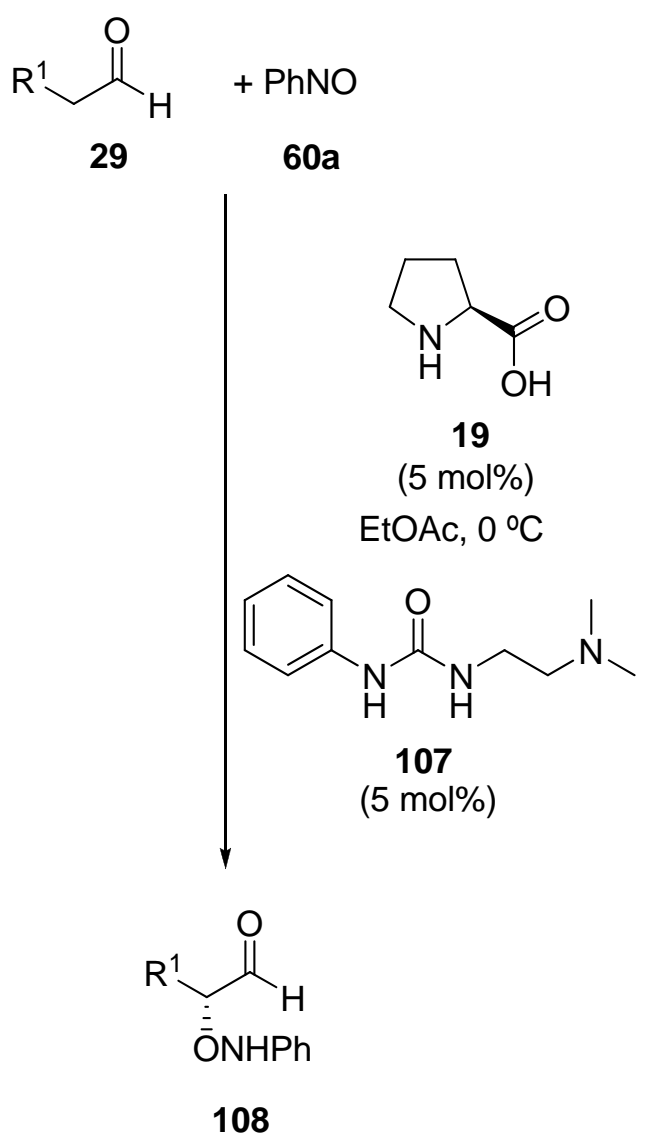

(55-96\%, ee $98-99 \%)$

\section{Scheme 23}

Although (S)-proline (19) was able to catalyze the $\alpha$-aminoxylation of cyclic ketones, the reaction with related non cyclic ketones has been elusive. Notwithstanding, an efficient and general route to prepare optically active $\alpha$-hydroxyketones has been achieved by a one-pot tandem aminoxylation of aldehydes using nitrosobenzene (60a) and (S)-proline $(\mathbf{1 9}, 10 \mathrm{~mol} \%)$ as catalyst in DMSO at room temperature, and chemoselective diazomethane homologation [90]. In order to perform the chemoselective diazomethane homologation, the addition of anhydrous magnesium chloride was necessary. Linear, $\beta$-branched, $\beta$-alkylthio and $\omega$-oxygenated aldehydes were suitable substrates under these reaction conditions, affording the corresponding aminoxylated methyl ketones in moderated yields and high enantioselectivities (41-60, 95-99\% ee). The usefulness of this process was demonstrated by the enantioselective synthesis of a chiral building block intermediate for the synthesis of epothilones. 
The tandem $\alpha$-aminoxylation of nitroalkenals 109 catalyzed by $(S)$-proline (19, 5-10 mol\%) followed by an aza-Michael reaction has permitted the synthesis of functionalized tetrahydro-1,2-oxazines 110 (Scheme 24) [91]. In order to avoid side reactions and to have good results, the reaction must be carried out in acetonitrile as solvent at $-20^{\circ} \mathrm{C}$. The variation of the $\mathrm{R}$ group in the nitroalkenal derivative $\mathbf{1 0 9}$ evidenced the small impact of the steric and electronic effects in the generation of the third stereogenic center, achieving the corresponding product 110 with high diastereo- and enantioselectivities. Also, the aromatic nitroso compound $\mathbf{6 0}$ had no influence in the obtained results, with different aryl nitroso derivatives being able to perform the reaction with consistent enantioselectivities. This tandem process could be also applied to 2-(5-oxopentylidene)malonate derivatives as substrates, affording the corresponding tetrahydro-1,2-oxazines with good yields (52-84\%) and excellent diastereo- and enantioselectivities ( $\mathrm{dr}>99: 1,92-99 \%$ ee) [91b].

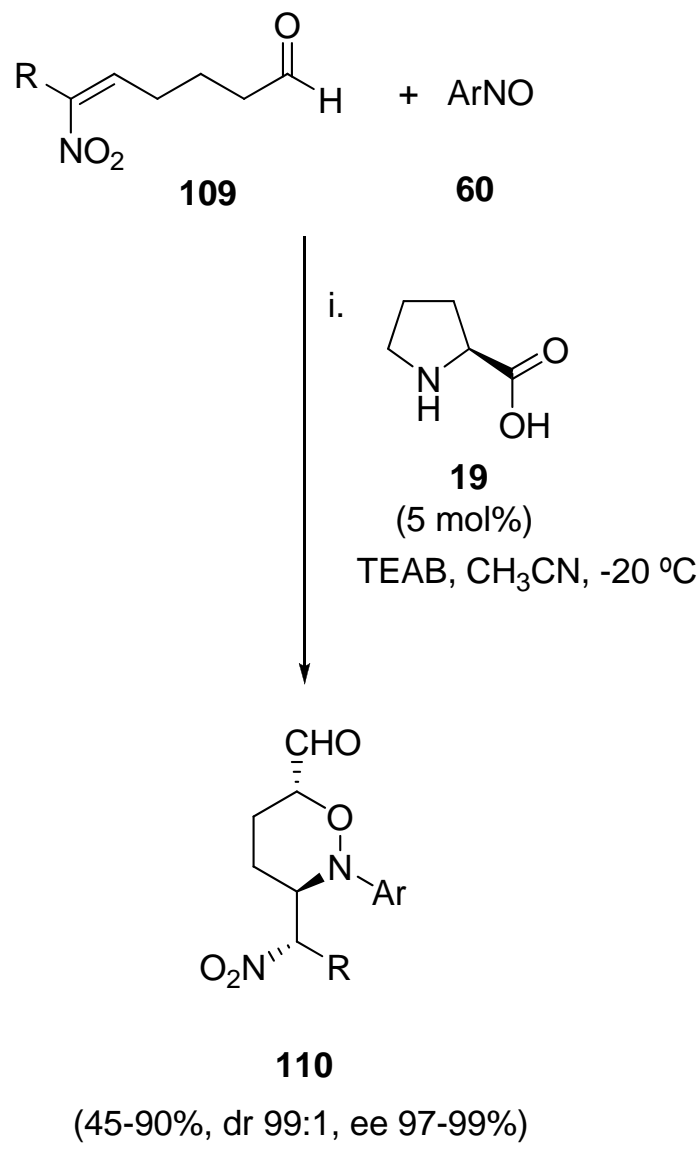

\section{Scheme 24}

But without any doubt, proline has shown its great potential as organocatalyst in the enantioselective $\alpha$ aminoxylation of aldehydes applied to the natural product synthesis. Thus, the formal synthesis of HRV 3C- 
protease inhibitor $(1 R, 2 S)$-thysanone has been accomplished in $98 \%$ enantiomeric excess using $(S)$-proline (19), catalyzing the asymmetric $\alpha$-aminoxylation of an aldehyde and oxa-Pictet-Spengler cyclization as key steps [92]. Following the same strategy, an efficient route for the synthesis of atorvastatin side chain, a building block present in the statin family, which acted as cholesterol regulator, was performed with high enantioselectivity [93].

Not only formal synthesis, but also total natural products or drug syntheses have been made using this useful reaction. For instance, $(S, S)$-ethambutol (23) [26], (R)-selegiline (24) [27] and (-)-anisomycin (27) [30], which could be alternatively synthesized by means of an organocatalyzed $\alpha$-amination reaction (see section 2.2 , Figure 2), could be prepared with similar results by using this transformation. In a similar way, the antiinflammatory halipeptin A (111) [94], the antitumor agents tarchonanthuslactone (112) [95], (+)-cytotrienin A [96] and (+)-harzialactone A and $(R)-(+)-4$-hexanolide [97], the antibacterials linezolid (113) and eperezolid [98], the antiepileptic drugs levetiracetam (114) [99], the pheromones (-)-endo-brevicomin (115) [100], (+)disparlure [101] and (2S,3S)-2-hydrohyhexylcyclopentanone [102], and the enzyme inhibitors (+)panephenanthrin (116) [103], and the $\beta$-adrenergic blockers (S)-propranolol (117) and (S)-naftopidil [104] have been synthesized using in all cases the $\alpha$-aminoxylation of aldehydes as a key step (Figure 12). 


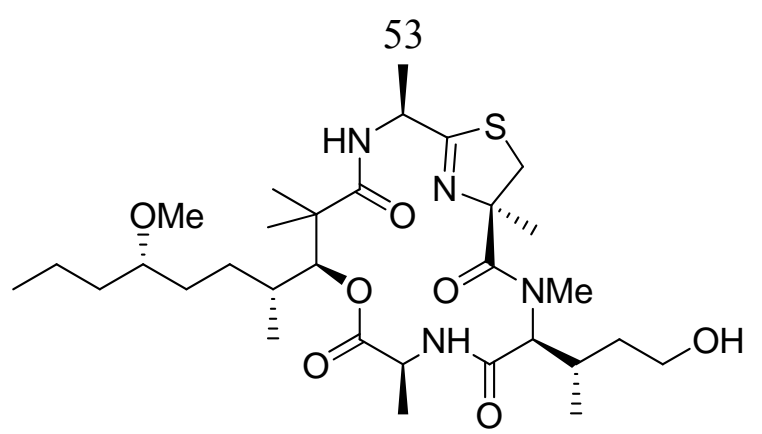

111<smiles>C[C@@H](CC1CC=CC(=O)O1)OC(=O)CCc1ccc(O)c(O)c1</smiles>

112<smiles>CCCNC[C@H]1CN(c2ccc(N3CCOCC3)c(F)c2)C(=O)O1</smiles><smiles>CCC(C(N)=O)[C@H]1CCCC1=O</smiles><smiles>CC[C@H]1OC2(C)CCC1O2</smiles>

114

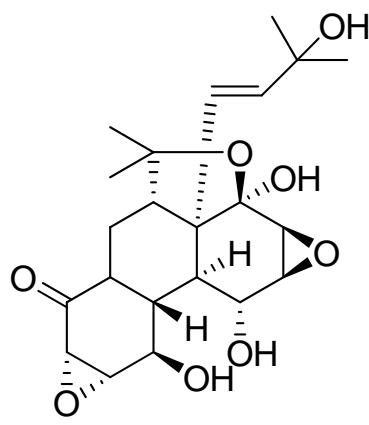

116<smiles>CC(C)NC[C@H](O)COc1cccc2ccccc12</smiles>

117

Figure 12

The scope of the $\alpha$-aminoxylation of aldehydes catalyzed by proline (19) was further extended to ketones as substrates. Using this protocol, (-)-4-hydroxycyclohex-2-enones, which has been extensively used as a synthetic building block in organic chemistry [105], could be prepared. For this purpose, cyclohexanedione monoketal was aminoxylated with nitrosobenzene using (S)-proline (19, $30 \mathrm{~mol} \%)$ in DMF as solvent, affording the oxidation product, which was further transformed in $(R)$-4-hydroxycyclohex-2-enone in $63 \%$ yield and $94 \%$ ee. 
The asymmetric desymmetrization of polysubstituted cyclic meso-ketones was also possible by using proline as catalyst, affording the expected chiral products in high diastereo- and enantioselectivities. DFT studies of this process revealed that the reaction was controlled by electrostatic/dipole-dipole interactions [106]. Computational results evidenced that the diastereoselectivity was due to the polar groups at the 4position of the cyclohexanone and due to differences in their possible conformations.

Although (S)-proline (19) is an inexpensive catalysts, the possibility of recovering and reusing it after the reaction completion would represent an additional advantage of this highly useful synthetic approach. Thus, proline has been incorporated to a Merrifield-type resin through click chemistry using trans-4-hydroxyproline to give a polymeric supported catalyst which was used (20 mol\%), in the $\alpha$-aminoxylation of cyclic ketones and aldehydes to give the corresponding aminoxylated products in moderated yields $(49-75 \%$ for ketones and 35 $86 \%$ for aldehydes) and excellent enantioselectivities (96-99\% ee for both substrates) [107]. The insoluble catalyst could be recovered and reused for three times without loss in the achieved enantioselectivities.

(S)-proline (19) was reused by using ionic liquids as media to perform the $\alpha$-aminoxylation of ketones and aldehydes. Thus, when the ionic liquid 1-n-butyl-3-methylimidazolium tetrafluoroborate ([bmim] $\left.\mathrm{BF}_{4}\right) \mathrm{was}$ used as solvent to perform the reaction between either aldehydes or ketones with nitrosobenzene catalyzed by proline $(19,20 \mathrm{~mol} \%)$ at room temperature, the $\alpha$-aminoxylation products were obtained in good yields $(50$ $98 \%$ ) and excellent enantioselectivities (97-99\% ee), with the ionic liquid containing (S)-proline being used at least six times without any detrimental effect in the results [108].

Pyrrodinyl tetrazole (30) [109] was also an efficient catalyst for the sequential $\alpha$-aminoxylation of aldehydes and Grignard addition processes giving 1,2-diols units, found frequently in natural products [110]. The reaction was performed using 2-nitrosotoluene $(\mathbf{6 0 b})$ as electrophile and tetrazole 30 or proline (19) as catalyst (10 mol\%, Scheme 25). A wide range of Grignard reagents such as tertiary, secondary or primary alkyl or aryl magnesium reagents were used in the second step, with the presence of $\mathrm{CeCl}_{3} \cdot 2 \mathrm{LiCl}$ being essential to favor the 1,2-addition of the reagent to the carbonyl compound versus the enolate formation, achieving the corresponding 1,2-diols 118 in high yield and diastereoselectivities. This transformation could be also carried in a one-pot way conducting the aminoxylation reaction in a DME:HMPA (9:1) as solvent and adding sequentially the Grignard reagent to the crude reaction mixture to obtain similar results. Furthermore, the carbonyl substrate was not only limited to aldehydes and also cyclohexanone could be used as substrate to give the related 
corresponding cis-1,2-diols 118 in good yields (62-95\%) and high diastereo- (dr form 87:13 to 99:1) and enantioselectivities (ee $>99 \%$ ).

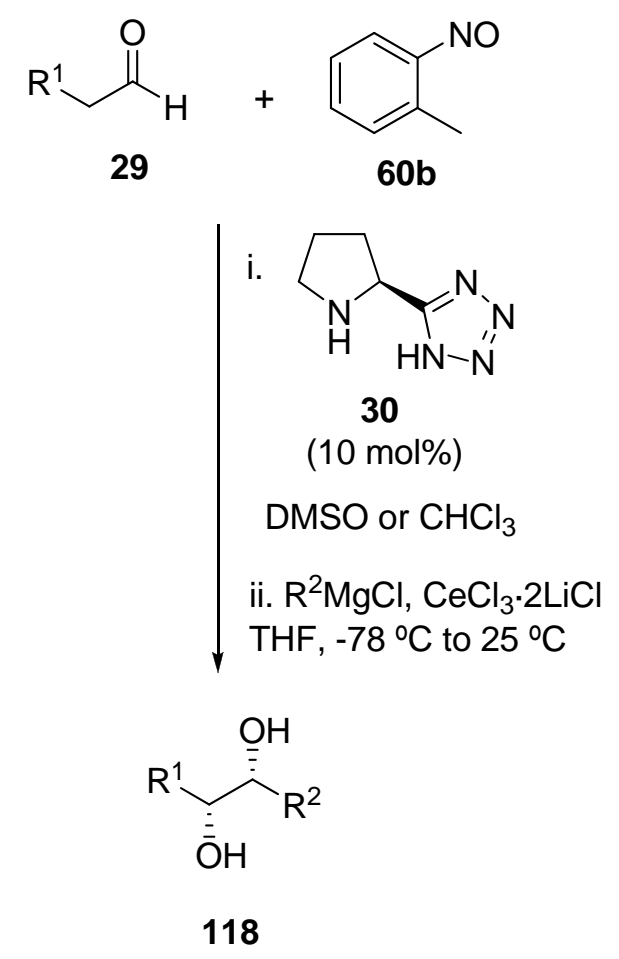

(24-77\%, dr up to $99: 1$, ee 93-99\%)

\section{Scheme 25}

Using the aforementioned pyrrodinyl tetrazole $(\mathbf{3 0}, 5 \mathrm{~mol} \%)$ as catalyst, it was possible the synthesis of chiral 1,2-oxazines by the reaction of cyclic and acyclic ketones with nitrosobenzene, followed by an intramolecular Wittig process, achieving the expected product in moderated yields (39-65\%) and total enantioselectivity [34b, 111].

Another tandem process in which pyrrodinyl tetrazole (30) has been successfully used as catalyst was the $\alpha$-aminoxylation of cyclohexanone/Michael reaction. DFT studies on the mechanism, showed that tetrazolic group plays an essential role for the $O$-selective process, being the reaction thermodynamically more favorable than the $N$-selective pathway [112]. Meanwhile, the regioselectivity of the tandem reaction was due to the different basicities of the nitrogen and oxygen atoms in the nitrosobenzene.

Other proline derivatives were able to catalyze the $\alpha$-aminoxylation of aldehydes. Thus, $(S)-3$ thiaproline promoted this reaction in the presence of water and tetrabutylammonium bromide. This reaction was followed by the in situ reduction to give the corresponding $\alpha$-aminoxy alcohols $\mathbf{1 0 8}$ in good yields and 
enantioselectivities $(74-88 \%, 93-98 \%$ ee), with linear, branched and protected functionalized aldehydes being well tolerated as substrates [113].

Besides proline and related proline catalyst, only a few structurally different catalysts have been reported as efficient promoters of the $\alpha$-aminoxylation reaction. So, binaphthyl-based chiral secondary amines 119 (5 mol\%) [114] have been applied in the $\alpha$-aminoxylation of aldehydes, yielding after the in situ reduction with $\mathrm{NaBH}_{4}$ the corresponding 2-aminoxy alcohols 120 (Scheme 26). For catalyst 119a $\left(\mathrm{R}^{2}=\mathrm{CO}_{2} \mathrm{H}, \mathrm{R}^{3}=\right.$ 3,4,5- $\left.\mathrm{F}_{3} \mathrm{C}_{6} \mathrm{H}_{2}\right)$, toluene was the solvent of choice, giving products $\mathbf{1 2 0}$ in moderated yields and good enantioselectivities $\left(69-89 \%, 86-88 \%\right.$ ee). However, for catalyst $119 b\left(R^{2}=N H T f, R^{3}=H\right)$, the best results were obtained in chloroform as solvent (49-96\%, 97-98\% ee), being the absolute configuration of product 120 opposite to that obtained using catalyst 119a. In the transition state, it was proposed that with catalyst 119b, the nitrosobenzene was activated and directed by the distal acidic proton of the triflamide group and would approach to the $S i$ face of the s-cis-enamine, providing the $S$ isomer predominantly. Meanwhile, for catalyst 119a, the carboxy group would activated and directed the electrophile attack to the $R e$ face of enamine, giving product 120. Surprisingly, the same sense of enantioselectivity was achieved in the $\alpha$-aminoxylation of cyclohexanone with both catalyst, with catalyst 119a proving better results $(63 \%$ and $99 \%$ ee) than catalyst 119b $(71 \%, 74 \%$ ee $)$. 


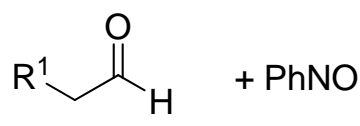

29 $60 a$

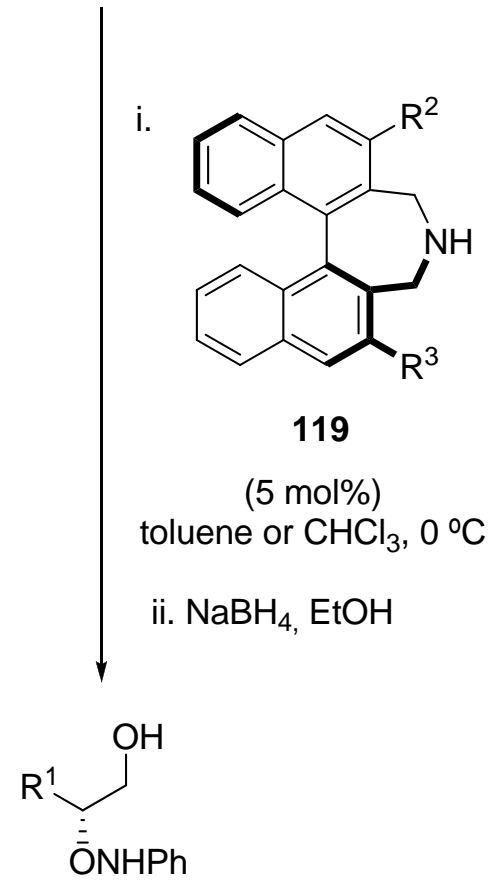

120

\section{Scheme 26}

Not only amines have been used as catalysts for this transformation, but also chiral Brønsted acids are able to promote this type of reaction. Hence, binaphthyl phosphoric acid $121\left(\mathrm{R}^{3}=\mathrm{SiPh}_{3}, 1 \mathrm{~mol} \%\right)$ was used in the $\alpha$-hydroxylation of cyclic 1,3-dicarbonyl compounds 44 with 4-chloronitrosobenzene (60c), affording the corresponding $\alpha$-hydroxy $\beta$-ketoesters in high $\mathrm{O} / \mathrm{N}$ selectivity (94:6), good yields and enantioselectivities (Scheme 27) [115]. Several ester derivatives such as methyl, ethyl, isopropyl or tert-butyl were well tolerated as well as several substituents with electro-donating or electron-withdrawing properties in the aromatic ring. This procedure was also applied for simple five or six membered ring $\beta$-ketoesters achieving similar levels of enantioselectivities, whereas seven membered ring and acyclic $\beta$-ketoesters gave lower results. The present protocol could be extended to $\beta$-diketones obtaining the corresponding $\alpha$-hydroxy- $\beta$-diketones with moderated yields and enantioselectivities (49-75\%, 68-84\% ee). 
<smiles>[R]C(=O)C1[R10](=O)c2ccccc2C1=O</smiles>

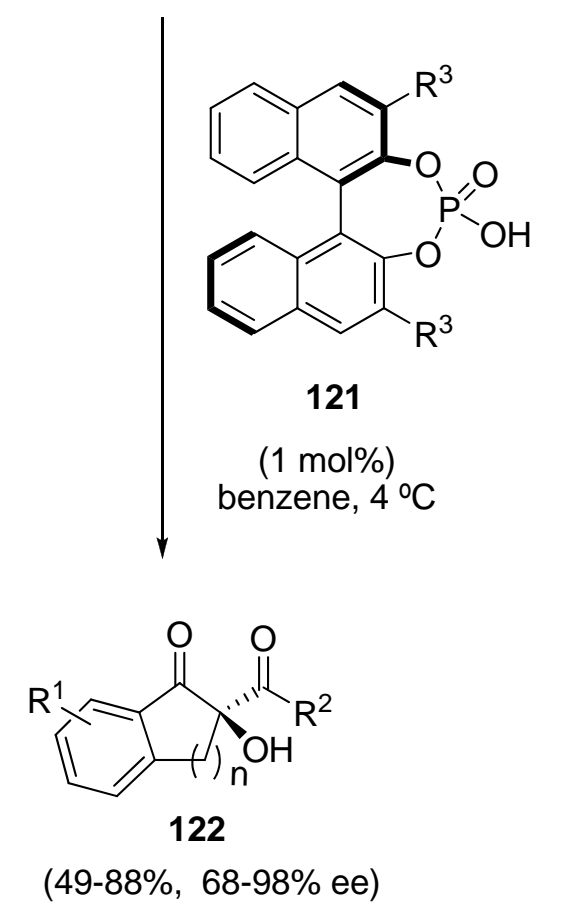

Scheme 27

\subsubsection{Miscellaneous oxidation processes}

The direct enantioselective organocatalytic $\alpha$-oxidation of carbonyl compounds is possible using other different methodologies. For instance, using trans-2-(p-methoxyphenylsulfonyl)-3-phenyloxaziridine as oxidant and proline (19), pyrrodinyl tetrazole (30) or its $\alpha$-methyl derivative (30 mol\%), several aldehydes and cyclohexanone could be oxidized in THF to provide the corresponding $\alpha$-hydroxy carbonyl derivative [116]. For the case of cyclohexanone, the use of $\alpha$-methyl substituted catalyst are less effective than its parent catalyst and the achieved enantioselectivies are low (9-36\%). However, for aldehydes, the use of $\alpha$-methyl substituted derivatives afforded the oxidation products in moderated yields (23-67\%) and with higher enantioselectivities $(12-45 \%$ ee) than those obtained with catalyst 19 or 30.

More efficient have been the recently reported use of benzoylperoxide (123) as oxidant for aldehydes using 2-tritylpyrrolidine (124) [117] or catalyst $15 c\left(\mathrm{R}^{2}=\mathrm{Bu}^{\mathrm{n}}\right)[118]$ (Scheme 28). When catalyst 124 (10 mol\%) was used in this reaction, hydroquinone (HQ, 10 mol\%) was added in order to increase the yield of products 125 (62-72\%), with high enantioselectivities being obtained (93-94\% ee). The obtained $\alpha$ - 
benzoyloxyladehydes could be converted into the corresponding chiral diols or monoprotected diols, by reduction using $\mathrm{NaBH}_{4}$ and further DBU treatment, respectively. Although, radical intermediates cannot be ruled out for the mechanism process, two possible ionic pathways were suggested, in which oxidant 123 would approach to the s-trans enamine, in which one face is shielded by the trityl group, providing the $S$ isomer predominantly. If catalyst 15c was used for the same process, the use of additives (acid or bases) did not increase the obtained yield (54-78\%). However, in order to achieve good yields and enantioselectivities (90$94 \%$ ee), the catalyst has to be added in two portions, one at the beginning of the reaction and the second portion after $4 \mathrm{~h}$ of reaction time. Under these conditions, linear aldehydes, aldehydes containing aromatic, silyl or double bonds moieties could be oxidized with good results.

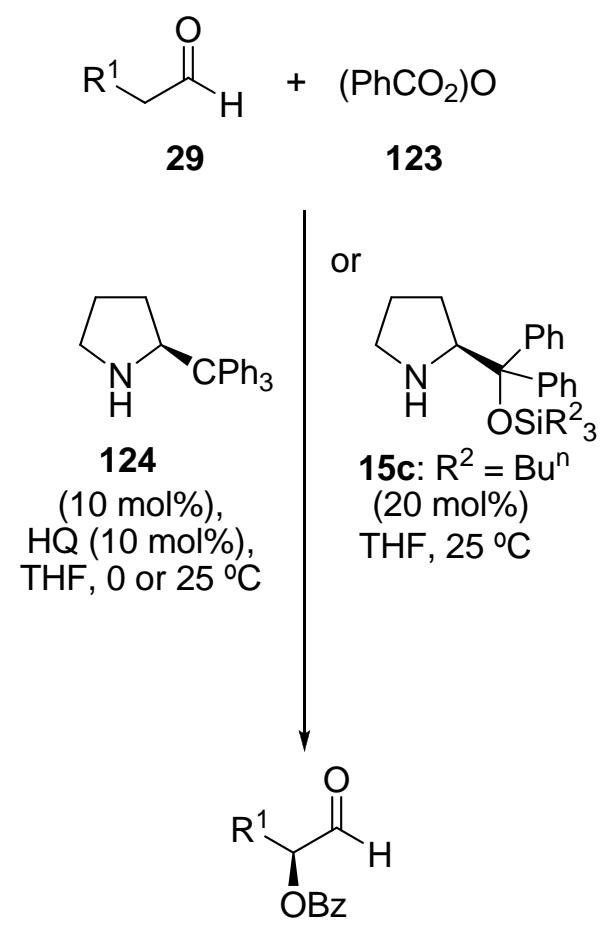

125

\section{Scheme 28}

The use of molecular oxygen, considered as a "green oxidant", to carry out the preparation of $\alpha$-hydroxy carbonyl compounds has been already reported, with the achieved enantioselectivities being moderated. Better results were obtained when catalyst $15 a(R=M e, 20$ mol\%) was employed in this reaction, in the presence of tetraphenylporphine ( $1 \mathrm{~mol} \%$ ), in $\mathrm{CHCl}_{3}$ at $0{ }^{\circ} \mathrm{C}$ and using ultraviolet light (UV) to generate singlet molecular oxygen [119]. After reduction of the aldehyde moiety, the corresponding 1,2-diols were obtained in good yields 
(50-71\%) with $74-98 \%$ ee. In particular, the reaction with 2-arylacetaldehydes containing electron-withdrawing groups as substituents in the phenyl rings proceeded with high enantioselectivities (98\% ee). Also, singlet molecular oxygen can be generated using $\mathrm{La}\left(\mathrm{NO}_{2}\right) \cdot 6 \mathrm{H}_{2} \mathrm{O}$ as catalysts and $\mathrm{H}_{2} \mathrm{O}_{2}$ ('dark ${ }^{1} \mathrm{O}_{2}$ '). Hence, the $\alpha$ oxidation of hexanal using ' $\operatorname{dark}{ }^{1} \mathrm{O}_{2}$ ' under the above mentioned organocatalytic conditions gave the expected product in $23 \%$ yield and $80 \%$ ee.

Phase transfer catalysis has been also used to perform the oxidation of carbonyl compound using molecular oxygen as oxidant. Thus, several 3-substituted oxindole alkaloids 126 were oxidated using cinchonidine catalyst $\mathbf{8 b}(20 \mathrm{~mol} \%)$ in the of presence triethyl phosphite $\left[(\mathrm{EtO})_{3} \mathrm{P}\right]$ and potassium hydroxide as a base (Scheme 29), affording the corresponding $\alpha$-hydroxy 3 -substited oxindole derivatives 127 with good results [120].<smiles>[R]C1C(=O)N([R16])c2ccccc21</smiles>

\section{6}

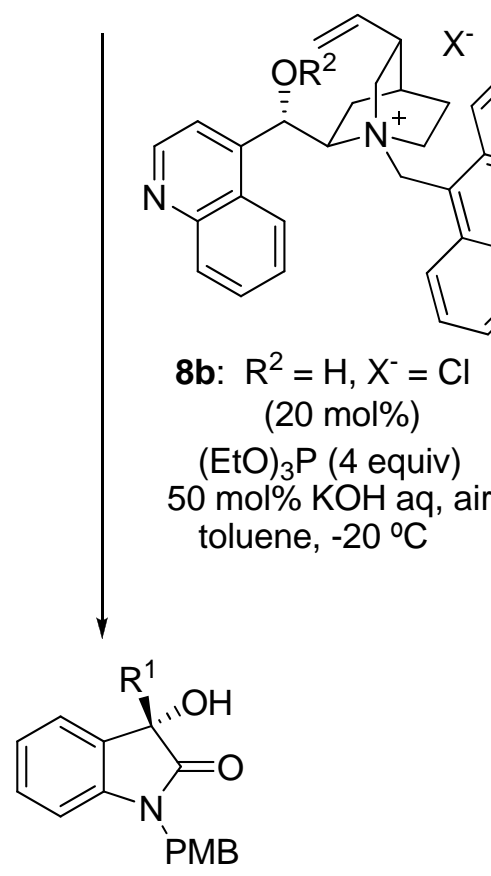

127

(91-99\%, ee 67-93\%)

\section{Scheme 29}


The radical $\alpha$-oxygenation of aldehydes has been accomplished by using a single electron transfer (SET) reagent such as iron trichloride and sodium nitrite and oxygen as a cooxidant in the presence of 2,2,6,6tetramethylpiperidine-1-oxyl (TEMPO, 128) and chiral imidazolidinone as tetrafluoroborate salt 129 to give the $\alpha$-oxygenated product in good yields and enantioselectivities (Scheme 30) [121], although in the strict sense, this is not a pure organocatalyzed reaction owing to the presence of a metallic salt. While, aryl and heteroaryl aldehydes provided the corresponding chiral products $\mathbf{1 3 0}$, aliphatic aldehydes were oxidized as a racemic product.

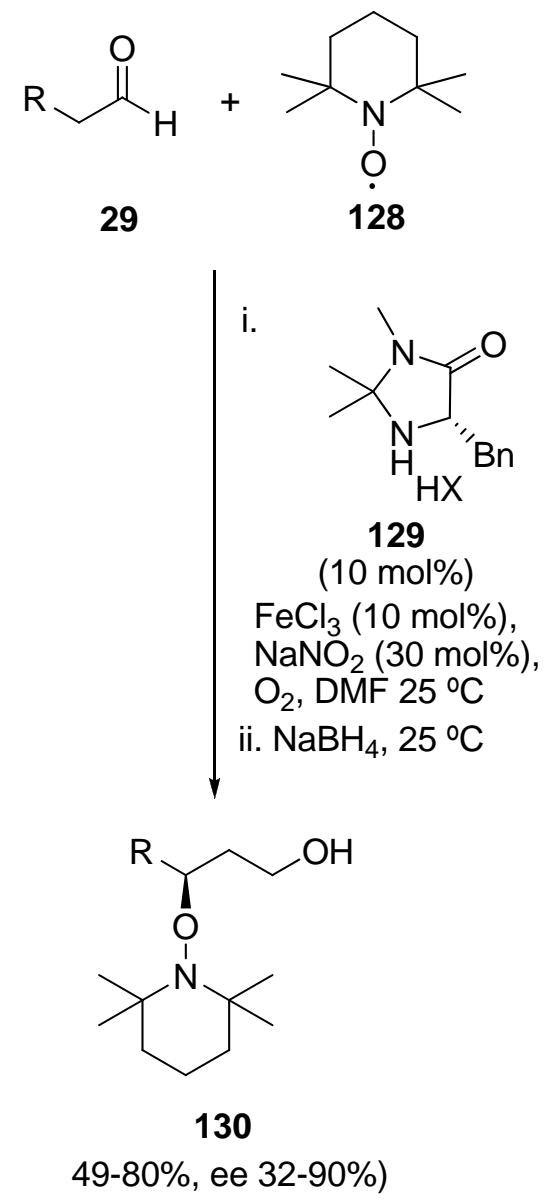

\section{Scheme 30}

Finally, ketones can be oxidized in a diastereoselective process using chiral iodoarenes as catalyst to carry out their $\alpha$-oxytosylation, affording the expected products in good yields (66-78\%) and low enantioselectivities (21-28\% ee) [122]. 
Although optically active sulfur and selenium compounds are an important type of chiral ligands and intermediates in organic synthesis, their preparation by organocatalytic methods has been scarcely reported. Thus, the combination of the organocatalytic $\alpha$-sulfenylation of an aldehyde with a stereospecific [2,3]sigmatropic rearrangement has provided a useful protocol for the enantioselective synthesis of vinyl glycines [123]. For this purpose, the first step was the one-pot synthesis of chiral allylic sulfides $\mathbf{1 3 2}$ by $\alpha$-sulfenylation organocatalyzed by diarylprolinol 72a $\left(\mathrm{Ar}=\left(\mathrm{CF}_{3}\right)_{2} \mathrm{C}_{6} \mathrm{H}_{2}, \mathrm{R}^{2}=\mathrm{SiMe}_{3}, 10 \mathrm{~mol} \%\right)$ using triazole sulfide 131 as electrophile, followed by the in situ olefination, giving the expected product with a good result, independently of the aldehyde used (Scheme 31). Subsequent reaction of compound 132 with an $N$-Boc-oxaziridine resulted in a $[2,3]$-sigmatropic rearrangement with complete diastereoselectivity, to give the expected glycine derivatives. Using a similar protocol, different chiral allenamides were prepared by a [2,3]-sigmatropic rearrangement of chiral propargylic sulfimides, which could be easily obtained in turn by $\alpha$-sulfenylation catalyzed by diarylprolinol 72a (10 mol\%) using triazole sulfide 131 as electrophile, followed by Corey-Fuchs alkynylation [123c].

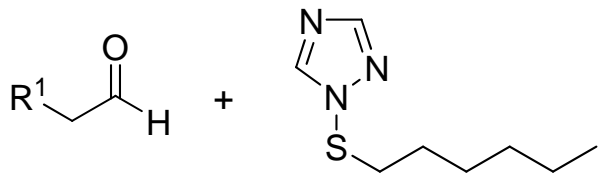

29

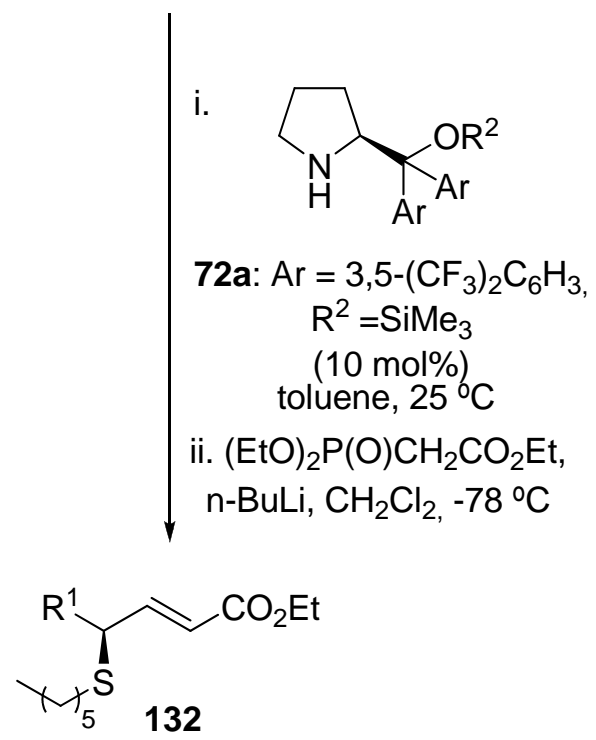

(52-79\%, E:Z 95:5, ee 88-93\%)

\section{Scheme 31}


Cyclic $\beta$-ketoesters 44 were also suitable substrates for the organocatalyzed $\alpha$-sulfenylation reaction. In this case, catalyst $72 \mathbf{b}(20 \mathrm{~mol} \%)$ gave the best result among all tested $\alpha, \alpha$-diaryl prolinol in the reaction between compound 44 and $N$-(phenylthio)phtalimides (133a, $\mathrm{Ar}^{1}=\mathrm{Ph}$, Scheme 32) [124]. Thus, several sulfur reagents 133 with electron-withdrawing or electron-donating groups on the aromatic ring were well tolerated in the reaction, with $\mathrm{N}$-(4-chlorophenyl)phtalimide $\left(\mathbf{1 3 3 b}, \mathrm{Ar}^{1}=4-\mathrm{ClC}_{6} \mathrm{H}_{4}\right)$ displaying the higher reactivity. Moreover, aliphatic five-membered ring $\beta$-ketoesters were also suitable substrates for this reaction affording the functionalizated products in good yields ( $88-89 \%)$ and enantioselectivities $(79-86 \%$ ee).<smiles>[R]C(=O)C1C(=O)c2ccccc2C1=[V]</smiles>

44

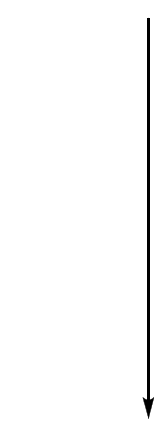<smiles>[R]C(=O)C1([Se])Nc2ccccc2C1=O</smiles>

134

(68-98\%, ee 30-97\%)

\section{Scheme 32}

A catalytic domino reaction between $\alpha, \beta$-unsaturated aldehydes 14 and $N$-(phenylthio)succinimide $($ 133a, $\mathrm{Ar}=\mathrm{Ph})$ provided a useful synthetic protocol to obtain the corresponding $\beta$-amino- $\alpha$-mercapto carbonyl derivatives 134 using as catalyst diaryl prolinol 15a (Scheme 33) [125]. Although the diastereoselectivity of the reaction was low, both diastereoisomers could be easily separated by column chromatography and isolated with high enantiomeric excess. Compounds 134 could be further converted into $\beta$-amino- $\alpha$-mercapto alcohols, esters and $\alpha, \beta$-unsaturated esters which could be rearranged to unsaturated $\alpha$-amino acids. A similar domino reaction 
was previously described to carry out the diamination of $\alpha, \beta$-unsaturated aldehydes using succinimide and diethyl azodicarboxylate (18d) catalyzed by 72a [126], affording the corresponding diaminated products in low yields (39-40\%), moderated diastereoselectivities ( $\mathrm{dr}$ 75:25-80:20) and high enantioselectivities (99\% ee).

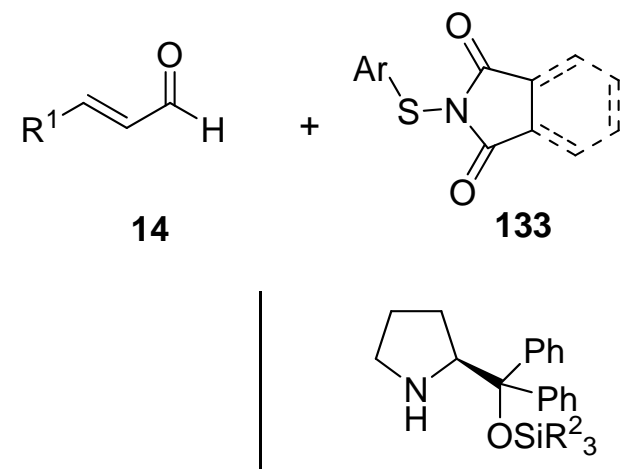

15a, $\mathrm{R}^{2}=\mathrm{Me},(10 \mathrm{~mol} \%)$

$\mathrm{CH}_{3} \mathrm{Cl}, 25^{\circ} \mathrm{C}$<smiles>O=C1CCC(=O)N1</smiles>

(10 mol\%)

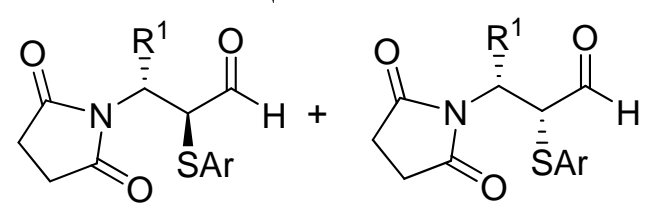

134

(67-83\%, dr 49.51-77:23, ee 95-99\%)

\section{Scheme 33}

Almost simultaneously, it was reported that $\alpha, \alpha$-diaryl prolinol catalysts $72 \mathbf{a}\left[\mathrm{Ar}=\left(\mathrm{CF}_{3}\right)_{2} \mathrm{C}_{6} \mathrm{H}_{2}, \mathrm{R}^{3}=\right.$ $\left.\mathrm{SiMe}_{3}, 5 \mathrm{~mol} \%\right]$ in combination with $p$-nitrobenzoic acid or $15 a\left(\mathrm{R}^{2}=\mathrm{Me}, 20 \mathrm{~mol} \%\right)$ were an efficient system to promote the $\alpha$-selenenylation of aldehydes using $N$-(phenylseleno)phtalimides (135) as electrophile (Scheme 34) [127]. For this reaction, toluene was the solvent of choice using both catalytic species and the in situ reduction of the obtained product to the corresponding alcohol was needed in order to preserve the achieved levels of enantioselectivities. A wide range of aldehydes, including alkyl, alkenyl and heterosubstituted aldehydes were suitable substrates, affording the expected products $\mathbf{1 3 6}$ with excellent enantioselectivities. 


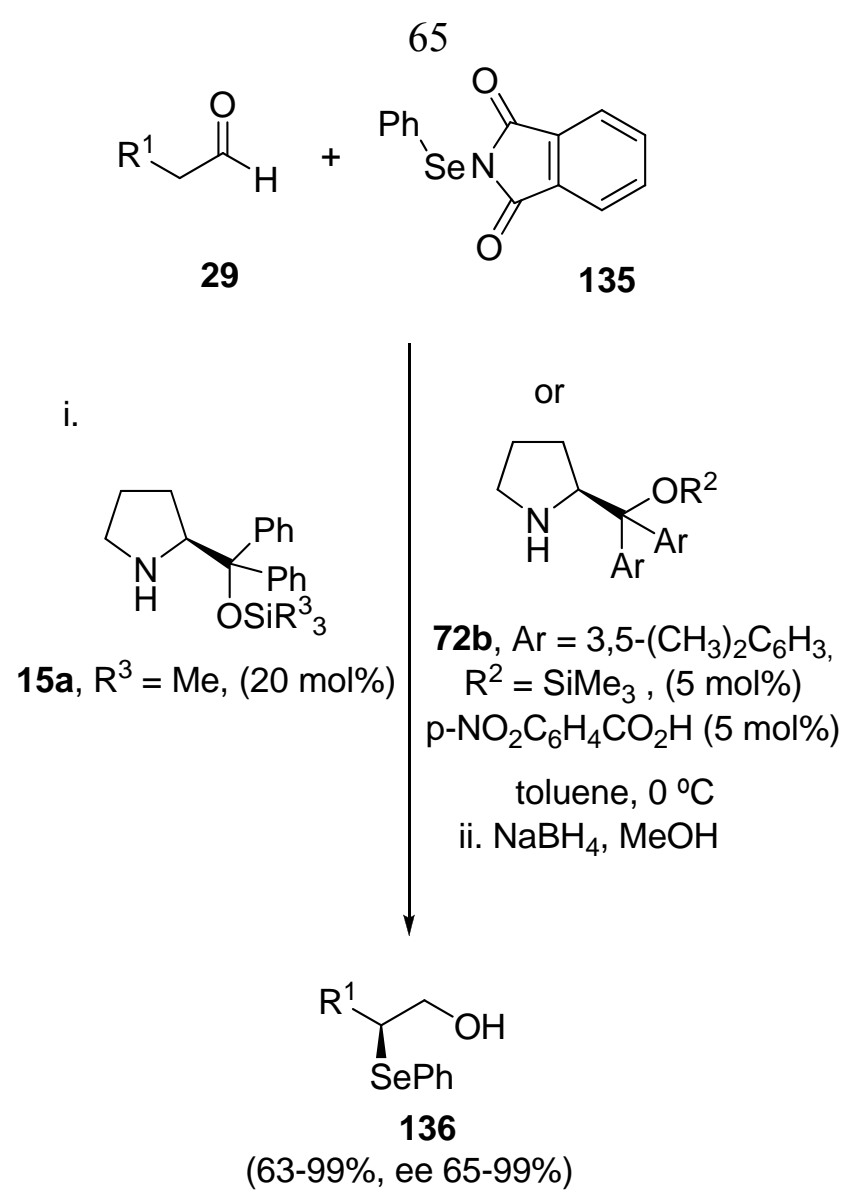

\section{Scheme 34}

The $\alpha$-selenylated products could easily reacted through an aldol-type reaction with an electron withdrawing group-stabilized carbanion, rendering the corresponding $\gamma$-selenyl- $\beta$-hydroxy sulfones or esters, which were further submitted to a one-pot selenide oxidation, in situ epoxide formation and finally ring opening to afford the corresponding $\gamma$-hydroxy- $\alpha, \beta$-unsaturated sulfones or esters in $50 \%$ overall yield and $95 \%$ enantiomeric excess [128]. This methodology was applied to the formal synthesis of alkaloid (+)- $\alpha$-conhydrine.

The $\alpha$-selenenylation of aldehydes was also accomplished by using a polystyrene-supported proline or prolinamide (30 mol\%) [129] obtaining the corresponding $\alpha$-selenylated products in high conversions but with low enantioselectivities. These supported catalysts could be reused up to four cycles without losing their activity.

\section{Enantioselective $\alpha$-halogenation of carbonyl compounds}


The construction of molecules bearing a stereogenic center with a carbon-halogen bond is an important goal in organic chemistry, due to the synthetic usefulness of these generated intermediates. Organocatalytic methods have been reported and reviewed in the recent past to pursue this objective [130].

Probably, from the four possible halogenation processes, the $\alpha$-fluorination of carbonylic compounds has been the most extensively studied owing to the unique and singular characteristics of the fluorinated compounds, being of special interest for medicinal, pharmaceutical and agrochemical applications [131]. The use of the organocatalyzed $\alpha$-fluorination reaction of aldehydes in combination with other synthetic processes has provided a valuable tool for the asymmetric synthesis of these privileged classes of chiral fluorine compounds. Thus, the one-pot $\alpha$-fluorination of aldehydes mediated by catalyst $72 \mathrm{a}(1 \mathrm{~mol} \%)$, followed by in situ trapping and homologation of the aldehyde using the Ohira-Bestmann reagent 138 in combination with methanol and potassium carbonate, afforded chiral propargylic fluorides $\mathbf{1 3 9}$ in moderated yields and excellent enantioselectivities (Scheme 35) [132]. Linear saturated and unsaturated aldehydes, arenecarbaldehydes with different substitution patterns and even functionalized aldehydes were suitable substrates for this transformation, showing its versatility. Furthermore, the Ohira-Bestmann reagent 138 could be in situ generated by addition of dimethyl 2-oxopropylphosphonate and 4-acetamidobenzenesulfonyl azide to the reaction mixture, obtaining similar results. The achieved propargylic fluorides $\mathbf{1 3 9}$ were used as starting materials to carry out the synthesis of optically active fluoro-containing azides through a typical click-chemistry process and for the generation of chiral fluorinated peptides and peptide-mimics through a multicomponent reaction between 139, pyridine and acid chloride/chloroformate catalyzed by copper-iodide. Not only propargylic fluorides could be obtained by one-pot procedure, but also allylic fluorides could be successfully achieved in $43-47 \%$ yield and $93-96 \%$ enantiomeric excesses by $\alpha$-fluorination followed by elongation through a Wittig reaction. 
<smiles></smiles>

29
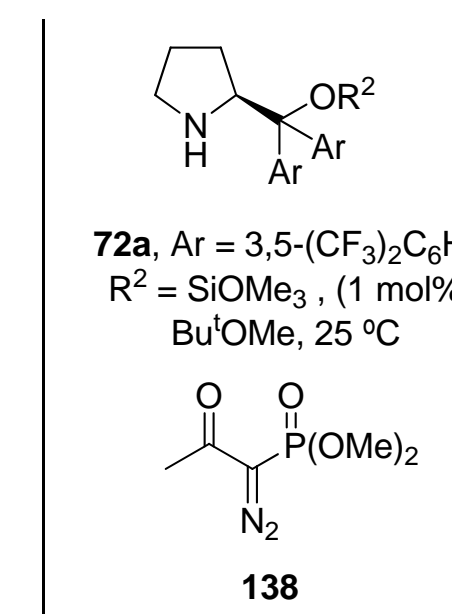

$$
\mathrm{K}_{2} \mathrm{CO}_{3}, \mathrm{MeOH}
$$

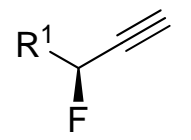

139

$(45-69 \%$, ee $91-99 \%)$

\section{Scheme 35}

Besides prolinols imidazolidinones such as 129 (20 mol\%) could be used to promote the $\alpha$-fluorination of aldehydes using $\mathrm{N}$-fluorobenzenesulfonimide (NFSI, 137) as a fluorine source, achieving fluorinated products in 70-96\% yields and with excellent enantiomeric excesses (91-99\% ee) [133]. The obtained $\alpha-$ fluoraldehydes were submitted to a reductive amination protocol using primary and secondary amines in a twopot process providing the corresponding $\beta$-fluoroamines in $65-82 \%$ yields and enantioselectivities up to $99 \%$. Using this methodology, more challenging tertiary $\beta$-fluoroamines could be prepared in good yields $(74-93 \%)$ albeit with low enantioselectivities (12-40\% ee). The synthesis of chiral $\beta$-fluoroamines was also possible using a one-pot procedure, affording the expected products with lower yields compared to the two-step procedure but with similar levels of enantioselectivity.

$\alpha$-Branched aldehydes $\mathbf{1 7}$ are suitable substrates for the $\alpha$-fluorination reaction using NFSI as fluorine source and chiral catalyst $140(10 \mathrm{~mol} \%)$ using a mixture of hexane/isopropanol as solvent in order to solubilize the substrates and to achieve the best results (Scheme 36) [134]. Whereas, good enantioselectivities 
were obtained when $\mathrm{R}^{1}$ was an aromatic substituent without substitution or with electron-withdrawing substituents (78-90\% ee), the enantioselectivities dropped significantly with two aliphatic substituents (7-31\% ee). Unfortunately, when the same procedure was applied to linear aldehydes or to ketones such as acetone or cyclohexanone, the reaction did not take place.

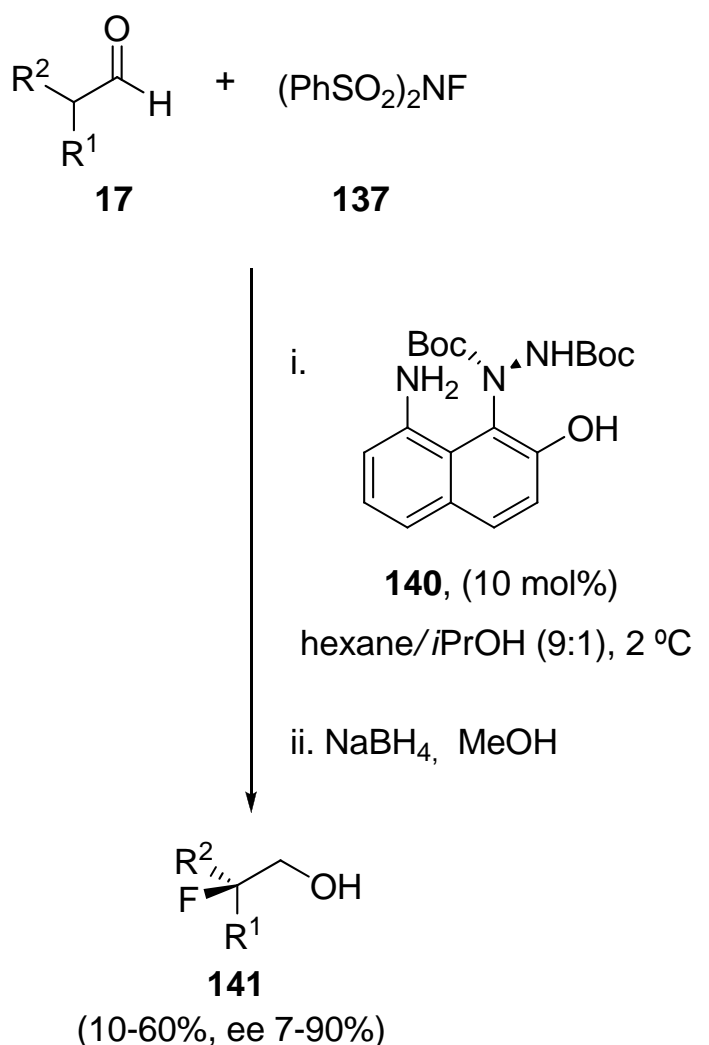

\section{Scheme 36}

The direct fluorination of ketones was an unsolved problem due to low conversions and enantioselectivities. However, this problem could be partially overcome by the use of substoichiometric amounts of cinchona alkaloids such as a catalyst $144(10 \mathrm{~mol} \%)$ for the fluorination of acyl enol ethers $\left(\mathrm{R}^{2}=\right.$ COEt in 142) using Selectflour ${ }^{\circledR}(\mathbf{1 4 3})$ as a fluorinating agent [135]. The achieved enantioselectivities were moderated in the case of indanones $(\mathbf{1 4 2}, \mathrm{n}=1,37-53 \%$ ee $)$ and very low in the case of tetralones $(\mathbf{1 4 2}, \mathrm{n}=2$, $3-24 \%$ ee). 
<smiles>[R]Oc1c([NH+])[nH]c2ccccc12</smiles>

142<smiles>F[N+]12CC[N+](CCl)(CC1)CC2Br</smiles>

143

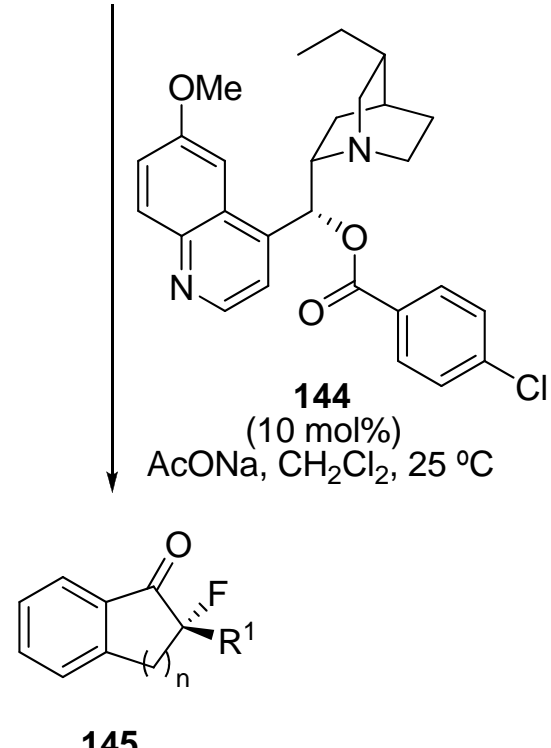

145

(17-88\%, ee 3-53\%)

\section{Scheme 37}

Better results for the preparation of chiral $\alpha$-fluoroketones were obtained in the fluorodesilylation of silyl enol ethers $142\left(\mathrm{R}^{2}=\mathrm{SiMe}_{3}, \mathrm{n}=2\right)$ mediated by bis-cinchona alkaloid 146 (10 mol\%, Figure 13) [136]. For this purpose, NFSI was used as a fluorinating agent, carrying out the reaction in the presence of potassium carbonate as a base in $\mathrm{CH}_{2} \mathrm{Cl}_{2}$ as solvent at $-40{ }^{\circ} \mathrm{C}$, to yield the corresponding $\alpha$-fluoroketones 145 with good results for arylmethyl substituted silyl enol ethers $\left(\mathrm{R}^{1}=\mathrm{ArCH}_{2}, \quad 74-90 \%, \quad 76-84 \%\right.$ ee). Lower enantioselectivities were found using ethyl substituted silyl enol ether $(95 \%, 67 \%$ ee). This procedure can be extended to the enantioselective fluorination of oxindoles using bis-cinchona alkaloid 147 (5 mol\%, Figure 13) as catalyst and cesium hydroxide as a base, affording the expected chiral fluoroderivatives in good yields (8999\%) and high enantioselectivities (79-87\% ee). 
<smiles>CCC1CC2CCN1C2C[C@H](Oc1nc(-c2ccccc2)nc(OC)c1-c1ccnc2ccc(OC)cc12)c1ccnc2ccc(OC)cc12</smiles>

146

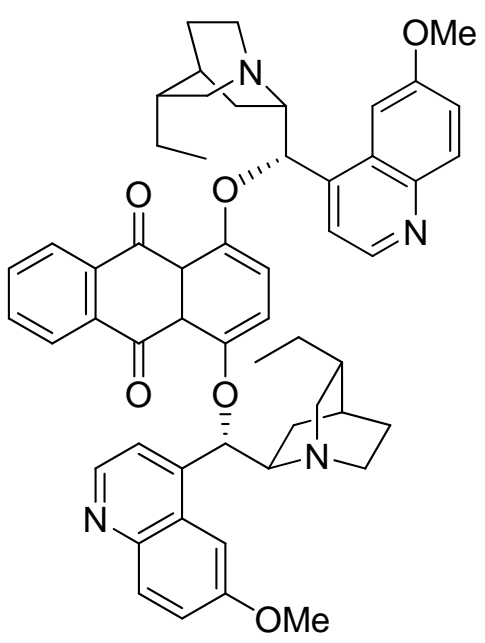

147

\section{Figure 13}

The asymmetric chlorination of pentanal and undecanal using $N$-chlorosuccinimide (NCS, 148) as chlorine source and diphenylpyrrolidine as catalyst $(\mathbf{1 4 9}, 10 \mathrm{~mol} \%)$ in $\mathrm{CH}_{2} \mathrm{Cl}_{2}$ as solvent provided an excellent method to obtain the corresponding products $\mathbf{1 5 0}$ in high yields and good enantioselectivities (Scheme 38). The chlorinated aldehydes served as starting materials for the synthesis of alkynyl, phenyl, alkyl and alkenyl epoxides by diastereoselective addition of an organolithium reagent followed by cyclization of the corresponding clorhydrine mediated by base. This procedure was applied to the synthesis of chiral transepoxides, which are present in several insect pheromones [137]. 


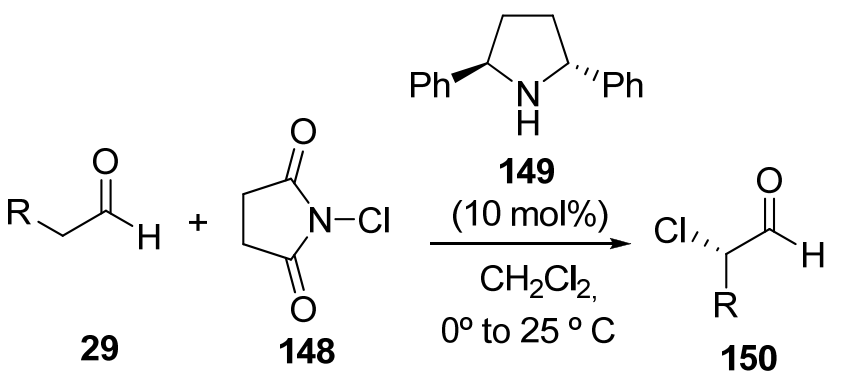

$(91-97 \%, 85-89 \%$ ee)

\section{Scheme 38}

The enantioselective synthesis of chiral $\alpha$-bromo carbonyl compounds could be achieved by a double $\alpha$ bromination-esterification process using acyl chlorides 151 as starting materials and brominating agent 152 catalyzed by the alkaloid derivative 153 (10 mol\%), giving esters 154 with good results (Scheme 39) [138]. The achieved enantioselectivities were high when aliphatic acid chlorides, unsubstituted arylacetyl chlorides or arylacetyl chlorides substituted with electron-donating groups were used as substrates, while racemic products were encountered when strong electron-withdrawing groups were present in the aromatic ring of the starting arylacetyl chlorides. The mechanism of the reaction was postulated to occur through the formation of a zwitterionic enolate intermediate formed by reaction of the acid chloride $\mathbf{1 5 1}$ with the catalysts and the base, which, in turn, abstracted $\mathrm{Br}^{+}$from the reagent 152, giving an ion-paired intermediate that underwent a transacetylation, producing the expected product 154 with the catalyst regeneration. This proposed mechanism was confirmed through a series of crossover experiments, ion-pairing tests, kinetic resolution studies and extensive molecular modeling to determine the transition state involved in the process [138b]. 
<smiles>[R]CC(=O)Cl</smiles>

151 152<smiles>C=CC1CC2CCN1C2[C@H](OC(=O)[C@@H]1CCCN1C(=O)OCc1ccccc1)c1ccnc2ccccc12</smiles>

153

(10 mol \%)

$\mathrm{NaH}, 15-\mathrm{crown}-5$

THF, $-78^{\circ} \mathrm{C}$<smiles>[R]C(Br)C(=O)OC(Br)(Br)Br</smiles>

154

(41-68\%, 83-99\% ee)

\section{Scheme 39}

Finally, only one example of the rare direct asymmetric $\alpha$-iodination of aldehydes has been recently reported. In this reaction, catalyst 119c $\left[5 \mathrm{~mol} \%, \mathrm{R}=\mathrm{C}\left(\mathrm{C}_{6} \mathrm{~F}_{5}\right)_{2} \mathrm{OH}\right]$, in the presence of benzoic acid as cocatalyst in ether at $0{ }^{\circ} \mathrm{C}$, was used to promote the $\alpha$-iodination of several aldehydes 29 using $N$-iodosuccinimide as a iodinating agent, affording the corresponding chiral $\alpha$-iodoaldehydes in moderated isolated yields (30$80 \%)$ and with excellent enantioselectivities (90-99\% ee) [139].

Due to the usefulness of the aforementioned methods to produce chiral $\alpha$-halogenated carbonyl compounds, which are valuable synthons, several mechanistic studies have been undertaken in order to investigate the origin of the enantioselectivity found in such processes. Some DFT calculations used to explore the enantioselectivity displayed by catalyst 72 in the $\alpha$-fluorination reaction using NFSI as a fluorine source, found that the optimal transition state occurred through a enamine type intermediate, being attacked from the less shielded Si face, more stable in energy than the Re face attack, and therefore leading to the $S$ configuration on the chiral product [140a]. However, recently other theoretical studies have proposed that the $\alpha$-fluorination 
reaction using NFSI promoted by catalyst 72, similar to the results encountered for other $\alpha$-functionalization reaction catalyzed by $\mathbf{7 2}$, occurred via a trans enol-catalyst complex reacting with NFSI through a new transition state $[140 \mathrm{~b}]$. This transition state consisted of simultaneous C-F bond formation between the enol and NFSI via fluorine-shift and H-shift from the oxygen of the enol to the nitrogen of the catalyst. Probably, a more conscientious study of the mechanism is necessary in order to clarify these apparently opposite reaction pathways. For instance, the use of spectroscopic techniques may help to elucidate the presence of intermediates in this transformation. In this sense, recently electrospray ionization mass spectrometry has permitted the interception and characterization of the iminium ion intermediate formed by reaction of prolinamide and aldehyde in the $\alpha$-chlorination using $N$-chlorosuccinimide as chlorine source, and also transients involving the presence of such a chlorine atom which allows a better understanding of the reaction process [140c], and seems to prove the first type of mechanism.

\section{Conclusions and outlook}

This review has shown the great number of contributions, which have been made in the last three years, in the field of the direct formation of a stereogenic carbon-heteroatom bond adjacent to a carbonyl functionality using organocatalysis. The use of this methodology has lead to the synthesis of significantly important optical active compounds in a very attractive way for industry and for the general chemical community, due to the advantages, such as the absence of the metal traces in the final products and the simple procedures used.

Although it might seem that a narrow area for original reactions are left, due to the vast amount of articles reported so far, this is not the case. For instance, they are up to date, unreported transformations, such as the $\alpha$-iodination of ketones. Furthermore, the improvement of the reaction conditions already reported, especially concerning catalyst loading together with the recyclability of the catalyst used is still an area for new development.

Probably a better understanding of the reaction mechanism would allow us to reach new perspectives and to extend the application of the synthesized chiral building blocks for the synthesis of important biologically active compounds, using more efficient methodologies such as domino, tandem or multicomponent processes. 


\section{Acknowledgements}

We are grateful to the Spanish Ministerio Ciencia e Innovación (Consolider Ingenio 2010 CSD2007-00006, CTQ2007-65218/BQU) and the Generalitat Valenciana (Proyecto Prometeo 2009/039), for the continuous financial support.

\section{Abbreviations}

Ac

apmin

AP-PLL

APTESi

Ar

ArH

BINOL

bmim

$\mathrm{Bn}$

Boc

$\mathrm{Bu}$

$\mathrm{Bu}^{\mathrm{t}}$

cat

$\mathrm{Cbz}$

CD

$\mathrm{CN}$

Cy

dba

DBU

$\mathrm{dr}$

DFT

DMAP

DME

DMF

DMSO

ee

Et

HQ acetyl

1-(3-aminopropyl)-3-methylimidazolium

aminopropyl functionalized polyleucine

3-(aminopropyl)triethoxysilane

aryl

arene

1,1'-bi-2-naphthol

1-n-butyl-3-methylimidazolium

benzyl

tert-butoxy carbonyl

n-butyl

tert-butyl

catalyst

benzyloxy carbonyl

circular dicroism

cyano group

cyclohexyl

dibenzylideneacetone

1,8-diazabicyclo[5.4.0] undec-7-ene

diasteromeric ratio

density functional theory

4-(dimethylamino)pyridine

1,2-dimethoxyethane

$N, N$-dimethylformamide

dimethylsulphoxide

enantiomeric excess

ethyl

hidroquinone 
HMPA hexamethylphosphoramide

m-xy

metha-xylyl

$\mathrm{Me}$

methyl

MS

molecular sieves

NCS

$\mathrm{N}$-chlorosuccinimide

NFSI

$\mathrm{N}$-fluorobenzenesulfonamide

NMR

nuclear magnetic resonance

$\mathrm{NsNIPh}$

(nosylimino)iodobenzene

OAc

acetate

PEG

polyethyleneglycol

$\mathrm{Ph}$

phenyl

PMB

para-methoxybenzyl

PLL

polyleucine

$\operatorname{Pr}^{\mathrm{n}}$

propyl

$\operatorname{Pr}^{\mathrm{i}}$

isopropyl

SET

single electron transfer

TADDol

$\alpha, \alpha, \alpha^{\prime}, \alpha^{\prime}$-tetraaryl-1,3-dioxolane-4,5-dimethanol

TBBA

tetrabutyl ammonium bromide

TBHP

tetrabutylhydroperoxide

TBS

tert-butyl dimethyl silyl

TCCA

trichloroisocyanuric acid

TEAB

tetraethyl ammonium bromide

TEMPO

2,2,6,6,-tetramethylpiperidine-1-oxyl

THF

tetrahydrofuran

TMS

trimethylsilyl

TRIP

3,3'-bis(2,4,6-triisopropylphenyl)-1,1'-bynphthyl-2,2'-diyl

hydrogen

phosphate

Ts

para-toluensulfonyl

UV

ultraviolet

\section{References}

[1] Izumi, Y. Methods of asymmetric synthesis - enantioselective catalytic hydrogenation. Angew. Chem. Int. Ed. Engl., 1971, 10, 871-881.

[2] a) Trost, B. M. The atom economy- a search for synthetic efficiency. Science, 1991, 254, 1471-1477. b)

Sheldon, R. A. Atom efficiency and catalysis in organic synthesis. Pure Appl. Chem., 2000, 72, 1233- 
1246. c) Trost, B. M. On inventing reactions for atom economy. Acc. Chem. Res., 2002, 35, 695-705. d)

Guillena, G.; Ramón, D. J.; Yus, M. Alcohols as electrophiles in C-C bond-forming reactions: The hydrogen autotransfer process. Angew. Chem. Int. Ed., 2007, 46, 2358-2364.

[3] a) Wong, C.-H.; Withesides, G. Enzymes in Organic Chemistry; Pergamon Press: Oxford, 1994. b) Enzyme Catalysis in Organic Synthesis: A Comprehensive Handbook; Drauz, K.; Waldmann, H., Eds.; Wiley-VCH: Weinheim, 2002; Vol. 1-3.

[4] a) Catalytic Asymmetric Synthesis; Ojima, I., Ed.; VCH: Weinheim, 1993. b) Noyori, R. Asymmetric Catalysis in Organic Synthesis; Wiley: New York, 1994. c) Stereoselective Synthesis (Houben-Weyl); Helmchen, G.; Hoffmann, R. W.; Mulzer, J.; Schaumann, E., Eds.; Thieme: Stuttgart, 1996; Vols. 1-10. d) Ramón, D. J.; Yus, M. Recent developments in enantioselective reactions promoted by titanium (IV) reagents bearing a chiral ligand. Recent Res. Devel. Org. Chem., 1998, 2, 489-523. e) Comprehensive Asymmetric Catalysis; Jacobsen, E. N.; Pfaltz, A.; Yamamoto, H., Eds.; Springer Verlag: Berlin, 1999; Vols. 1-3. f) Yus, M.; Ramón, D. J. Recent developments in the enantioselective 1,2-addition of organometallic reagents to carbonyl compounds. Recent Res. Devel. Org. Chem., 2002, 6, 297-378. g) Comprehensive Asymmetric Catalysis, Suppl. 1; Jacobsen, E. N.; Pfaltz, A.; Yamamoto, H., Eds.; Springer Verlag: Berlin, 2004. h) Comprehensive Asymmetric Catalysis, Suppl. 2; Jacobsen, E. N.; Pfaltz, A.; Yamamoto, H., Eds.; Springer Verlag: Berlin, 2004. i) Ramón, D. J.; Yus, M. Chiral tertiary alcohols made by catalytic enantioselective addition of unreactive zinc reagents to poorly electrophilic ketones?. Angew. Chem. Int. Ed., 2004, 43, 284-287. j) Ramón, D. J.; Yus, M. Alkylation of ketones and imines. In Quaternary Stereocenters: Challenges and Solutions for Organic Synthesis; Christoffers, J.; Baro, A., Eds.; Wiley-VCH: Weinheim, 2005. k) Yus, M.; Ramón, D. J. Enantioselective addition of organozinc reagents to carbonyl compounds. Pure Appl. Chem., 2005, 77, 2111-2119. 1) Ramón, D. J.; Yus, M. In the arena of enantioselective synthesis, titanium complexes wear the laurel wreath. Chem. Rev., 2006, 106, 2126-2208.

[5] For comprehensive books and selected reviews, see: a) Dalko, P. I.; Moisan, L. In the golden age of organocatalysis. Angew. Chem. Int. Ed., 2004, 43, 5138-5175. b) Berkessel, A.; Gröger, H. Asymmetric Organocatalysis: From Biomimetic Concepts to Applications in Asymmetric Synthesis, Wiley-VCH: Weinheim, 2005. c) Seayad, J.; List, B. Asymmetric organocatalysis. Org. Biomol. Chem., 2005, 3, 719- 
724. d) Kočovský, P.; Malkov, A. V. Issue Eds.; Organocatalysis in organic synthesis. Tetrahedron, 2006, 62, 255. e) Lelais, G.; McMillan, D. W. C. Modern strategies in organic catalysis: The advent and development of iminium activation. Aldrichimica Acta, 2006, 39, 79-87. f) Pellissier, H. Asymmetric organocatalysis. Tetrahedron, 2007, 63, 9267-9331. g) Enantioselective Organocatalysis, Dalko, P. I. Ed.; Wiley-VCH: Weinheim, 2007. h) List, B. Organocatalysis. Chem. Rev., 2007, 107, 5413 i). de Figueiredo, R. M.; Christmann, M. Organocatalytic synthesis of drugs and bioactive natural products. Eur. J. Org. Chem., 2007, 2575-2600. j) Kotsuki, H.; Ikishima, H.; Okuyama, A. Organocatalytic asymmetric synthesis using proline and related molecules. Part 1. Heterocycles, 2008, 75, 493-529. K) Kotsuki, H.; Ikishima, H.; Okuyama, A. Organocatalytic asymmetric synthesis using proline and related molecules. Part 2. Heterocycles, 2008, 75, 757-797.

[6] Marckwald, W. An Asymmetric synthesis. Ber. Dtsch. Chem. Ges., 1904, 37, 349-354.

[7] a) Guillena, G.; Nájera, C.; Ramón, D. J. Enantioselective direct aldol reaction: The blossoming of modern organocatalysis. Tetrahedron: Asymmetry, 2007, 18, 2249-2293. b) Guillena, G.; Ramón, D. J.; Yus, M. Organocatalytic enantioselective multicomponent reactions (OEMCRs). Tetrahedron: Asymmetry, 2007, 18, 693-700.

[8] Enders, D.; Grondal, C.; Hüttl, M. R. M. Asymmetric organocatalytic domino reactions. Angew. Chem. Int. Ed., 2007, 46, 1570-1581.

[9] Noyori, R. Pursuing practical elegance in chemical synthesis. Chem. Commun., 2005, 1807-1811.

[10] a) Marigo, M.; Jørgensen, K. A. Organocatalytic direct asymmetric $\alpha$-heteroatom functionalization of aldehydes and ketones. Chem. Commun., 2006, 2001-2011. b) Guillena, G.; Ramón, D. J. Enantioselective $\alpha$-heterofunctionalisation of carbonyl compounds: Organocatalysis is the simplest approach. Tetrahedron: Asymmetry, 2006, 17, 1465-1492.

[11] Amino group chemistry: From Synthesis to the Life Sciences, Ricci, A. Ed.; Wiley-VCH: Weinheim, 2007.

[12] Aziridines and Epoxides in Organic Synthesis, Yudin, A. K. Ed.; Wiley-VCH: Weinheim, 2006.

[13] For a review on the use of azodicarboxylates for this type of reaction, see: Nair, V.; Biju, A. T.; Mathew, S.C; Babu B. P. Carbon-nitrogen bond-forming reactions of dialkyl azodicarboxylate: A promising synthetic strategy. Chem. Asian J., 2008, 3, 810-820. 
[14] Maruoka, K. Practical aspects of recent asymmetric phase-transfer catalysis. Org. Process Res. Dev., 2008, 12, 676-697.

[15] Shen, Y.-M.; Zhao, M.-X.; Xu, J.; Shi, Y. An amine-promoted aziridination of chalcones. Angew. Chem. Int. Ed., 2006, 45, 8005-8008.

[16] Armstrong, A.; Baxter, C. A.; Lamont, S. G.; Pape, A.R.; Wincewicz, R. Amine-promoted, organocatalytic aziridination of enones. Org. Lett., 2007, 9, 351-353.

[17] Minakata, S.; Murakami, Y.; Tsuruoka, R.; Kitanaka, S.; Komatsu, M. Catalytic aziridination of electron-deficient olefins with an $N$-chloro- $N$-sodio carbamate and application of this novel method to asymmetric synthesis. Chem. Commun., 2008, 6363-6365.

[18] Pesciaioli, F.; De Vicentiis, F.; Galzerano, P.; Bencivenni, G.; Bartoli, G.; Mazzanti, A.; Melchiorre, P. Organocatalytic asymmetric aziridination of enones. Angew. Chem. Int. Ed., 2008, 47, 8703-8706.

[19] Vesely, J.; Ibrahem, I.; Zhao, G.-L.; Rios, R.; Córdova, A. Organocatalytic enantioselective aziridination of $\alpha, \beta$-unsaturated aldehydes., Angew. Chem. Int. Ed., 2007, 46, 778-781.

[20] Arai, H.; Sugaya, N.; Sasaki, N.; Makino, K.; Lectard, S.; Hamada, Y. Enantioselective aziridination reaction of $\alpha, \beta$-unsaturated aldehydes using an organocatalyst and tert-butyl $N$ arenesulfonyloxycarbamates. Tetrahedron Lett., 2009, 50, 3329-3332.

[21] a) Ramón, D. J.; Yus, M. Enantioselective synthesis of oxygen-, nitrogen- and halogen-substitutted quaternary carbon centers. Curr. Org. Chem., 2004, 8, 149-183. b) Quaternary StereocentersChallenges and Solutions for Organic Synthesis; Christoffers, J.; Baro, A., Eds.; Wiley-VCH: Weinheim, 2005.

[22] Baumann, T.; Vogt, H.; Bräse, S. The proline-catalyzed asymmetric amination of branched aldehydes. Eur. J. Org. Chem., 2007, 266-282.

[23] Baumann, T.; Bächle, M.; Hartamann, C.; Bräse, S. Thermal effects in the organocatalytic asymmetric $\alpha$-amination of disubstituted aldehydes with azodicarboxylates: A high-temperature organocatalysis. Eur. J. Org. Chem., 2008, 2207-2212.

[24] Vogt, H.; Baumann, T.; Nieger, M.; Bräse, S. Direct asymmetric $\alpha$-sulfamidation of $\alpha$-branched aldehydes: A novel approach to enamine catalysis. Eur. J. Org. Chem., 2006, 5315-5338. 
[25] Mathew, S. P.; Klussmann, M.; Iwamura, H.; Wells, D. H.; Armstrong, A.; Blackmond, D. G. A mechanistic rationalization of unusual kinetic behavior in proline-mediated $\mathrm{C}-\mathrm{O}$ and $\mathrm{C}-\mathrm{N}$ bond forming reactions. Chem. Commun., 2006, 4291-4293.

[26] Kotkar, S. P.; Sudalai, A. Enantioselective synthesis of $(S, S)$-ethambutol using proline-catalyzed asymmetric $\alpha$-aminooxylation and $\alpha$-amination. Tetrahedron: Asymmetry, 2006, 17, 1738-1742.

[27] Talluri, S. K.; Sudalai, A. An organo-catalytic approach to the enantioselective synthesis of $(R)$ selegiline. Tetrahedron, 20067 63, 9758-9763.

[28] Kalch, D.; De Rycke, N.; Moreau, X.; Greck, C. Efficient syntheses of enantioenriched (R)-pipecolic acid and (R)-proline via electrophilic organocatalytic amination. Tetrahedron Lett., 2009, 50, 492-494.

[29] Chandrasekhar, S.; Parimala, G.; Tiwari, B.; Narsihmulu, C. Sarma, G. D. Asymmetric synthesis of a protected dihydroxypiperazic acid derivative. Synthesis, 2007, 1677-1682.

[30] Chouthaiwale, P. V.; Kotkar, S. P.; Sudalai, A. Formal synthesis of (-)-anisomycin via organocatalysis. ARKIVOC, 2009, ii, 88-94.

[31] a) Nishikawa, Y.; Kitajima, M.; Takayama, H. First asymmetric total syntheses of Cernuane-type Lycopodoim alkaloids Cernuine, and Cermizine D. Org. Lett., 2008, 10, 1987-1990. b) Nishikawa, Y.; Kitajima, M.; Kogure, N.; Takayama, H. A divergent approach for the total syntheses of cernuane-type and quinolizidine-type Lycopodoim alkaloids. Tetrahedron, 2009, 65, 1608-1617.

[32] Umbreen, S.; Brockhaus, M.; Ehrenberg, H.; Schmidt, B. Norstatines from aldehydes by sequential organocatalytic $\alpha$-amination and Passerini reaction. Eur. J. Org. Chem., 2006, 4585-4595.

[33] Kotkar, S. P.; Chavan, V. B.; Sudalai, A. Organocatalytic sequential $\alpha$-amination-Horner-WadsworthEmmons olefination of aldehydes: Enantioselective synthesis of $\gamma$-amino- $\alpha, \beta$-unsaturated esters. Org. Lett., 2007, 9, 1001-1004.

[34] a) Oelke, A. J.; Kumarn, S.; Longbottom, D. A.; Ley, S. V. An enantioselective organocatalytic route to chiral 3,6-dihydropyridazines from aldehydes. Synlett, 2006, 2548-2552. b) Kumarn, S.; Oelke, A. J.; Shaw, D. M.; Longbottom, D. A.; Ley, S. V. A sequential enantioselective, organocatalytic route to chiral 1,2-oxazines and chiral pyridazines. Org. Biomol. Chem., 2007, 5, 2678-2689.

[35] Lim, A.; Choi, J. H.; Tae, J. Organocatalytic $\alpha$-amination-allylation -RCM strategy: Enantioselective synthesis of cyclic hydrazines. Tetrahedron Lett., 2008, 49, 4882-4885. 
[36] Simmons, B.; Walji, A. M.; MacMillan, D. W. C. Cycle-specific organocascade catalysis: Application to olefin hydroamination, hydro-oxidation, and amino-oxidation, and to natural product synthesis. Angew. Chem. Int. Ed., 2009, 48, 4349-4353.

[37] Hayashi, Y.; Aratake, S.; Imai, Y.; Hibino, K.; Chen, Q.-Y.; Yamaguchi, J.; Uchimaru, T. Direct asymmetric $\alpha$-amination of cyclic ketones catalyzed by siloxyproline. Chem. Asian J., 2008, 3, 225-232.

[38] Lacoste, E.; Vaique, E.; Berlande, M.; Pianet, I.; Vicent, J.-M.; Landais, Y. Benzimidazolepyrrolidine $/ \mathrm{H}^{+}\left(\mathrm{BIP} / \mathrm{H}^{+}\right)$, a highly reactive organocatalyst for asymmetric processes. Eur. J. Org. Chem., 2007, $167-177$.

[39] Liu, T.-Y.; Cui, H.-L.; Zhang, Y.; Jiang, K.; Du, W.; He, Z.-Q.; Chen, Y.-C. Organocatalytic and highly enantioselective direct $\alpha$-amination of aromatic ketones. Org. Lett., 2007, 9, 3671-3674.

[40] a) He, R.; Wang, X.; Hashimoto, T.; Maruoka, K. Binaphthyl-modified quaternary phosphonium salts as chiral phase-transfer catalysts: asymmetric amination of $\beta$-keto esters. Angew. Chem. Int. Ed., 2008, 47, 9466-9468. b) Lan, Q.; Wang, X.; He, R.; Ding, C.; Maruoka, K. Highly efficient asymmetric amination of $\beta$-keto esters catalyzed by chiral quaternary ammonium bromides. Tetrahedron Lett., 2009, 50, 32803282. c) He, R.; Maruoka, K. Binaphthyl-modified quaternary phosphonium salts as chiral phasetransfer catalysts: Application to asymmetric amination of $\beta$-keto esters. Synthesis, 2009, 2289-2292.

[41] Jung, S. H.; Kim, D. Y. Catalytic enantioselective electrophilic $\alpha$-hydrazination of $\beta$-ketoesters using bifunctional organocatalysts. Tetrahedron Lett., 2008, 49, 5527-5530.

[42] Zhu, R.; Zhang, D.; Wu, J.; Liu, C. Theoretical study on the enantioselective $\alpha$-amination reaction of 1,3-dicarbonyl compounds catalyzed by a bifunctional-urea. Tetrahedron: Asymmetry, 2007, 18, 16551662.

[43] Terada, M.; Nakano, M.; Ube, H. Axially chiral guanidine as highly active and enantioselective catalyst for electrophilic amination of unsymmetrically substituted 1,3-dicarbonyl compounds. J. Am. Chem. Soc., 2006, 128, 16044-16045.

[44] Kim, S. M.; Lee, J. H.; Kim, D. Y. Enantioselective direct amination of $\alpha$-cyanoketones catalyzed by bifunctional organocatalysts. Synlett, 2008, 2659-2662. 
[45] a) Liu, Y.; Melgar-Fernández, R.; Juaristi, E. Enantioselective amination of $\alpha$-phenyl- $\alpha$-cyanoacetate catalyzed by chiral amines incorporating the $\alpha$-phenylethyl auxiliary. J. Org. Chem., 2007, 72, 15221525. b) Melgar-Fernández, R.; González-Olvera, R.; Olivares-Romero, J. L.; González-López, V.; Romero-Ponce, L.; Ramírez-Zárate, M. R.; Demare, P.; Regla, I.; Juaristi, E. Synthesis of novel derivatives of $(1 S, 4 S)$-2,5-diazabicyclo[2.2.1]heptanes and their evaluation as potential ligands in asymmetric catalysis. Eur. J. Org. Chem., 2008, 655-672.

[46] For an excellent review on this subject, see: Paull, D. H.; Weatherwax, A. Lectka, T. Catalytic, asymmetric reactions of ketenes and ketene enolates. Tetrahedron, 2009, 65, 6771-6803.

[47] Berlin, J. M.; Fu, G. Enantioselective nucleophilic catalysis: The synthesis of aza- $\beta$-lactams trough [2+2] cycloadditions of ketenes with azo compounds. Angew. Chem. Int. Ed., 2008, 47, 7048-7050.

[48] Akakura, M.; Kawasaki, M.; Yamamoto, H. DFT study of Brønsted acid catalyzed nitroso aldol reaction between achiral enamines and nitrosobenzene: The reason for regio- and enantioselectivity. Eur. J. Org. Chem., 2008, 4245-4249.

[49] Kano, T.; Ueda, M.; Maruoka, K. Direct asymmetric hydroxyamination reaction catalyzed by an axially chiral secondary amine catalyst. J. Am. Chem. Soc., 2006, 128, 6046-6047.

[50] Palomo, C.; Vera, S.; Velilla, I.; Mielgo, A.; Gómez-Bengoa, E. Regio- and enantioselective direct oxyamination reaction of aldehydes catalyzed by $\alpha, \alpha$-diphenylprolinol trimethylsilyl ether. Angew. Chem. Int. Ed., 2007, 46, 8054-8056.

[51] Wong, C. T. A theoretical investigation on the mechanism of the $\alpha, \alpha$-diphenylprolinol trimethylsilyl ether-catalyzed oxyamination reaction. Tetrahedron Lett., 2009, 50, 811-813.

[52] a) Kim, S.-G.; Park, T.-H. Organocatalyzed asymmetric $\alpha$-hydroxyamination of $\alpha$-branched aldehydes: asymmetric synthesis of optically active $N$-protected $\alpha, \alpha$-disubstituted amino aldehydes and amino alcohols. Tetrahedron Lett., 2006, 47, 9067-9071. b) Kim, S.-G.; Ahn, E. J. Park, T.-H. Direct organocatalytic regioselective $\alpha$-hydroxyamination of $\alpha$-branched aldehydes. Bull. Korean Chem. Soc., 2007, 28, 1665-1669.

[53] Momiyama, N.; Yamamoto, Y.; Yamamoto, H. Diastereo- and enantioselective synthesis of nitroso Diels-Alder-type bicycloketones using dienamine: Mechanistic insight into sequential nitroso 
Aldol/Michael reaction and application for optically pure 1-amino-3,4-diol synthesis. J. Am. Chem. Soc., 2007, 129, 1190-1195.

[54] López-Cantarero, J.; Cid, M. B.; Poulsen, T. B.; Bella, M.; García Ruano, J. L.; Jørgensen, K. A. Intriguing behavior of Cinchona alkaloids in the enantioselective organocatalytic hydroxyamination of

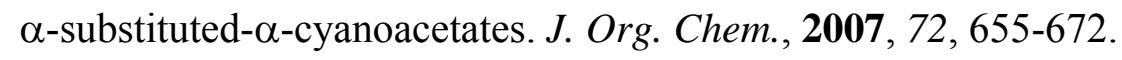

[55] Marigo, M.; Bertelsen, S.; Landa, A.; Jørgensen, K. A. One-pot organocatalytic domino Michael-aldol and intramolecular $\mathrm{S}_{\mathrm{N}} 2$ reactions. Asymmetric synthesis of highly functionalized epoxycyclohexanone derivatives. J. Am. Chem. Soc., 2006, 128, 5475-5479.

[56] a) Novák, T.; Bakó, P.; Keglevich, G.; Greiner, I. Enantioselective phase transfer catalytic reactions. A comparative study on the use of cinchonidine salts and glucose-based lariat ethers including phosphinoxidomethyl derivatives. Phosphorous, Sulfur Silicon Relat. Elem., 2007, 182, 2449-2456. b) Makó, A.; Szöllősy, A.; Keglevich, G.; Menyhárd, D. K.; Bakó, P.; Tőke, L. Synthesis of methyl- $\alpha$-Dglucopyranoside-based azacrown ethers and their application in enantioselective reactions. Monatsh. Chem., 2008, 139, 525-535.

[57] Ku, J.-M.; Yoo, M.-S.; Park, H.-g.; Jew, S.-s.; Jeong, B.-S. Asymmetric synthesis of $\alpha, \beta$-epoxysulfones via phase-transfer catalytic Darzens reaction. Tetrahedron, 2007, 63, 8099-8103.

[58] For selected reviews, see: a) Kelly, D. R.; Roberts, S. M. Oligopeptides as catalysts for asymmetric epoxidation. Biopolymers, 2006, 84, 74-89. b) Lattanzi, A. Advances in asymmetric epoxidation of $\alpha, \beta$ unsaturated carbonyl compounds: The organocatalytic approach. Curr. Org. Synth., 2008, 5, 117-133. c) Wong, A. C.; Shi, Y. Organocatalytic oxidation. Asymmetric epoxidation of olefins catalyzed by chiral ketones and iminium salts. Chem. Rev., 2008, 108, 3958-3987. d) Colonna, S.; Perdicchia, D.; Di Mauro, E. Enantioselective reactions catalyzed by synthetic enzymes. A model for chemical evolution. Tetrahedron: Asymmetry, 2009, 20, 1709-1714.

[59] a) Lygo, B. Gardiner, S. D.; McLeod, M. C.; To, D. C. M. Diastereo- and selective synthesis of $\alpha, \beta-$ epoxyketones using aqueous $\mathrm{NaOCl}$ in conjunction with dihydrocinchonidine derived phase-transfer catalysis at room temperature. Scope and limitations. Org. Biomol. Chem., 2007, 5, 2283-2290. b) Lygo, B. Gardiner, S. D.; To, D. C. M. Selective synthesis of the epoxysuccinyl peptide E-64c. Synlett, 2006, 2063-2066. 
[60] Jew, S.-s.; Lee, J.-H.; Jeong, B.-S.; Yoo, M.-S.; Kim, M.-J.; Lee, Y.-J.; Choi, S.-h.; Lee, K. Lah, M. S.; Park, H.-g. Highly enantioselective epoxidation of 2,4-diarylenones by using dimeric cinchona phasetransfer catalysts: Enhancement of enantioselectivity by surfactants. Angew. Chem. Int. Ed., 2005, 44, 1383-1385.

[61] Lv, J.; Wang, X.; Liu, J.; Zhang, L.; Wang, Y. Catalytic asymmetric epoxidation of chalcones under poly(ethyleneglycol)-supported Cinchona ammonium salt catalyzed conditions. Tetrahedron: Asymmetry, 2006, 17, 330-335.

[62] Hori, K.; Tamura, M.; Tani, K.; Nishiwaki, N.; Ariga, M.; Tohda, Y. Asymmetric epoxidation catalyzed by novel azacrown ether-type chiral quaternary ammonium salts under phase-transfer catalytic conditions. Tetrahedron Lett., 2006, 47, 3115-3118.

[63] Pál, K.; Kállay, M.; Kubinyi, M.; Bakó, P.; Makó, A. Circular dichroism spectra of trans-chalcone epoxides. Tetrahedron: Asymmetry, 2007, 18, 1521-1528.

[64] Makó, A.; Menyhárd, D. K.; Bakó, P.; Keglevich, G.; Töke, L. Theoretical study of the asymmetric phase-transfer mediated epoxidation of chalcone catalyzed by chiral crown ethers derived from monosaccharides. J. Mol. Struct., 2008, 892, 336-342.

[65] Kita, T.; Shin, B.; Hasimoto, Y.; Nagasawa, K. Nucleophilic asymmetric epoxidation catalyzed by cyclic guanidines. Heterocycles, 2007, 73, 241-247.

[66] Shin, B.; Tanaka, S.; Kita, T.; Hasimoto, Y.; Nagasawa, K. Development of bifunctional acyclic hydroxyl-guanidine organocatalyst: Application to asymmetric nucleophilic epoxidation. Heterocycles, 2008, 76, 801-810.

[67] Terada, M.; Nakano, M. Asymmetric epoxidation of $\alpha, \beta$-unsaturated ketones with hydrogen peroxide catalyzed by axially chiral guanidine base. Heterocycles, 2008, 76, 1049-1055.

[68] Tanaka, S.; Nagasawa, K. Guanidine-urea bifunctional organocatalyst for asymmetric epoxidation of 1,3-diarylenones with hydrogen peroxide. Synlett, 2009, 667-670.

[69] Berkessel, A.; Guixà, M.; Schmidt, F.; Neudörfl, J. M.; Lex, J. Highly enantioselective epoxidation of 2methylnaphthoquinone (vitamin $\mathrm{K}_{3}$ ) mediated by new Cinchona alkaloid phase-transfer catalysts. Chem. Eur. J., 2007, 13, 4483-4498. 
[70] Wang, Y., Ye, J., Liang, X. Convenient preparation of chiral $\alpha, \beta$-epoxy ketones via Claisen-Schmidt condensation-epoxidation sequence. Adv. Synth. Catal., 2007, 349, 1033-1036.

[71] Mathew, S. P.; Gunathilagan, S.; Roberts, S. M.; Blackmond, D. G. Mechanistic insights from reaction progress kinetic analysis of the polypeptide-catalyzed epoxidation of chalcone. Org. Lett., 2005, 7, 4847-4850.

[72] Geller, T.; Gerlach, A.; Krüger, C.M. Militzer, H.-C. The Juliá-Colonna epoxidation: Access to chiral, non-racemic epoxides. J. Mol. Catal. A: Chem., 2006, 251, 71-77.

[73] Qui, W.; He, L.; Chen, Q.; Luo, W.; Yu, Z.; Yang, F.; Tang, J. Imidazolium-modified poly(L-leucine) catalyst: An efficient and recoverable catalyst for Juliá-Colonna reactions. Tetrahedron Lett., 2009, 50, $5225-5227$.

[74] Yang, F.; He, L.-M.; Yi, H.; Zou, G.; Tang, J.; He, M.-Y. An efficient silica-grafted poly-(L)-leucine catalyst for asymmetric epoxidation of $\alpha, \beta$-unsaturated ketone. J. Mol. Catal. A: Chem., 2007, 273, 1-4.

[75] Kee, S.-P.; Gavriiliidis, A. Batch versus continuous mg-scale synthesis of chalcone epoxide with soluble polyethylene glycol poly-L-leucine catalyst. J. Mol. Catal. A: Chem., 2007, 263, 156-162.

[76] Maeda, K.; Tanaka, K.; Morino, K.; Yashima, E. Synthesis of optically active helical poly(phenylacetylene)s bearing oligopeptide pendants and their use as polymeric organocatalysts for asymmetric epoxidation. Macromolecules, 2007, 40, 6783-6785.

[77] a) Zhao, G.-L.; Dziedzic, P.; Ibrahem, I.; Córdova, A. Organocatalytic asymmetric synthesis of 1,2,3prim,sec,sec-triols. Synlett, 2006, 3521-3524. b) Zhao, G.-L.; Ibrahem, I.; Sundén, H.; Córdova, A. Amine-catalyzed asymmetric epoxidation of $\alpha, \beta$-unsaturated aldehydes. Adv. Synth. Catal., 2007, 349, $1210-1224$.

[78] Lee, S. MacMillan, D. W. C. Enantioselective organocatalytic epoxidation using hypervalent iodine reagents. Tetrahedron, 2006, 62, 11413-11424.

[79] Wang, X.; List, B. Asymmetric counteranion-direct catalysis for the epoxidation of enals. Angew. Chem. Int. Ed., 2008, 47, 1119-1122.

[80] a) Lattanzi, A.; Russo, A. Diaryl-2-pyrrolidinemethanols catalyzed enantioselective epoxidation of $\alpha, \beta-$ enones: New insight into the effect of structural modification of the catalyst on reaction efficiency. Tetrahedron, 2006, 62, 12264-12269. b) Russo, A.; Lattanzi, A. Asymmetric epoxidation of trans- 
chalcones organocatalyzed by $\beta$-amino alcohols. Eur. J. Org. Chem., 2008, 2767-2773. c) Russo, A.; Lattanzi, A. Asymmetric oxidations of electron-poor alkenes promoted by the $\beta$-amino alcohol/TBHP system. Synthesis, 2009, 1551-1556.

[81] a) Li, Y.; Liu, X.; Yang, Y.; Zhao, G. 4-Substituted- $\alpha, \alpha$-diaryl-prolinols improve the enantioselective catalytic epoxidation of $\alpha, \beta$-enones. J. Org. Chem., 2007, 72, 288-291. b) Zheng, C.; Li, Y.; Yang, Y.; Wang, H.; Cui, H.; Zhang, J.; Zhao, G. Highly efficient asymmetric epoxidation of electron-deficient $\alpha, \beta$-enones and related applications to organic synthesis. Adv. Synth. Catal., 2009, 351, 1685-1691.

[82] Lu, J.; Xu, Y.-H.; Liu, F.; Loh, T.-P. Enantioselective epoxidation of $\alpha, \beta$-enones promoted by (1R,3S,4S)-2-azanorbornyl-3-methanol as an organocatalyst. Tetrahedron Lett., 2008, 49, 6007-6008.

[83] Cui, H.; Li, Y.; Zheng, C.; Zhao, G.; Zhu, S. Enantioselective catalytic epoxidation of $\alpha, \beta$-enones promoted by fluorous $\alpha, \alpha$-diaryl-L-prolinols. J. Fluor. Chem., 2008, 129, 45-50.

[84] Liu, X.; Li, Y.; Wang, G.; Chai, Z.; Wu, Y.; Zhao, G. Effective and recyclable dendritic ligands for the enantioselective epoxidation of enones. Tetrahedron: Asymmetry, 2006, 17, 750-755.

[85] a) Reisinger, C. M.; Wang, X.; List, B. Catalytic asymmetric hydroperoxidation of $\alpha, \beta$-unsaturated ketones: An approach to enantiopure peroxyhemiketals, epoxides, and aldols. Angew. Chem. Int. Ed., 2008, 47, 8112-8115. b) Lu, X.; Liu, Y. Sun; B.; Cindric, B.; Deng, L. Catalytic enantioselective peroxidation of $\alpha, \beta$-unsaturated ketones. J. Am. Chem. Soc., 2008, 130, 8134-8135.

[86] Wang, X.; Reisinger, C. M. List, B. Catalytic asymmetric epoxidation of cyclic enones. J. Am. Chem. Soc., 2008, 130, 6070-6071.

[87] a) Ager, D. J.; Anderson, K.; Oblinger, E.; Shi, Y.; Vanderroest, J. An epoxidation approach to a chiral lactone: Application of the Shi epoxidation. Org. Proc. Res. Devolp., 2007, 11, 44-61. b) Zhang, Z.; Tang, J.; Wang, X.; Shi, H. Chiral ketone- or chiral amine-catalyzed asymmetric epoxidation of cis-1propenylphosphonic acid using hydrogen peroxide as oxidant. J. Mol. Catal. A: Chem., 2008, 285, 6871. c) Seki, M. A practical synthesis of a key chiral drug intermediate via asymmetric organocatalysis. Synlett, 2008, 164-176. 
[88] Poe, S. L.; Bogdan, A.R.; Mason, B. P.; Steinbacher, J. L.; Opalka, S. M.; MacQuade, D. T. Use of bifunctional ureas to increase the rate of proline-catalyzed $\alpha$-aminoxylations. J. Org. Chem., 2009, 74, $1574-1580$.

[89] Seebach, D.; Beck, A. K. ; Badine, D. M. Limbach, M.; Eschenmoser, A.; Tresurywala, A. M.; Hobi, R.; Prikoszovich, W.; Linder, B. Are Oxazolidinones Really Unproductive, Parasitic Species in Proline Catalysis? - Thoughts and Experiments Pointing to an Alternative View. Helv. Chim. Acta, 2007, 90, $425-471$

[90] Yang, L.; Liu, R.-H.; Wang, B.; Weng, L.-L.; Zheng, H. Asymmetric synthesis of 3-hydroxyl-2alkanones via tandem organocatalytic aminoxylation of aldehydes and chemoselective diazomethane homologation. Tetrahedron Lett., 2009, 50, 2628-2631.

[91] a) Lu, M.; Zhu, D.; Lu, Y.; Hou, Y.; Tan, B.; Zhong, G. Organocatalytic asymmetric $\alpha-$ aminoxylation/aza-Michael reactions for the synthesis of functionalized tetrahydro-1,2-oxazines. Angew. Chem. Int. Ed., 2008, 47, 10187-10191. Erratum: Angew. Chem. Int. Ed., 2008, 47, 10003. b) Zhu, D.; Lu, M.; Chua, P. J. Tan, B.; Wang, F.; Zhong, G. A highly stereoselective organocatalytic tandem aminoxylation/aza-Michael reaction for the synthesis of tetrahydro-1,2-oxazines. Org. Lett., 2008, 10, 4585-4588. Erratum: Org. Lett., 2008, 10, 5629.

[92] Sawant, R. T.; Waghmode, S. B. Organocatalytic enantioselective formal synthesis of HRV 3C-protease inhibitor (1R,3S)-thysanone. Tetrahedron, 2009, 65, 1599-1602.

[93] George, S.; Sudalai, A. An efficient organocatalytic route to the atorvastatin side-chain. Tetrahedron Lett., 2007, 48, 8544-8546.

[94] Hara, S.; Makino, K.; Hamada, Y. Total synthesis of halipeptin A, a potent anti-inflammatory cyclodepsipeptide from a marine sponge. Tetrahedron Lett., 2006, 47, 1081-1085.

[95] George, S.; Sudalai, A. Enantioselective synthesis of tarchonanthuslactone using proline-catalyzed asymmetric $\alpha$-aminooxylation. Tetrahedron: Asymmetry, 2007, 18, 975-981.

[96] Hayashi, Y.; Shoji, M.; Ishikawa, H.; Yamaguchi, J.; Tamura, T.; Imai, H.; Nishigaya, Y.; Takabe, K.; Kakeya, H.; Onose, R.; Osada, H. The asymmetric total synthesis of (+)-cytotrienin A, an ansamycintype anticancer drug. Angew. Chem. Int. Ed., 2008, 47, 6657-6660. 
[97] Kotkar, S. P.; Suryanvanshi, G. S.; Sudalai, A. A short synthesis of (+)-harzialactone A and (R)-(+)-4hexanolide via proline-catalyzed sequential $\alpha$-aminooxylation and Horner-Wadsworth-Emmons olefination of aldehydes. Tetrahedron: Asymmetry, 2007, 18, 1795-1798.

[98] Narina, S. V.; Sudalai, A. Short and practical enantioselective synthesis of linezolid and eperezolid via proline-catalyzed asymmetric $\alpha$-aminooxylation. Tetrahedron Lett., 2006, 47, 6799-6802.

[99] Kotkar, S. P.; Sudalai, A. A short enantioselective synthesis of the antiepileptic agent, levetiracetam based on proline-catalyzed asymmetric $\alpha$-aminooxylation. Tetrahedron Lett., 2006, 47, 6813-6815.

[100] Kim, S. G.; Park, T.-H.; Kim, B. J. Efficient total synthesis of (+)-exo-, (-)-endo-brevicomin and their derivatives via asymmetric organocatalysis and olefin cross-metathesis. Tetrahedron Lett., 2006, 47, 6369-6372.

[101] Kim, S.-G. Concise total synthesis of (+)-disparlure and its trans-isomer using asymmetric organocatalysis. Synthesis, 2009, 2418-2422.

[102] Kondekar, N. B.; Kumar, P. Iterative approach to enantiopure syn/anti-1,3-polyols via proline-catalyzed sequential $\alpha$-aminooxylation and Horner-Wadsworth-Emmons olefination of aldehydes. Org. Lett., 2009, 11, 2611-2614.

[103] Matsuzawa, M.; Kakeya, H.; Yamaguchi, J.; Shoji, M.; Onose, R.; Osada, H.; Hayashi, Y. Enantio- and diastereoselective total synthesis of (+)-panepophenanthrin, a ubiquitin-activating enzyme inhibitor, and biological properties of its new derivatives. Chem. Asian J., 2006, 1, 845-851.

[104] Panchgalle, S. P.; Gore, R. G.; Chavan, S. P.; Kalkote, U. R. Organocatalytic enantioselective synthesis of $\beta$-blockers: (S)-propranolol and (S)-naftopidil. Tetrahedron: Asymmetry, 2009, 20, 1767-1770.

[105] Bickley, J. F.; Evans, P.; Meek, A.; Morgan, B. S.; Raoberst, S. M. Novel preparation of (-)-4hydroxycyclohex-2-enone: reaction of 4-hydroxycyclohex-2-enone and 4-hydroxycyclopent-2-enone with some thiols. Tetrahedron: Asymmetry, 2006, 17, 355-362.

[106] Joseph, J.; Ramachary, D. B.; Jemmis, E. D. Electrostatic repulsion as an additional selectivity factor in asymmetric proline catalysis. Org. Biomol. Chem., 2006, 4, 2685-2689.

[107] Font, D.; Bastero, A.; Sayalero, S.; Pericàs, M. A. Highly enantioselective $\alpha$-aminoxylation of aldehydes and ketones with a polymer-supported organocatalyst. Org. Lett., 2007, 9, 1943-1946. 
[108] a) Guo, H.-M.; Niu, H.-Y.; Xue, M.-X.; Guo, Q.-X.; Cun, L.-F.; Mi, A.-Q.; Jiang, Y.-Z.; Wang, J.-J. LProline in an ionic liquid as an efficient and reusable catalyst for direct asymmetric $\alpha$-aminoxylation of aldehydes and ketones. Green Chem., 2006, 8, 682-684. b) Huang, K.; Huang, Z.-Z.; Li, X.-L. Highly enantioselective $\alpha$-aminoxylation of aldehydes and ketones in ionic liquids. J. Org. Chem., 2006, 71, 8320-8323.

[109] For a review, see: Longbottom, D. A.; Franckevičius, V.; Ley, S. V. (S)- and (R)-5-pyrrolidin-2-yl-1Htetrazoles: Enantiomeric organocatalysts of broad utility in organic synthesis. Chimia, 2007, 61, 247256.

[110] Jiao, P.; Kawasaki, M.; Yamamoto, H. A sequential O-nitrosoaldol and Grignard addition process: An enantio- and diastereoselective entry to chiral 1,2-diols. Angew. Chem. Int. Ed., 2009, 48, 3333-3336.

[111] Kumarn.S.; Shaw, D. M.; Ley, S. V: A highly selective, organocatalytic route to chiral 1,2-oxazines from ketones. Chem. Commun., 2006, 3211-3213.

[112] Zhu, R.; Zhang, D.; Wu, J.; Liu, C. A DFT study on the mechanism and regioselectivity of the tandem O-nitroso aldol/Michael reaction of nitrosobenzene and cyclohexenone. J. Mol. Struct. (THEOCHEM), 2007, 815, 105-109.

[113] Chua, P. J.; Tan, B.; Zhong, G. Highly enantioselective L-thiaproline catalyzed $\alpha$-aminoxylation of aldehydes in aqueous media. Green Chem., 2009, 11, 543-547.

[114] a) Kano, T.; Yamamoto, A.; Mii, H.; Takai, J.; Shirakawa, S.; Maruoka, K. Direct asymmetric aminoxylation reaction catalyzed by axially chiral amino acids. Chem. Lett., 2008, 37, 250-251. b) Kano, T.; Yamamoto, A.; Maruoka, K. Direct asymmetric aminoxylation reaction catalyzed by a binaphthyl-based chiral amino sulfonamide with high catalytic performance. Tetrahedron Lett., 2008, 49, 5369-5371. c) Kano, T.; Yamamoto, A.; Shirozu, F.; Maruoka, K. Enantioselectivity switch in direct asymmetric aminoxylation catalyzed by binaphthyl-based chiral secondary amines. Synthesis, 2009, $1557-1563$.

[115] Lu, M.; Zhu, D.; Lu, Y.; Zeng, X.; Tan, B.; Xu, Z.; Zhong, G. Chiral Brønsted acid-catalyzed enantioselective $\alpha$-hydroxylation of $\beta$-dicarbonyl compounds. J. Am. Chem. Soc., 2009, 131, 45624563. 
[116] Tong, S.-T.; Brimble, M. A.; Barker, D. Influence of $\alpha$-methyl substitution of proline-based organocatalysts on the asymmetric $\alpha$-oxidation of aldehydes. Tetrahedron, 2009, 65, 4801-4807.

[117] Kano, T.; Mii, H.; Maruoka, K. Direct asymmetric benzoyloxylation of aldehydes catalyzed by 2tritylpyrrolidine. J. Am. Chem. Soc., 2009, 131, 3450-3451.

[118] Gotoh, H.; Hayashi, Y. Diphenylprolinol silyl ether as a catalyst in an asymmetric catalytic and direct $\alpha$-benzoyloxylation of aldehydes. Chem. Commun., 2009, 3083-3085.

[119] Ibrahem, I.; Zhao, G.-L.; Sundén, H.; Córdova, A. A route to 1,2-diols by enantioselective organocatalytic $\alpha$-oxidation with molecular oxygen. Tetrahedron Lett., 2006, 47, 4659-4663.

[120] Sano, D.; Nagata, K.; Itoh, T. Cataltytic asymmetric hydroxylation of oxindoles by molecular oxygen using phase-transfer catalyst. Org. Lett., 2008, 10, 1593-1595.

[121] Sibi, M. P. ; Hasegawa, M. Organocatalysis in radical chemistry. Enantioselective $\alpha$-oxyamination of aldehydes. J. Am. Chem. Soc., 2007, 129, 4124-4125.

[122] a) Richardson, R. D.; Page, T. P.; Altermann, S.; Paradine, S. M.; French, A., N.; Wirth, T. Enantioselective $\alpha$-oxytosylation of ketones catalysed by iodoarenes. Synlett, 2007, 538-542. b) Altermann, S.; Richardson, R. D.; Page, T. P.; Schmidt, R. K.; Holland, E.; Mohammed, U.; Paradine, S. M.; French, A., N.; Richter, C.; Bahar, A. M.; Witulski, B.; Wirth, T. Catalytic enantioselective $\alpha-$ oxysulfonylation of ketones mediated by iodoarenes. Eur. J. Org. Chem., 2008, 5315-5328.

[123] a) Armstrong, A.; Challinor, L.; Cooke, R. S.; Moir, J. H.; Treweeke, N. J. Oxaziridine-mediated amination of branched allylic sulfides: Stereospecific formation of allylic amine derivatives via [2,3]sigmatropic rearrangement. J. Org. Chem., 2006, 71, 4028-4030. b) Armstrong, A.; Challinor, L.; Moir, J. H. Exploiting organocatalysis: Enantioselective synthesis of vinyl glycines by allylic sulfimide [2,3] sigmatropic rearrangement. Angew. Chem. Int. Ed., 2007, 46, 5369-537. c) Armstrong, A.; Emmerson, D. P. G. Enantioselective synthesis of allenamides via sulfimide [2,3] sigmatropic rearrangement. Org. Lett., 2009, 11, 1547-1550.

[124] Fang, L.; Lin, A.; Hu, H.; Zhu, C. Highly enantioselective sulfenylation of $\beta$-ketoesters: H-bond acceptor catalysis. Chem. Eur. J., 2009, 15, 7039-7043. 
[125] Zhao, G.-L.; Rios, R.; Vesely, J.; Eriksson, L.; Córdova, A. Organocatalytic enantioselective aminosulfenylation of $\alpha, \beta$-unsaturated aldehydes. Angew. Chem. Int. Ed., 2008, 47, 8468-8472.

[126] Jiang, H.; Nielsen, J. B.; Nielsen, M.; Jørgensen, K. A. Organocatalysed asymmetric $\beta$-amination and multicomponent syn-selective diamination of $\alpha, \beta$-unsaturated aldehydes. Chem. Eur. J., 2007, 13, 90689075.

[127] a) Tiecco, M.; Carlone, A.; Sternativo, S.; Marini, F.; Bartoli, G.; Melchiorre, P. Organocatalytic asymmetric $\alpha$-selenenylation of aldehydes. Angew. Chem. Int. Ed., 2007, 46, 6882-6885. b) Sundén, H.; Rios, R.; Córdova, A. Organocatalytic highly enantioselective $\alpha$-selenenylation of aldehydes. Tetrahedron Lett., 2007, 48, 7865-7869.

[128] Petersen, K. S.; Posner, G. H. Asymmetric, organocatalytic, three-step synthesis of $\gamma$-hydroxy- $(E)-\alpha, \beta-$ unsaturated sulfones and esters. Org. Lett., 2008, 10, 4685-4687.

[129] Giacalone, F.; Gruttadauria, M.; Marculescu A. M.; Noto, R. Polystyrene-supported proline and prolinamide. Versatile heterogeneous organocatalysis both for symmetric aldol reaction in water and $\alpha$ selenenylation of aldehydes. Tetrahedron Lett., 2007, 48, 255-259.

[130] Ueda, M.; Kano, T.; Maruoka, K. Organocatalyzed direct asymmetric $\alpha$-halogenation of carbonyl compounds. Org. Biomol. Chem., 2009, 7, 2005-2012.

[131] For reviews, see: a) Pihko, P. M. Enantioselective $\alpha$-fluorination of carbonyl compounds: Organocatalysis or metal catalysis. Angew. Chem. Int. Ed., 2006, 45, 544-547. b) Prakash, G. K. S.; Beier, P. Construction of asymmetric fluorinated carbon centers. Angew. Chem. Int. Ed., 2006, 45, 2172-2174. c) Bobbio, C.; Gouverneur, V. Catalytic asymmetric fluorinations. Org. Biomol. Chem. 2006, 4, 2065-2075. d) Shibata, N.; Ishimaru, T.; Nakamura, S.; Toru, T. New approches to enantioselective fluorination: Cinchona alkaloids combination and chiral ligands/metal complexes. $J$. Fluor. Chem., 2007, 128, 469-483.

[132] Jiang, H.; Falcicchio, A.; Jensen, K. L.; Paixão, M. W.; Bertelsen, S.; Jørgensen, K. A. Target-directed organocatalysis: A direct asymmetric catalytic approach to chiral propargylic and allylic fluorides. $J$. Am. Chem. Soc., 2009, 131, 7153-7157. 
[133] Fadeyi, O. O.; Lindsley, C. W. Rapid, general access to chiral $\beta$-fluoromines and $\beta, \beta$-difluoroamines via organocatalysis. Org. Lett., 2009, 11, 943-946.

[134] Brandes, S.; Niess, B.; Bella, M.; Prieto, A.; Overgaard, J.; Jørgensen, K. A. Non-biaryl atropoisomers in organocatalysis. Chem. Eur. J., 2006, 12, 6039-6052.

[135] Fukuzumi, T.; Shibata, N.; Sugiura, M.; Nakamura, S.; Toru, T. Enantioselective fluorination mediated by cinchona alkaloids/selecfluor combinations: A catalytic approach. J. Fluor. Chem., 2006, 127, 548551.

[136] Ishimaru, T.; Shibata, N.; Horikawa, T.; Yaasuda, N.; Nakamura, S.; Toru, T.; Shiro, M. Cinchona alkaloid catalyzed enantioselective fluorination of allyl silanes, silyl enol ethers, and oxoindoles. Angew. Chem. Int. Ed., 2008, 47, 4157-4161.

[137] Kang, B.; Britton, R. A general method for the synthesis of nonracemic trans-epoxide-containing insect sex pheromones. Org. Lett., 2007, 9, 5083-5086.

[138] a) Dogo-Isonagie, C.; Bekele, T.; France, S.; Wolfer, J.; Weatherwax, A.; Taggi, A. E.; Lectka, T. Scalable methodology for the catalytic asymmetric $\alpha$-bromination of acid chlorides. J. Org. Chem., 2006, 71, 8946-8949. b) Dogo-Isonagie, C.; Bekele, T.; France, S.; Wolfer, J.; Weatherwax, A.; Taggi, A. E.; Paull, D. H.; Dudding, T.; Lectka, T. A mechanistic study on the catalytic, asymmetric $\alpha-$ bromination of acid chlorides. Eur. J. Org. Chem., 2007, 1091-1100.

[139] Kano, T.; Ueda, M.; Maruoka, K. Direct asymmetric iodination of aldehydes using a axially chiral bifunctional amino alcohol catalyst. J. Am. Chem. Soc., 2008, 130, 3728-3729.

[140] a) Dinér, P.; Kjærsgaard, A.; Lie, M. A.; Jørgensen, K. A. On the origin of the stereoselectivity in organocatalysed reactions with trimethylsilyl-protected diarylprolinol. Chem. Eur. J., 2008, 14, 122127. b) Wong, C. T. Mechanism of the $\alpha, \alpha$-diarylprolinol trimethylsilyl ether-catalyzed enantioselective C-C, C-N, C-F, C-S, and C-Br bond forming reactions. Tetrahedron, 2009, 65, 7491-7497.c) Marquéz, C. A.; Fabbretti, F.; Metzger, J. O. Electrospray ionization mass spectrometric study on the direct organocatalytic $\alpha$-halogenation of aldehydes. Angew. Chem. Int. Ed., 2007, 46, 6915-6917. 